\title{
Heat Pump Test Apparatus for the Evaluation of Low Global Warming Potential Refrigerants
}

\author{
Harrison Skye
}

http://dx.doi.org/10.6028/NIST.TN.1895

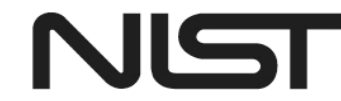

National Institute of Standards and Technology U.S. Department of Commerce 
NIST Technical Note 1895

\title{
Heat Pump Test Apparatus for the Evaluation of Low Global Warming Potential Refrigerants
}

\author{
Harrison Skye \\ Engineering Laboratory \\ Energy and Environment Division
}

This publication is available free of charge from:

http://dx.doi.org/10.6028/NIST.TN.1895

November 2015

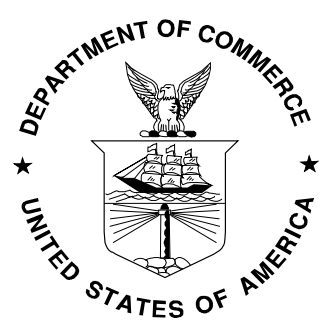

U.S. Department of Commerce

Penny Pritzker, Secretary 
Certain commercial entities, equipment, or materials may be identified in this document in order to describe an experimental procedure or concept adequately. Such identification is not intended to imply recommendation or endorsement by the National Institute of Standards and Technology, nor is it intended to imply that the entities, materials, or equipment are necessarily the best available for the purpose.

National Institute of Standards and Technology Technical Note 1895 Natl. Inst. Stand. Technol. Tech. Note 1895, 48 pages (November 2015) http://dx.doi.org/10.6028/NIST.TN.1895

CODEN: NTNOEF 


\begin{abstract}
-
International efforts to reduce human-induced global warming include restrictions on the use of chemicals with a high global warming potential (GWP). The heating, ventilation, airconditioning, and refrigeration (HVAC\&R) industry subsequently faces a phasedown of many commonly used hydrofluorocarbon (HFC) refrigerants that have a relatively high GWP. A new family of refrigerants known as hydrofluoroolefins (HFOs), including their mixtures with HFCs, show promise as replacements. The overall GWP impact of refrigerant use includes both the direct GWP related to inadvertent release of the fluid into the atmosphere, as well as an indirect GWP caused by emissions from the power source used to energize the associated HVAC\&R equipment. In nearly all HVAC\&R applications, the indirect emissions far outweigh the direct emissions, so the efficiency of candidate replacements must be carefully quantified to guide the selection of fluids that actually achieve a reduction in the overall GWP.

A $3.4 \mathrm{~kW}$ ( 1 ton) heat pump test apparatus has been constructed and instrumented for measuring the cycle performance of low-GWP refrigerants; the description of that apparatus is the focus of this report. Details are described for the system components, instrumentation, data reduction, and uncertainty analysis. Results from baseline experiments with R134a were used to test and verify the apparatus and data reduction procedure. The data will be used to provide a relative comparison between the low-GWP refrigerants as quantified by metrics including coefficient of performance and volumetric capacity.

Future tests with low-GWP refrigerants will be compared with those from baseline refrigerants R134a and R410A. Additionally, the test data will be used to verify a new NIST heat pump modeling tool, CYCLE_D-HX, which captures both thermodynamic and heat transfer processes in HVAC\&R equipment. Refrigerants, refrigerant mixtures, and cycle configurations that are difficult and/or time consuming to test can be rapidly explored using the verified model.
\end{abstract}




\section{Acknowledgements -}

This apparatus was constructed by John Wamsley based on the initial design by David Yashar. Dr. Yashar also helped create the outline of the report, which was valuable for keeping the presentation of information organized and complete. I would like to acknowledge Vance Payne for his help in determining the operating procedures and target operating parameters. Patrick Goenner refined the instrumentation and collected early sets of data while visiting as a guest researcher from Germany. I would also like to thank Piotr Domanski and Riccardo Brignoli for reviewing data sets and working on the CYCLE_D-HX model. Thanks to Mark Kedzierski for thoughtful insight into the calibration and uncertainty analysis for the test rig. Tara Fortin, of the NIST Applied Chemicals and Materials Division, performed differential scanning calorimeter measurements of the heat transfer fluid specific heat; these data were critical for achieving an acceptable energy balance. Finally, I would like to thank the reviewers for their helpful suggestions, including Piotr Domanski and Amanda Pertzborn at NIST, and Steve Brown at The Catholic University of America. 


\section{Table of Contents -}

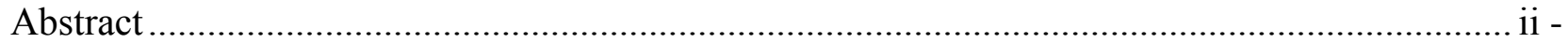

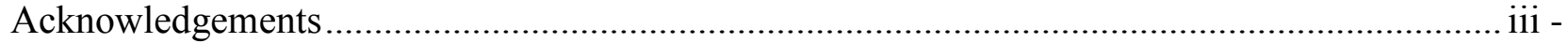

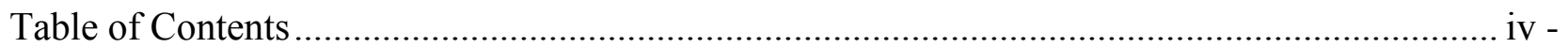

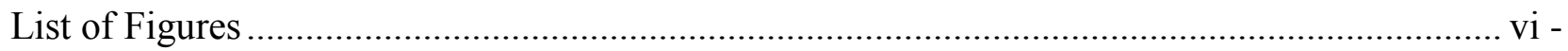

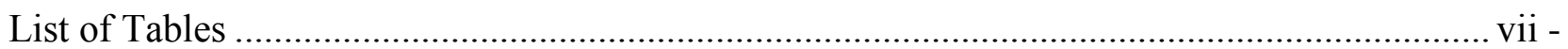

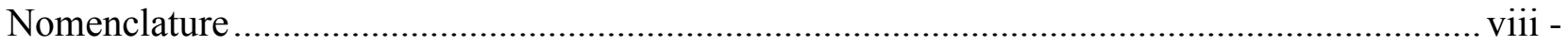

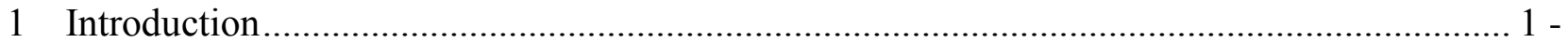

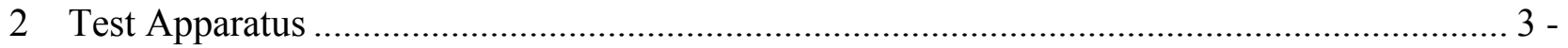

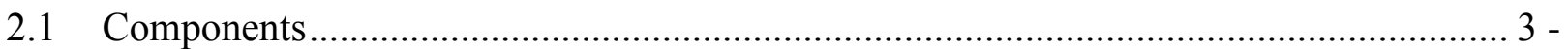

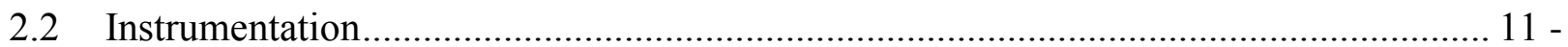

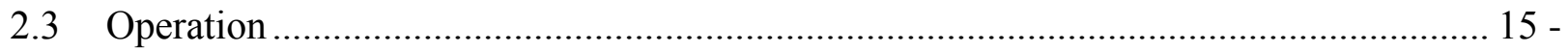

2.3.1 Test Rig Control Parameters ........................................................................ 15 -

2.3.2 Test Rig Operating Parameters .......................................................................... 15 -

2.3.2.1 - Operating Parameters $1 \& 2$ : Evaporator and Condenser Saturation
Temperature....................................................................................... 15 -

2.3.2.2 - Operating Parameters 3, 4, \& 5: Capacity and Heat Flux ............................. 17 -

2.3.2.3 - Operating Parameters 6 \& 7: HTF-side Thermal Resistance Ratio ................. 18 -

2.3.2.4 - Operating Parameters $8 \&$ 9: Subcool and Superheat .................................... 18 -

2.3.2.5 Operating Parameter 10: LLSL-HX included or bypassed ............................ 19 -

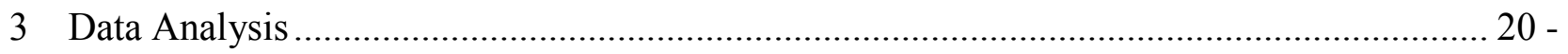

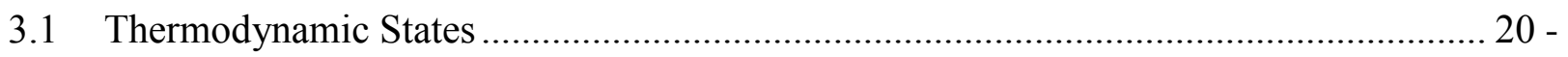

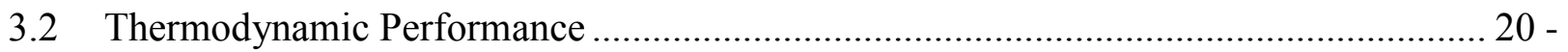

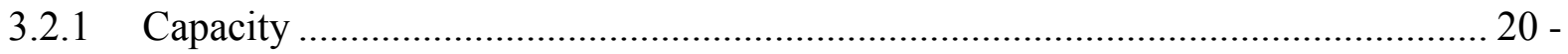

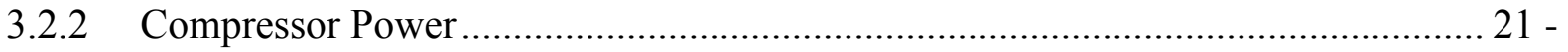

3.2.3 Coefficient of Performance ............................................................................ 22 -

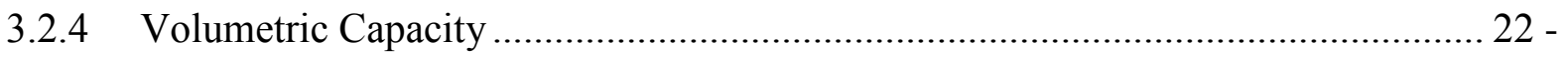

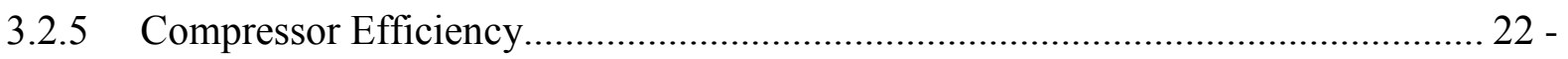

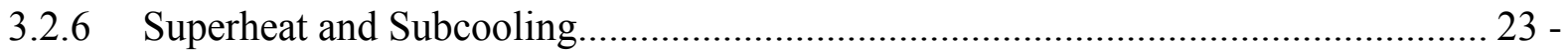

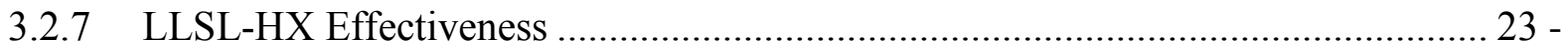

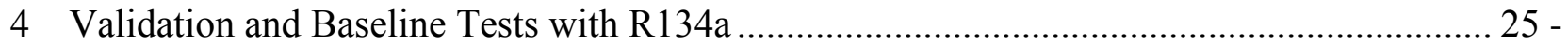

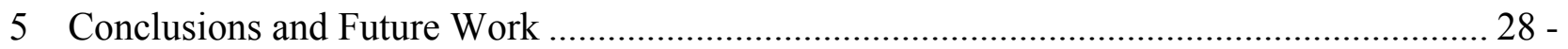

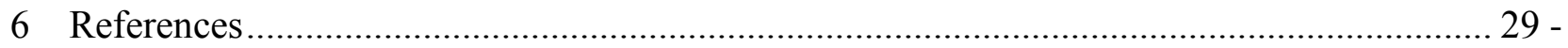




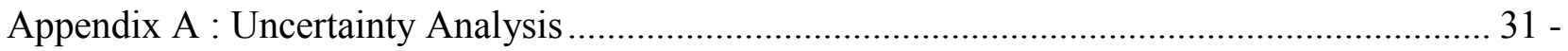

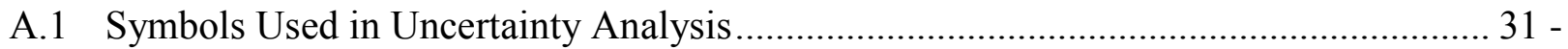

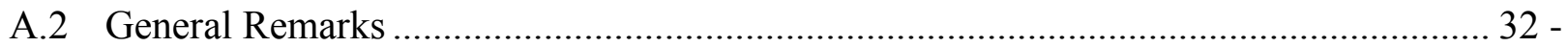

A.3 Thermocouples with CJC Compensation .............................................................. 32 -

A.4 Thermocouples with Ice-Water Bath Compensation ................................................. 33 -

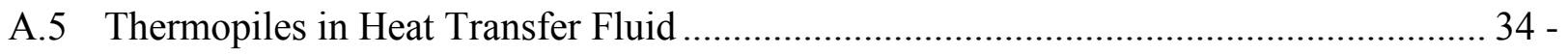

A.6 Evaporator Heat Transfer Fluid Specific Heat ......................................................... 36 -

A.7 Condenser Heat Transfer Fluid Specific Heat............................................................... 37 -

A.8 Evaporator and Condenser Insulation Conductance .............................................. 37 -

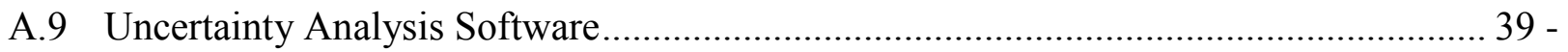

A.10 Moving Window and Steady State Uncertainty ................................................ 40 -

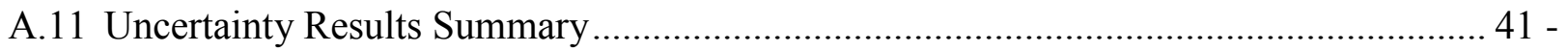

A.11.1 Uncertainty Results Summary: Cooling .......................................................... 41 -

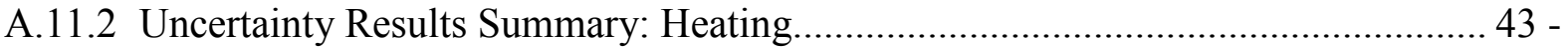

Appendix B : Instrumentation Schematic with DAQ Number Convention .............................. 46 -

Appendix C : Microfin Tube Surface Area.......................................................................... 48 - 


\section{List of Figures -}

Figure 2-1: Schematic of MBBHP test apparatus............................................................ 5

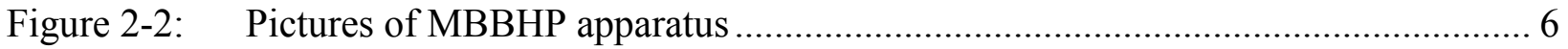

Figure 2-3: Pictures of MBBHP compressor (a) without and (b) with safety cage.................... 7

Figure 2-4: Schematic showing the tube numbering convention in the (a) condenser and (b) -

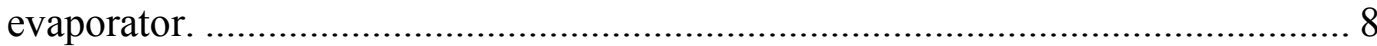

Figure 2-5: Schematics of annular heat exchanger including (a) refrigerant tube lengths, (b) cross section of annular heat exchanger, (c) detail cross-section of microfin tube, and (d) helix angle of microfins.

Figure 2-6: Capacity and heat flux for baseline R134a tests for (a) evaporator and (b) condenser

Figure 3-1: Temperature profile in (a) evaporator, showing superheat and (b) condenser, showing subcooling 23

Figure 4-1: Energy imbalance in the evaporator and condenser ............................................ 25

Figure 4-2: Heat pump cycle pressures on the (a) high pressure side and (b) low pressure side

Figure 4-3: $\quad$ Performance metrics including (a) compressor power and (b) mass flow and mass flux

Figure 4-4: Performance metrics including (a) COP, (b) capacity, (c) volumetric capacity, and (d) compressor isentropic and volumetric efficiency.... 27

Figure 4-5: Flow regime map for microfin tube (a) evaporation and (b) condensation ........... 28

Figure A-1: Temperature calibration for CJC compensated thermocouples where (a) data are divided by each of the 5 calibrations and (b) all data are combined. 33

Figure A-2: Ice-water bath referenced thermocouple calibration data....................................... 34

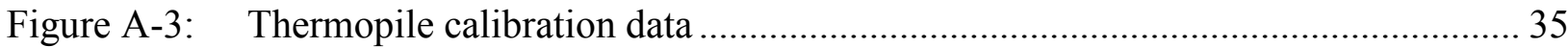

Figure A-4: Contours of thermopile (a) uncertainty and (b) relative contribution to

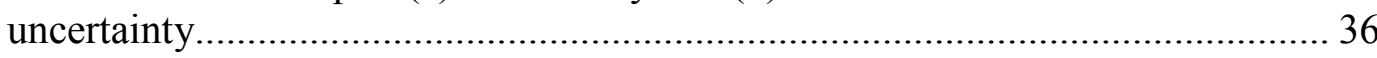

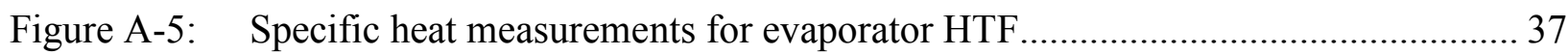

Figure A-6: Specific heat of condenser HTF (water) ……………………………………..... 37

Figure A-7: Insulation conductance for evaporator and condenser.......................................... 39

Figure A-8: Uncertainty in temperature due to fluctuations at steady state for (a) evaporator outlet and (b) evaporator inlet. 


\section{List of Tables -}

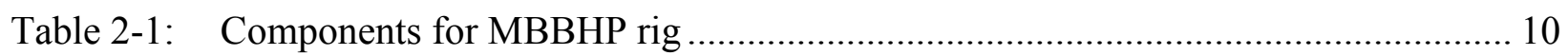

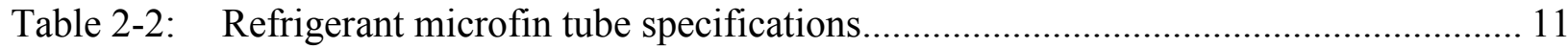

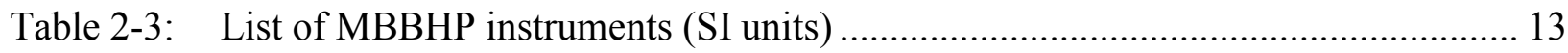

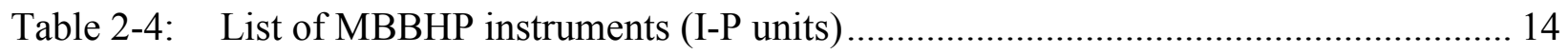

Table 2-5: List of the Control Parameters and Operating Parameters ..................................... 15

Table 2-6: Evaporator and condenser fluid temperatures for standard rating tests.................... 17

Table 3-1: Measurements and equations used to define the thermodynamic states................... 20

Table A-1: Condenser \& evaporator thermopile polynomial coefficients ................................... 35

Table A-2: Evaporator HTF specific heat polynomial coefficients ............................................. 37

Table A-3: Uncertainty of refrigerant-side evaporator cooling capacity ................................... 42

Table A-4: Uncertainty of HTF-side evaporator cooling capacity ………………………….... 42

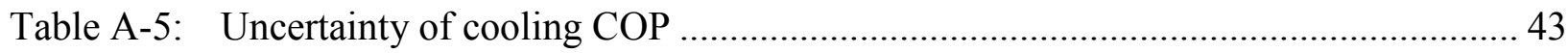

Table A-6: Uncertainty of refrigerant-side condenser heating capacity ..................................... 44

Table A-7: Uncertainty of HTF-side condenser heating capacity............................................... 44

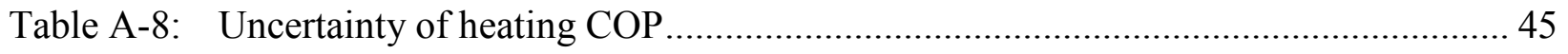


Nomenclature -

\begin{tabular}{|c|c|c|}
\hline Symbol & $\underline{\text { Units }}$ & Definition \\
\hline$A$ & $\mathrm{~m}^{2}$ & $\overline{\text { Area }}$ \\
\hline$A_{\text {total }}$ & $\mathrm{m}^{2}$ & Total combined heat transfer area from evaporator and condenser \\
\hline $\mathrm{COP}_{\text {heat }}$ & -- & Coefficient of Performance - Heating \\
\hline $\mathrm{COP}_{\text {cool }}$ & -- & Coefficient of Performance - Cooling \\
\hline$C_{p}$ & $\mathrm{~kJ} \mathrm{~kg}^{-1} \mathrm{~K}^{-1}$ & Specific heat \\
\hline$d_{o}$ & $\mathrm{~mm}$ & Microfin tube outer diameter \\
\hline$d_{i}$ & $\mathrm{~mm}$ & Microfin tube inner diameter \\
\hline$D_{\text {comp }}$ & $\mathrm{m}^{3}$ & Compressor displacement \\
\hline$h$ & $\mathrm{~kJ} \mathrm{~kg}^{-1}$ & Specific enthalpy \\
\hline$L$ & $\mathrm{~m}$ & Tube length \\
\hline$\dot{m}$ & $\mathrm{~kg} \mathrm{~s}^{-1}$ & Mass flow rate \\
\hline$N$ & $\mathrm{~Hz}$ & Compressor frequency \\
\hline$N_{f}$ & -- & Number of microfins on inner circumference of refrigerant tube \\
\hline NT & -- & Number of heat exchanger tubes \\
\hline$P$ & $\mathrm{kPa}$ & Pressure \\
\hline$\Delta P$ & $\mathrm{kPa}$ & Pressure difference \\
\hline$R$ & $\mathrm{KkW}^{-1}$ & Thermal resistance \\
\hline$R_{\text {total }}$ & $\mathrm{KkW}^{-1}$ & Total resistance in heat exchanger including both fluids and tube wall \\
\hline$\dot{Q}$ & $\mathrm{~kW}$ & Energy transfer \\
\hline$\dot{Q}_{L L S L, v}$ & $\mathrm{~kW}$ & Energy transfer in LLSL-HX, on the vapor side \\
\hline$\dot{Q}_{L L S L, \max }$ & $\mathrm{kW}$ & Maximum possible energy transfer in LLSL-HX \\
\hline$T$ & ${ }^{\circ} \mathrm{C}$ & Temperature \\
\hline$\Delta T$ & $\mathrm{~K}$ & Temperature difference \\
\hline$t_{b}$ & $\mathrm{~mm}$ & Microfin tube bottom wall thickness \\
\hline$s_{f}$ & $\mathrm{~mm}$ & Spacing between microfins \\
\hline$s$ & $\mathrm{~kJ} \mathrm{~kg}^{-1} \mathrm{~K}^{-1}$ & Specific entropy \\
\hline$S C$ & $\mathrm{~K}$ & Condenser subcooling \\
\hline SH & $\mathrm{K}$ & Evaporator superheat \\
\hline$U A$ & $\mathrm{~W} \mathrm{~K}^{-1}$ & Thermal conductance \\
\hline$v$ & $\mathrm{~m}^{3} \mathrm{~kg}^{-1}$ & Specific volume \\
\hline$V C C$ & $\mathrm{~kJ} \mathrm{~m}^{-3}$ & Volumetric Cooling Capacity \\
\hline VHC & $\mathrm{kJ} \mathrm{m}^{-3}$ & Volumetric Heating Capacity \\
\hline$\dot{W}_{\text {comp }}$ & $\mathrm{kW}$ & Compressor power, computed using enthalpy change of refrigerant \\
\hline$\dot{W}_{\text {shaft }}$ & $\mathrm{kW}$ & Compressor power, computed using torque and speed of driveshaft \\
\hline$x$ & -- & Vapor quality (mass of vapor divided by total mass of fluid) \\
\hline
\end{tabular}




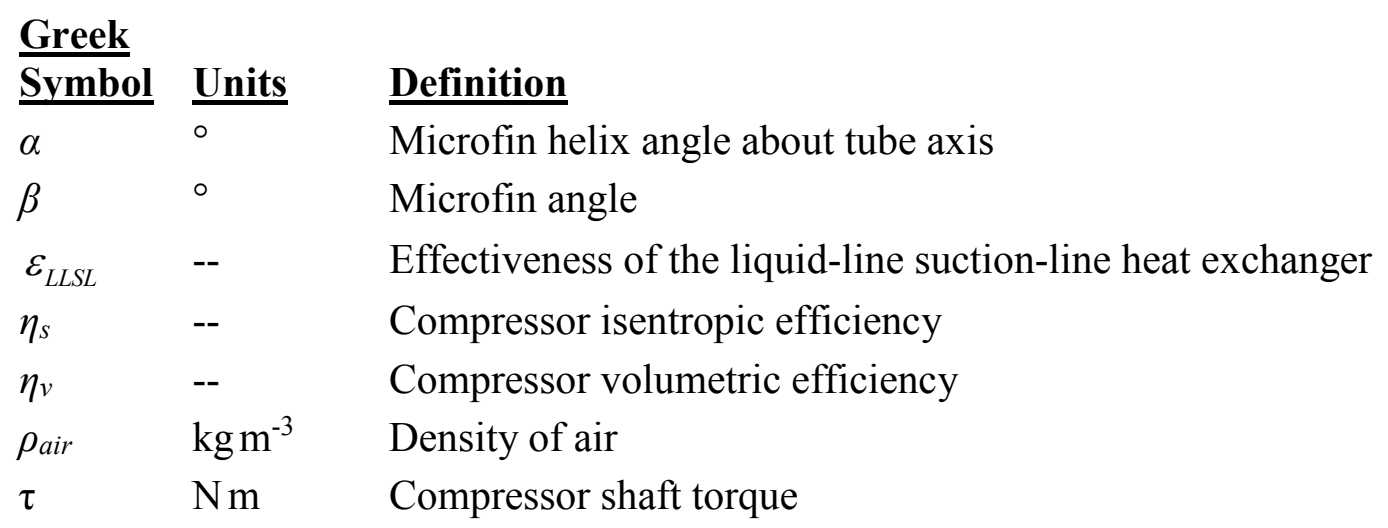

\section{Subscript Definition}

active Active refrigerant heat exchanger tubes -

air Air -

amb Ambient air surrounding test apparatus -

avg Average -

c Condenser

e Evaporator

HTF Heat Transfer Fluid

in Inlet

ins Insulation

inactive Inactive refrigerant heat exchanger tubes

out Outlet

ref Refrigerant

1 to 11 Refrigerant thermodynamic states as defined in Figure 2-1 


\begin{tabular}{|c|c|}
\hline Abbreviation & Definition \\
\hline AHRI & Air-Conditioning, Heating, and Refrigeration Institute \\
\hline ANSI & American National Standards Institute \\
\hline CFC & Chlorofluorocarbon \\
\hline $\mathrm{COP}$ & Coefficient of Performance ( $\mathrm{W}$ of capacity per $\mathrm{W}$ of electric input) \\
\hline CYCLE_D-HX & $\begin{array}{l}\text { A NIST heat pump cycle simulation model currently under development. } \\
\text { The simulation captures both thermodynamic and transport processes in the } \\
\text { cycle. }\end{array}$ \\
\hline DAQ & Data Acquisition \\
\hline DOE & Department of Energy (United States) \\
\hline EER & Energy Efficiency Ratio (Btu of capacity per W of electric input) \\
\hline EOS & Equation of State \\
\hline GWP & Global Warming Potential \\
\hline HFC & Hydrofluorocarbon \\
\hline $\mathrm{HFO}$ & Hydrofluoroolefin \\
\hline HTF & Heat Transfer Fluid \\
\hline HVAC\&R & Heating, Ventilation, Air-Conditioning, and Refrigeration \\
\hline LLSL-HX & Liquid-Line Suction-Line Heat Exchanger \\
\hline MBBHP & Mini Breadboard Heat Pump \\
\hline NIST & National Institute of Standards and Technology (United States) \\
\hline PID & Proportional Integral Derivative controller \\
\hline RPM & Revolutions per Minute (compressor shaft) \\
\hline
\end{tabular}




\section{Introduction -}

Concerns about the environmental impacts of global warming (i.e., global climate change) are driving an effort to limit anthropogenic sources of atmospheric pollutants that trap longwave radiation emitted from the earth's surface. The chlorinated- and fluorinated-hydrocarbon working fluids (i.e., refrigerants) employed by the heating, ventilation, air-conditioning, and refrigeration (HVAC\&R) industry exhibit a particularly large global warming potential (GWP) with 100-year GWP values hundreds to thousands of times larger than an equivalent mass of carbon dioxide (Solomon, et al., 2007, p. 212). In the European Union, the F-gas regulation (EU, 2014) mandates a phase-down of hydrofluorocarbons (HFCs) with high GWP to $21 \%$ of the average levels from years 2009 through 2012 by 2030. The current North American proposal would amend the Montreal Protocol to limit HFC consumption to have a weighted GWP of $15 \%$ of average levels from years 2011 through 2013 by 2036 (EPA, 2015).

Major efforts are underway to identify alternative refrigerants with a lower GWP. Chemical manufacturers are proposing halogenated olefins (e.g., hydrofluoroolefins, or HFOs), which offer substantially lower GWP due to short atmospheric lifetimes. For some HFOs, the lower GWP comes at the cost of an increase in flammability. The Air-Conditioning, Heating, and Refrigeration Institute (AHRI) is leading a collaborative effort to evaluate the drop-in and softoptimized performance of low-GWP alternatives largely consisting of HFOs and HFO/HFC blends (AHRI, 2015). The National Institute of Standards and Technology (NIST) investigated the maximum thermodynamic potential expected for working fluids by optimizing the parameters governing the Equations of State (EOS) (Domanski et al., 2014). In a companion NIST study, a coarse filter criteria was developed (based on the atomic elements, GWP, toxicity, flammability, critical temperature, and stability) to sift through the 100 million chemicals currently listed in the public-domain PubChem database for possible low-GWP refrigerant candidates, 1234 of which were identified (Kazakov et al., 2012). The candidate list was further refined to 62 by limiting the critical temperature to the range $300 \mathrm{~K}$ to $400 \mathrm{~K}$, which is typical for fluids in HVAC\&R equipment (McLinden et al., 2014).

The remaining 62 candidates, and their mixtures, must be evaluated using more stringent criteria that consider detailed performance in HVAC\&R equipment. In particular, the criteria must include the cycle efficiency of the fluid since the carbon dioxide emissions from the power source (i.e., "indirect emissions") far outweighs the direct GWP impact (i.e., the GWP from the release of the fluid into the atmosphere) of the working fluid in nearly all HVAC\&R equipment. A cycle modeling tool, CYCLE_D-HX, is being developed at NIST to evaluate the efficiency of low-GWP refrigerants and refrigerant mixtures. The model expands upon the thermodynamic considerations from CYCLE_D (Brown et al., 2011) by including transport phenomena. In this way, appropriate penalties can be applied to refrigerants whose thermodynamic properties are favorable but exhibit poor performance in HVAC\&R systems because of large pressure drops or poor heat transfer. The consideration of transport processes represents a lesson learned from the previous effort to find replacements for chlorofluorocarbon (CFC) fluids that were found to cause stratospheric ozone destruction. R410A, the dominant replacement for the CFC R22, was initially considered to be a significantly inferior replacement based on thermodynamic properties alone. However, later practice showed that the lower pressure drop (due to high operating pressure) and superior heat transfer of R410A could be exploited with optimized heat exchangers to yield performance competitive with R22. Including transport processes also allows for the 
optimization of mass flux; the number of parallel heat exchanger tube circuits are adjusted to balance performance enhancement/degradation of increased heat transfer/pressure drop with higher mass flux. The more sophisticated capabilities of the new model will allow for more accurate identification of optimal low-GWP fluids using computational methods.

A heat pump test apparatus has been constructed for the purpose of generating cycle performance data to compare low-GWP refrigerants and to tune and verify the new NIST model; that test apparatus is the focus of this report. The apparatus is highly configurable, which allows the system to operate with a wide variety of working fluids as if tailored to each one. Specifically, the apparatus features a variable-speed compressor, variable-area heat exchangers, and a manually adjusted throttle valve. These adjustable components allow for operation at constant capacity per total combined evaporator and condenser conductance $\left(\dot{Q} / U A_{\text {total }}\right)$ across all test fluids, a condition required for equitable comparison of refrigerants (as well as fixed heat transfer fluid inlet/outlet temperatures) (McLinden et al., 1987). In practice, it is difficult to hold $\dot{Q} / U A_{\text {total }}$ constant because the conductance depends on the refrigerant side heat transfer coefficient, which changes for each fluid and operating condition. Rather, a fixed capacity per total heat exchanger area $\left(\dot{Q} / A_{\text {total }}\right)$ is used as a close approximation. For example, with a fixed heat exchanger area, $\dot{Q} / A_{\text {total }}$ is held constant from R134a (low volumetric capacity) to R410A (high volumetric capacity) by decreasing the compressor speed. If adjustment of compressor speed is insufficient to maintain constant $\dot{Q} / A_{\text {total }}$ between refrigerants, the heat exchanger area can be adjusted as well. The adjustability and relatively small capacity of $1.7 \mathrm{~kW}$ to $3.5 \mathrm{~kW}(0.5$ ton to 1 ton) provide the etymology for the apparatus name, the Mini Breadboard Heat Pump (MBBHP). Measurements of cycle performance with legacy high-GWP HFCs and novel lowGWP fluids in the MBBHP will provide a rich data set to test the predictive capability of the new NIST model.

This report describes the construction and operation of the test apparatus, the data analysis used to quantify performance, an uncertainty analysis of the performance metrics, and baseline and validation results using refrigerant $\mathrm{R} 134 \mathrm{a}$. 


\section{Test Apparatus -}

\subsection{Components}

The test apparatus, shown in Figure 2-1 through Figure 2-3, was designed to emulate refrigerant-side operating conditions of typical HVAC\&R equipment. (Figure B-1 and Figure B2 in Appendix B show the instrument numbering convention used in the raw data files). The rig design is partially based on one used in a previous NIST effort to investigate alternatives to CFCs (Pannock et al., 1991). The refrigerant circuit includes a variable-speed compressor powered by an electric motor and inverter, where the speed controls cooling/heating capacity. The evaporator and condenser, shown in detail in Figure 2-4 and Figure 2-5 (a) and (b), are single-circuit (i.e., there are no parallel tube branches) annular heat exchangers where the refrigerant is on the inner tube and the liquid heat transfer fluid (HTF) is in the annular space. As shown in Figure 2-5(c), the refrigerant tube is smooth on the outside and enhanced with rifled microfins on the inside. The size of the heat exchangers can be adjusted by changing the number of active refrigerant tubes; the valves on the side of the heat exchanger allow for up to 10 (in increments of 2) of the 20 refrigerant tubes to be bypassed (this section of the rig is referred to as the "bypass valve header"). When operating these bypass valves, care is taken to avoid trapping subcooled liquid in a closed section; a section completely filled with subcooled liquid will experience a catastrophic increase in pressure if the temperature rises enough to vaporize the refrigerant. A liquid-line suction-line heat exchanger (LLSL-HX) can be included or bypassed as needed. Each of three heat exchangers (evaporator, condenser and LLSL-HX) are arranged in counterflow configuration. Two sizes of manually controlled Vernier-handled needle valves are used to throttle the refrigerant and can be used individually or in tandem; the needle valve sizes were selected using a correlation for short tubes (Kim et al., 2005). A filter-dryer is used to control contaminants, and an oil separator is used to ensure proper oil return to the compressor and to minimize oil circulation in the heat exchangers. The system refrigerant charge is adjusted using two Shrader access valves, where refrigerant is removed from or added to the liquid/suction line valves, respectively. Two $40 \mathrm{~W}$ heaters preheat the compressor before startup to avoid foam in the oil (the heaters are turned off after the discharge temperature has warmed to about $60^{\circ} \mathrm{C}$ ). A safety cage was constructed around the compressor because during cooling tests with high pressure fluids such as R410A, the compressor will be operated slightly above the manufacturer's specified maximum pressure of $2600 \mathrm{kPa}$ (363 psig). Finally, a series of sight glasses provide visual confirmation of fully subcooled liquid exiting the condenser, vapor only (i.e., no liquid) entering the compressor suction port, proper oil level in the compressor, and proper oil return from the oil separator. Detailed component specifications are listed in Table 2-1. The microfin tube parameters are shown in Figure 2-5 and Table 2-2, and Appendix C shows how the microfin surface area was calculated.

The HTF circuits include a water heater/chiller to respectively control the evaporator and condenser HTF inlet temperatures, where the heater/chiller contains a pump for circulating the fluid. The evaporator HTF is a potassium formate and water solution with freeze protection to $-40^{\circ} \mathrm{C}\left(-40^{\circ} \mathrm{F}\right)$, whereas water is used for the HTF in the condenser. Flow control provided by three valves in each HTF circuit allows for a wide range of flowrates: two in-line valves are used where the larger/smaller (gate/needle) valve provides gross/fine flow adjustment and the third valve bypasses the heater (or chiller) for flow and pressure control. Air bubbles in the condenser HTF circuit are controlled by drawing from the bottom of the vented chiller reservoir 
tank. The evaporator HTF circuit is pressurized with an expansion tank, so air bubbles can be removed by venting trapped air from local high spots using Shrader valves. Experience operating the test apparatus has shown that the vented reservoir tank (in the chiller) is a superior solution for minimizing air bubbles. The temperature of the fluid delivered to the heat exchangers is regulated using proportional-integral-derivative (PID) controllers. 


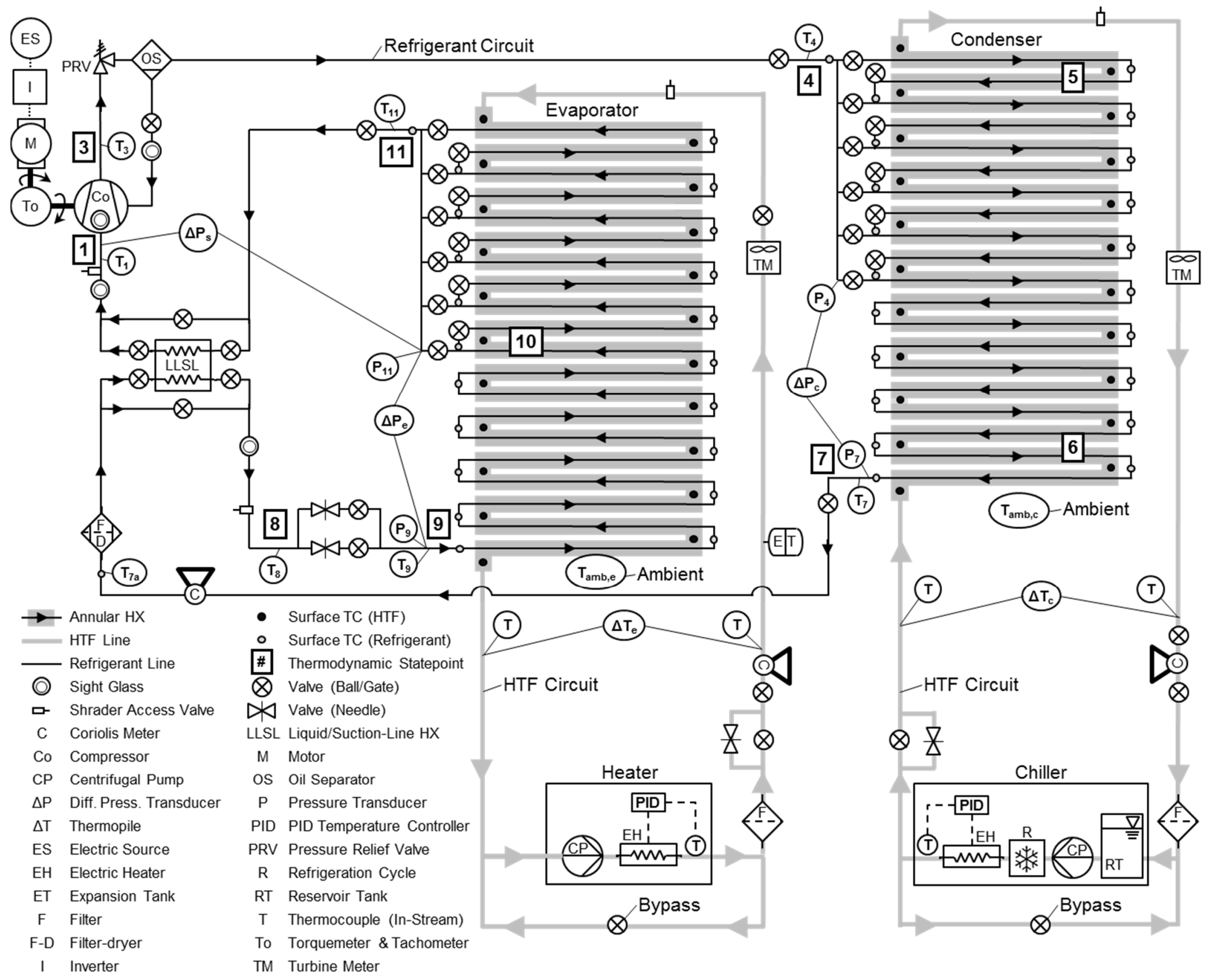

Figure 2-1: Schematic of MBBHP test apparatus 

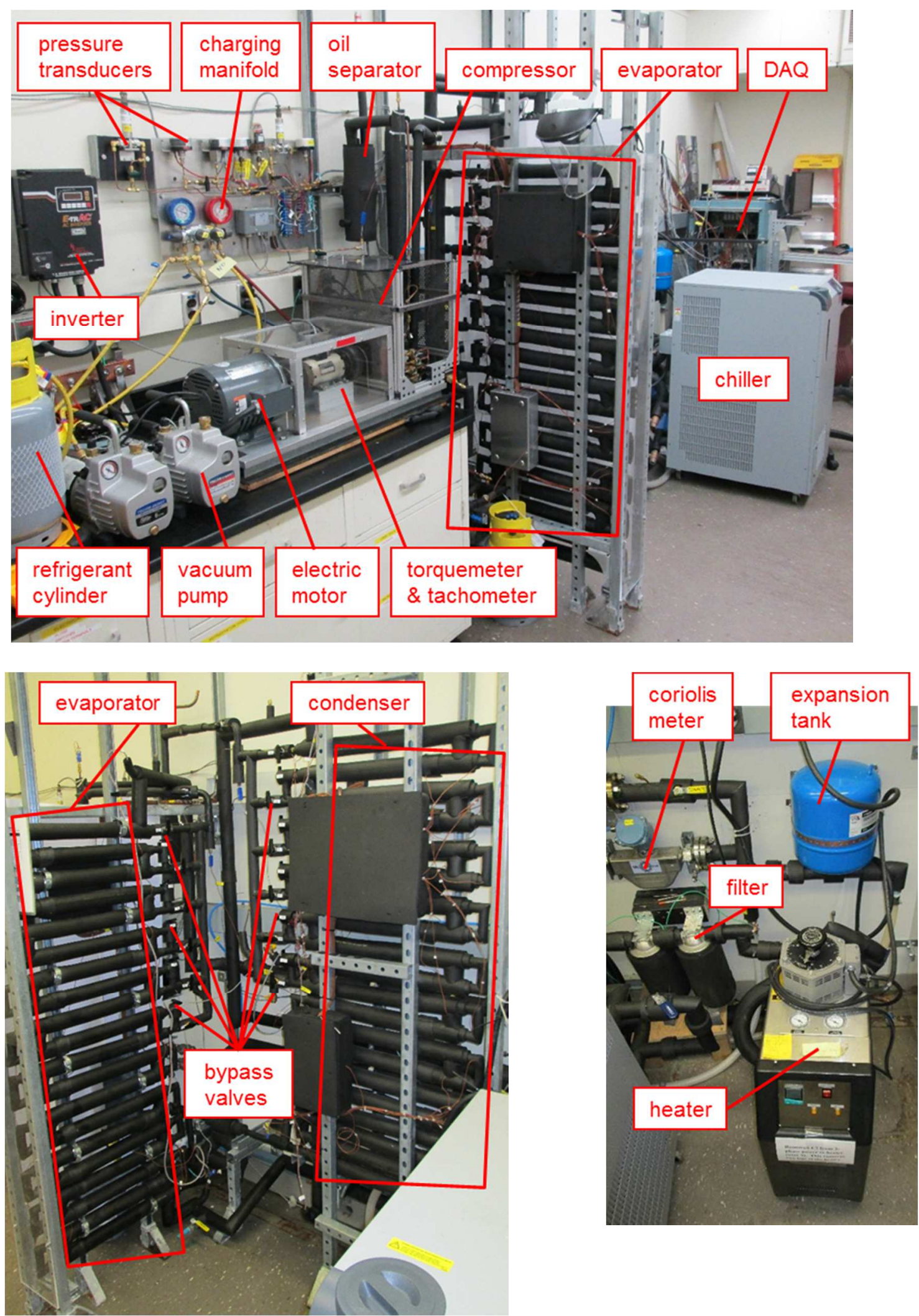

Figure 2-2: Pictures of MBBHP apparatus 


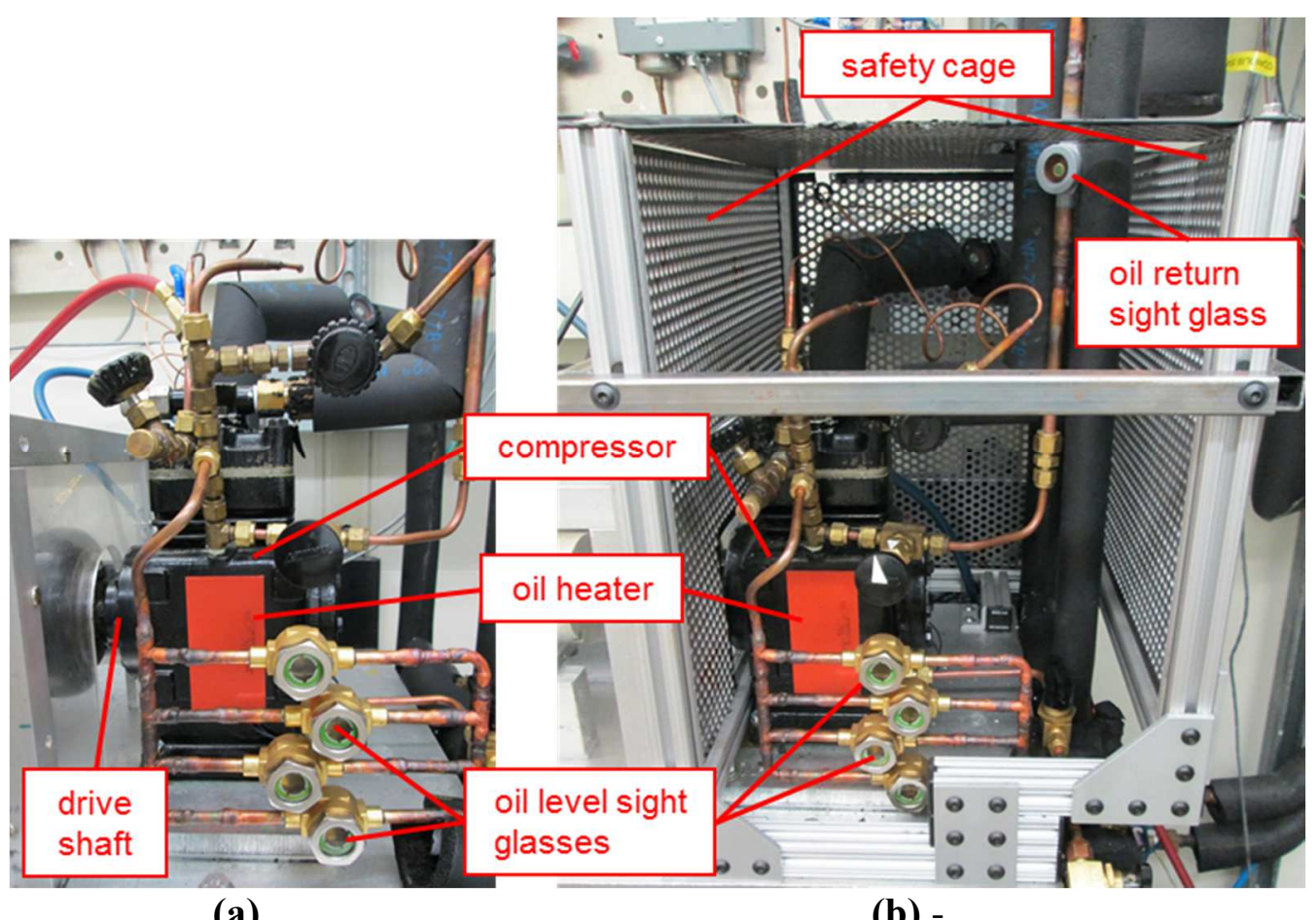

(a)

(b) -

Figure 2-3: Pictures of MBBHP compressor (a) without and (b) with safety cage. - 


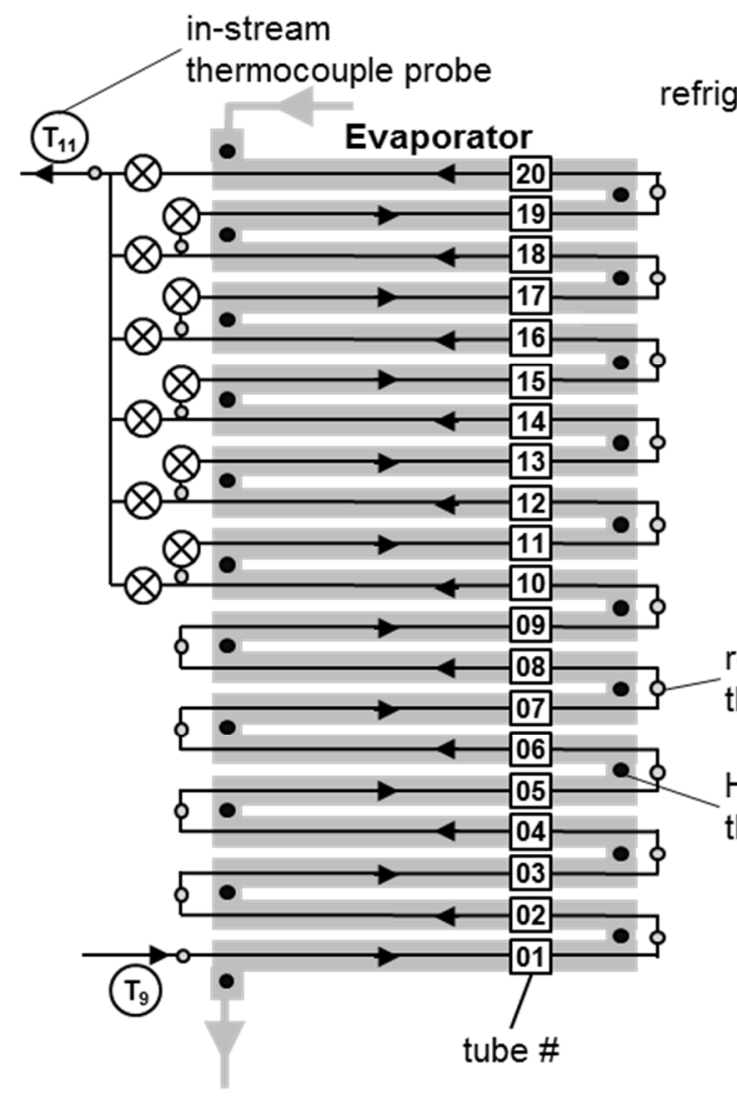

(a) -

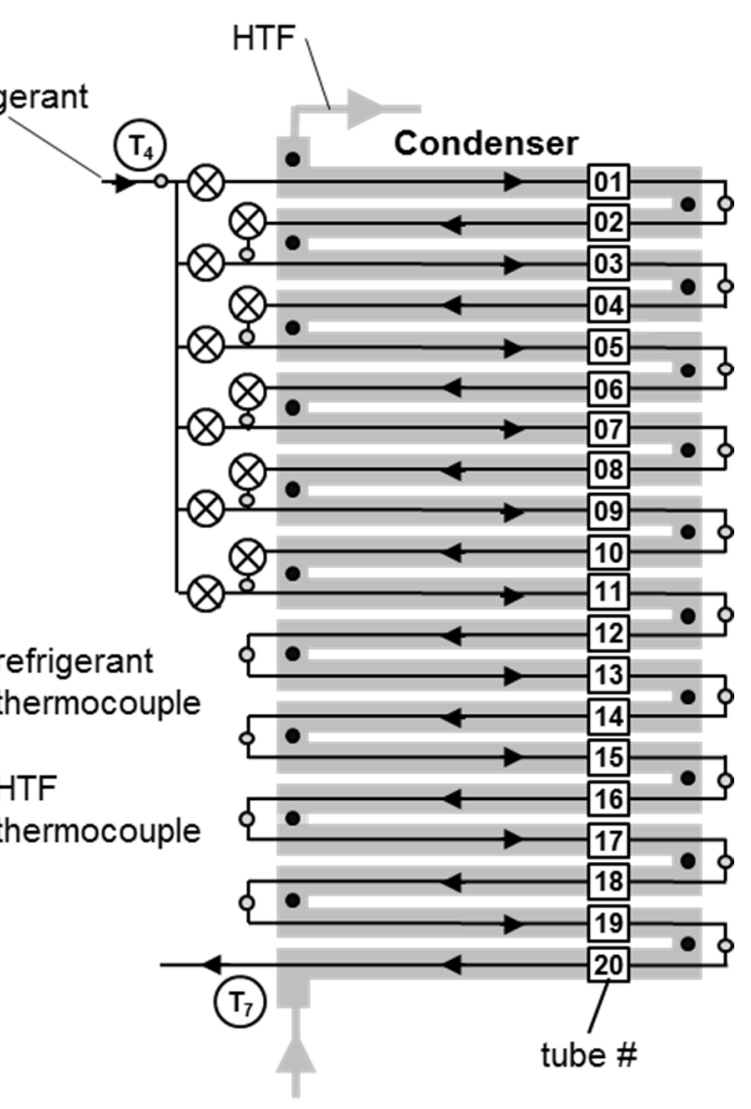

(b)

Figure 2-4: - Schematic showing the tube numbering convention in the (a) condenser and (b) evaporator. 


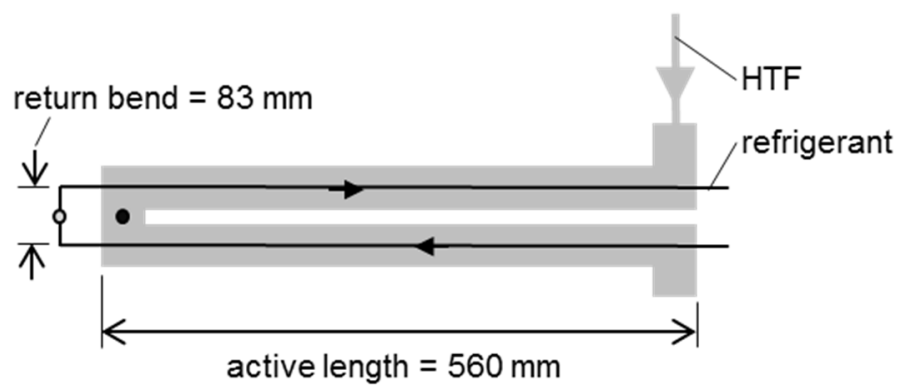

(a) -

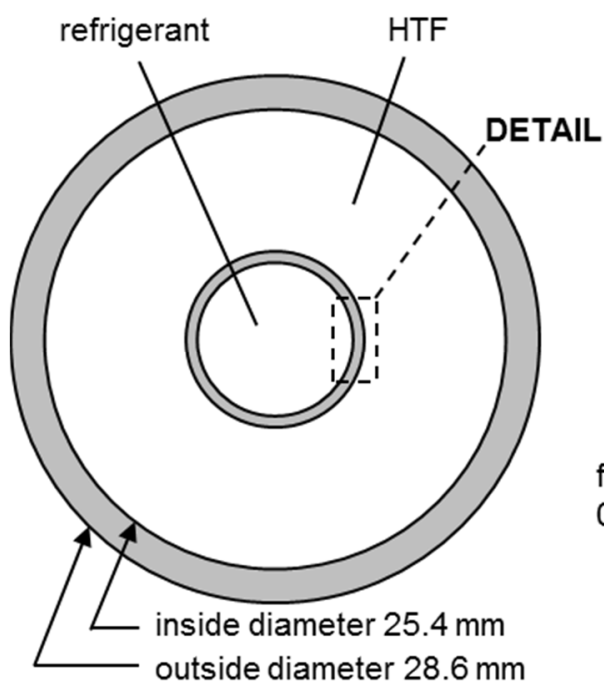

(b) -

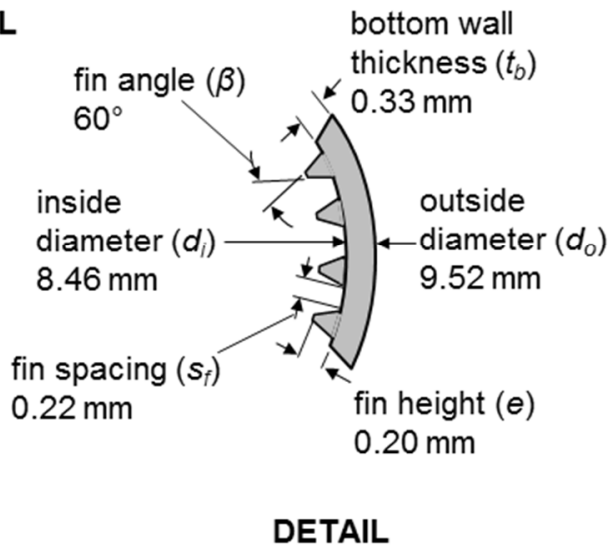

(c) helix angle $(\alpha)=18^{\circ}$

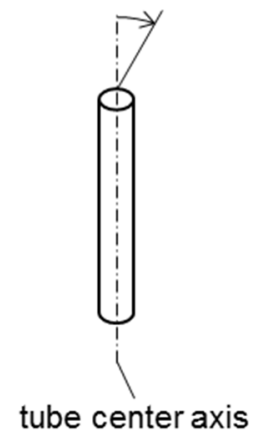

(d)

Figure 2-5: - Schematics of annular heat exchanger including (a) refrigerant tube lengths, (b) cross section of annular heat exchanger, (c) detail crosssection of microfin tube, and (d) helix angle of microfins. 


\section{Table 2-1: Components for MBBHP rig}

Component

\begin{tabular}{|c|c|c|}
\hline Chiller & Cooling capacity: & $2500 \mathrm{~W}$ ( 0.7 ton $)$ \\
\hline Compressor & $\begin{array}{l}\text { Type: } \\
\text { Cylinders: } \\
\text { Speed: } \\
\text { Displacement rate: } \\
\text { Displacement: } \\
\text { Max pressure: }\end{array}$ & $\begin{array}{l}\text { Reciprocating } \\
2 \\
8.3 \mathrm{~Hz} \text { to } 66.7 \mathrm{~Hz} \\
(500 \mathrm{RPM} \text { to } 4000 \mathrm{RPM}) \\
1.31 \mathrm{~m}^{3} \mathrm{~h}^{-1} \text { to } 10.81 \mathrm{~m}^{3} \mathrm{~h}^{-1} \\
7.165 \mathrm{~cm}^{3} \\
2604 \mathrm{kPa}(363 \text { psia })\end{array}$ \\
\hline Electric motor & Maximum power: & $3.73 \mathrm{~kW}(5 \mathrm{hp})$ \\
\hline Expansion tank (HTF) & Size: & 19 liter (5 gallon) \\
\hline Filter (HTF) & Filter size: & $50 \mu \mathrm{m}$ \\
\hline Filter-dryer (refrig.) & Line size: & $9.5 \mathrm{~mm}(0.375 \mathrm{in})$ \\
\hline Inverter & $\begin{array}{l}\text { Voltage: } \\
\text { Maximum power: }\end{array}$ & $\begin{array}{l}230 \mathrm{VAC}, 3 \text {-phase } \\
3.73 \mathrm{~kW}(5 \mathrm{hp})\end{array}$ \\
\hline Heater & Heating capacity: & $10 \mathrm{~kW}$ (2.8 ton) \\
\hline $\begin{array}{l}\text { Heat exchanger } \\
\text { (evaporator/condenser) }\end{array}$ & $\begin{array}{l}\text { Number of tubes: } \\
\text { Tube active length: } \\
\text { Return bend length: } \\
\text { Outer tube ID: } \\
\text { Outer tube OD: } \\
\text { Outer tube material: } \\
\text { Inner tube: }\end{array}$ & $\begin{array}{l}10 \text { to } 20 \text {, increments of } 2 \\
560 \mathrm{~mm}(22 \mathrm{in}) \\
83 \mathrm{~mm}(3.25 \mathrm{in}) \\
25.4 \mathrm{~mm}(1 \mathrm{in}) \\
26.8 \mathrm{~mm}(1.125 \mathrm{in}) \\
\text { Copper } \\
\text { See Table } 2-2\end{array}$ \\
\hline $\begin{array}{l}\text { Liquid-line suction-line heat } \\
\text { exchanger (LLSL-HX) }\end{array}$ & $\begin{array}{l}\text { Nominal capacity: } \\
\text { Shell O.D.: } \\
\text { Type: }\end{array}$ & $\begin{array}{l}370 \mathrm{~W}(0.5 \mathrm{hp}) \\
51 \mathrm{~mm}(2 \mathrm{in}) \\
\text { Corrugated (liquid side) }\end{array}$ \\
\hline Needle valves (refrig.) & $\begin{array}{l}\text { Valve 1 } \\
\text { Orifice: } \\
\text { Flow coeff. }\left(\mathrm{C}_{\mathrm{v}}\right) \text { : } \\
\text { Valve } 2 \\
\text { Orifice: } \\
\text { Flow coeff. }\left(\mathrm{C}_{\mathrm{v}}\right) \text { : }\end{array}$ & $\begin{array}{l}\text { Valve } 1 \\
1.42 \mathrm{~mm}(0.056 \mathrm{in})^{*} \\
0.03^{*} \\
\text { Valve } 2 \\
3.25 \mathrm{~mm}(0.128 \mathrm{in})^{*} \\
0.16^{*}\end{array}$ \\
\hline Needle valves (HTF) & $\begin{array}{l}\text { Orifice: } \\
\text { Flow coeff. }\left(\mathrm{C}_{\mathrm{v}}\right) \text { : }\end{array}$ & $\begin{array}{l}6.4 \mathrm{~mm}(0.25 \mathrm{in})^{*} \\
0.73^{*}\end{array}$ \\
\hline Oil separator & $\begin{array}{l}\text { Diameter: } \\
\text { Height: } \\
\text { Capacity: }\end{array}$ & $\begin{array}{l}102 \mathrm{~mm}(4 \mathrm{in}) \\
356 \mathrm{~mm}(14 \mathrm{in}) \\
10 \text { to } 17 \mathrm{~kW}(3 \text { to } 5 \text { ton })\end{array}$ \\
\hline Pressure relief valve & Cracking pressure: & 800 psig \\
\hline
\end{tabular}

*Note: valve orifice sizes and flow coefficients $\left(\mathrm{C}_{\mathrm{v}}\right)$ can vary between 0 and the listed maximum values 
Table 2-2: Refrigerant microfin tube specifications

\begin{tabular}{lcll} 
Parameter & Symbol & Value & Uncertainty \\
\hline Inside diameter & $d_{i}$ & $8.46 \mathrm{~mm}(0.333 \mathrm{in})$ & Unknown \\
\hline Outside diameter & $d_{o}$ & $9.52 \mathrm{~mm}(0.375 \mathrm{in})$ & $\pm 0.050 \mathrm{~mm}( \pm 0.002 \mathrm{in})$ \\
\hline Bottom wall thickness & $t_{b}$ & $0.33 \mathrm{~mm}(0.013 \mathrm{in})$ & $\pm 0.025 \mathrm{~mm}( \pm 0.001 \mathrm{in})$ \\
\hline Fin height & $e$ & $0.20 \mathrm{~mm}(0.008 \mathrm{in})$ & $\pm 0.025 \mathrm{~mm}( \pm 0.001 \mathrm{in})$ \\
\hline Spacing between fins & $s_{f}$ & $0.22 \mathrm{~mm}(0.009 \mathrm{in})$ & Unknown \\
\hline Number of fins & $N_{f}$ & 60 & -- \\
\hline Fin angle & $\beta$ & $60^{\circ}$ & Unknown \\
\hline Helix angle & $\alpha$ & $18^{\circ}$ & $2^{\circ}$ \\
\hline $\begin{array}{l}\text { Internal surface area } \\
\text { per unit tube length }\end{array}$ & $A_{i} / L$ & $0.0424 \mathrm{~m}(1.67 \mathrm{in})$ & \\
\hline \begin{tabular}{l} 
Material \\
\hline
\end{tabular} & & Copper & \\
\hline
\end{tabular}

\subsection{Instrumentation}

Refrigerant-side instrumentation is selected to capture the key thermodynamic state points in the cycle. Specifications for the instruments (including instrument uncertainty) in both the refrigerant and HTF circuits are listed in Table 2-3 (Table 2-4 shows I-P units). The pressure transducers and in-stream thermocouple probes are numbered in Figure 2-1 according to the eleven states computed in Section 3.1; the thermodynamic state number convention is also consistent with that used in the new CYCLE_D-HX model. The thermocouple probes are referenced to a cold junction in an ice-water bath. Differential pressure transducers quantify the pressure drop in the condenser, evaporator, and suction line. The location of the heat exchanger pressure taps has been selected at the bottom of the bypass valve header, where the pressure is equal to that of the refrigerant leaving the heat exchanger regardless of how many tubes are bypassed. A coriolis flowmeter measures the refrigerant mass flow and density, and provides confirmation of fully subcooled liquid in the liquid line (a two-phase mixture will exhibit large oscillations in measured flowrate). The compressor shaft power is captured by the in-line torque meter and tachometer.

On the HTF fluid side, energy transfers are measured in the evaporator and condenser to provide verification of the refrigerant-side calculations. The mass flow and temperature difference in the heat exchangers are measured with coriolis meters and thermopiles (in thermowells), which are combined with the fluid heat capacity to compute energy transfer. Thermocouples inserted into the thermowells with the thermopiles provide the measure of absolute temperature required for applying the thermopile calibration. Additionally, the thermocouples provide verification of the thermopile temperature difference measurement.

Figure 2-1 and Figure 2-4 also show the tube-surface-mounted thermocouples used to measure both refrigerant and HTF temperature profiles in the evaporator and condenser. As shown in Section 3.2.6, these temperature profiles are useful for determining refrigerant tube 
number where the phase transitions (superheat, subcooling, two-phase) occur. The refrigerantand HTF-side sensors are mounted on the return bends of each inner/outer tube, respectively.

The instruments are scanned once per minute by the data acquisition (DAQ) system, and when steady state is achieved, the measurements are calculated as the average of a moving window of 30 readings (i.e., the average over the last 30 minutes). The measurements inevitably fluctuate during steady state, which contributes to the uncertainty of the measurement. This "steady state" uncertainty has been quantified for a nominal test condition and is listed in Table 2-3. The total measurement uncertainty (last column of Table 2-3) is found by adding the instrument error and the steady state error in quadrature. A detailed discussion of the selection of the steady state moving window size and computation of steady state uncertainty is shown in Appendix A.10. 
Table 2-3: List of MBBHP instruments (SI units)

\begin{tabular}{|c|c|c|c|c|}
\hline Instrument & Range & $\begin{array}{l}\text { Instrument } \\
\text { Uncertainty }^{1}\end{array}$ & $\begin{array}{l}\text { Steady State } \\
\text { Uncertainty }^{1}\end{array}$ & $\begin{array}{l}\text { Total } \\
\text { Uncertainty }{ }^{1,2}\end{array}$ \\
\hline \multirow[t]{2}{*}{ Coriolis meter (HTF) } & $\begin{array}{l}\text { Mass flow: } \\
(0 \text { to } 756) \mathrm{gs}^{-1}\end{array}$ & $\begin{array}{l}\text { Mass flow }{ }^{3} \text { : } \\
\pm 0.1 \% \text { rdg. }\end{array}$ & $\begin{array}{l}\text { Mass flow: } \\
\pm 0.23 \mathrm{~g} \mathrm{~s}^{-1}\end{array}$ & $\begin{array}{l}\text { Mass flow: } \\
\pm 0.26 \mathrm{~g} \mathrm{~s}^{-1}\end{array}$ \\
\hline & $\begin{array}{l}\text { Density: } \\
\text { (0 to } 3) \mathrm{g} \mathrm{cm}^{-3}\end{array}$ & $\begin{array}{l}\text { Density: } \\
\pm 0.001 \mathrm{gcm}^{-3}\end{array}$ & $\begin{array}{l}\text { Density: } \\
\pm 0.0001 \mathrm{gcm}^{-3}\end{array}$ & $\begin{array}{l}\text { Density: } \\
\pm 0.001 \mathrm{~g} \mathrm{~cm}^{-3}\end{array}$ \\
\hline \multirow[t]{2}{*}{ Coriolis meter (refrigerant) } & $\begin{array}{l}\text { Mass flow: } \\
(0 \text { to } 60) 5 \mathrm{gs}^{-1}\end{array}$ & $\begin{array}{l}\text { Mass flow }{ }^{4}: \\
\pm 0.1 \% \text { rdg. }\end{array}$ & $\begin{array}{l}\text { Mass flow: } \\
\pm 0.01 \mathrm{gs}^{-1}\end{array}$ & $\begin{array}{l}\text { Mass flow: } \\
\pm 0.016 \mathrm{~g} \mathrm{~s}^{-1}\end{array}$ \\
\hline & $\begin{array}{l}\text { Density: } \\
\text { (0 to } 3) \mathrm{g} \mathrm{cm}^{-3}\end{array}$ & $\begin{array}{l}\text { Density: } \\
\pm 0.0005 \mathrm{~g} \mathrm{~cm}^{-3}\end{array}$ & $\begin{array}{l}\text { Density: } \\
\pm 0.0001 \mathrm{gcm}^{-3}\end{array}$ & $\begin{array}{l}\text { Density: } \\
\pm 0.0005 \mathrm{~g} \mathrm{~cm}^{-3}\end{array}$ \\
\hline Data acquisition system & $(-10$ to 10$) \mathrm{V}$ & $\pm 1 \mu \mathrm{V}$ & -- & $\pm 1 \mu \mathrm{V}$ \\
\hline Press. transducer (diff.) - condenser & (0 to 172$) \mathrm{kPa}$ & $\pm 0.7 \mathrm{kPa}$ & $\pm 0.8 \mathrm{kPa}$ & $\pm 1.3 \mathrm{kPa}$ \\
\hline Press. transducer (diff.) - evaporator & $(0$ to 345$) \mathrm{kPa}$ & $\pm 0.1 \mathrm{kPa}$ & $\pm 0.8 \mathrm{kPa}$ & $\pm 0.8 \mathrm{kPa}$ \\
\hline Press. transducer (diff.) - suction & $(0$ to 69$) \mathrm{kPa}$ & $\pm 0.01 \mathrm{kPa}$ & $\pm 0.3 \mathrm{kPa}$ & $\pm 0.3 \mathrm{kPa}$ \\
\hline Press. transducer (high press.) & (0 to 3447$) \mathrm{kPa}$ & $\pm 3.4 \mathrm{kPa}$ & $\pm 0.7 \mathrm{kPa}$ & $\pm 3.5 \mathrm{kPa}$ \\
\hline Press. transducer (low press.) & (0 to 1724$) \mathrm{kPa}$ & $\pm 3.4 \mathrm{kPa}$ & $\pm 0.7 \mathrm{kPa}$ & $\pm 3.5 \mathrm{kPa}$ \\
\hline Tachometer & $\begin{array}{l}(0.17 \text { to } 1667) \mathrm{Hz} \\
(10 \text { to } 99999) \mathrm{RPM}\end{array}$ & $\begin{array}{l} \pm 0.0167 \mathrm{~Hz} \\
\pm 1 \mathrm{RPM}\end{array}$ & $\begin{array}{l} \pm 0.005 \mathrm{~Hz} \\
\pm 0.3 \mathrm{RPM}\end{array}$ & $\begin{array}{l} \pm 0.0173 \mathrm{~Hz} \\
\pm 1.04 \mathrm{RPM}\end{array}$ \\
\hline Thermocouple (in-stream probe, ice ref.) & $(-10 \text { to } 100)^{\circ} \mathrm{C}$ & $\pm 0.08{ }^{\circ} \mathrm{C}$ & $\pm 0.06{ }^{\circ} \mathrm{C}$ & $\pm 0.09{ }^{\circ} \mathrm{C}$ \\
\hline Thermocouple (surface-mount, CJC) & $(-10$ to 60$){ }^{\circ} \mathrm{C}$ & $\pm 0.6^{\circ} \mathrm{C}$ & $\pm 0.04{ }^{\circ} \mathrm{C}$ & $\pm 0.6^{\circ} \mathrm{C}$ \\
\hline Thermopile $^{5}$ & $(1$ to 10$) \mathrm{K}$ & $\pm 0.015 \mathrm{~K}$ & $\pm 0.013 \mathrm{~K}$ & $\pm 0.0153 \mathrm{~K}$ \\
\hline Thermopile voltage & $(-10$ to 10$) \mathrm{V}$ & $\pm 1 \mu \mathrm{V}$ & $\pm 6.5 \mu \mathrm{V}$ & $\pm 7 \mu \mathrm{V}$ \\
\hline Torque meter & $(0$ to 40$) \mathrm{Nm}$ & $\pm 0.33 \mathrm{Nm}$ & $\pm 0.005 \mathrm{Nm}$ & $0.33 \mathrm{Nm}$ \\
\hline
\end{tabular}

${ }^{1} 95 \%$ confidence interval $(k=2)$ -

$2 \%$ rdg values have been applied to nominal values -

${ }^{3}$ Maximum of $0.1 \%$ and (z.s./flowrate) $* 100 \%$, where z.s. is zero stability $=0.0491 \mathrm{~g} \mathrm{~s}^{-1}$. -

${ }^{4}$ Maximum of $0.1 \%$ and (z.s./flowrate)* $100 \%$, where z.s. is zero stability $=0.0075 \mathrm{~g} \mathrm{~s}^{-1}$. -

${ }^{5}$ For temperature differences in $1 \mathrm{~K}$ to $10 \mathrm{~K}$ range. Outside range, uncertainty is higher. See Appendix A.5 for more detail. 
Table 2-4: List of MBBHP instruments (I-P units)

\begin{tabular}{|c|c|c|c|c|}
\hline Instrument & Range & $\begin{array}{l}\text { Instrument } \\
\text { Uncertainty }^{1} \\
\end{array}$ & $\begin{array}{l}\text { Steady State } \\
\text { Uncertainty }^{1}\end{array}$ & $\begin{array}{l}\text { Total } \\
\text { Uncertainty } 1,2\end{array}$ \\
\hline \multirow[t]{2}{*}{ Coriolis meter (HTF) } & $\begin{array}{l}\text { Mass flow: } \\
\text { ( } 0 \text { to } 100) \mathrm{lb} \mathrm{min}^{-1}\end{array}$ & $\begin{array}{l}\text { Mass flow }{ }^{3} \text { : } \\
\pm 0.1 \% \text { rdg. }\end{array}$ & $\begin{array}{l}\text { Mass flow: } \\
\pm 0.03 \mathrm{lb} \mathrm{min}^{-1}\end{array}$ & $\begin{array}{l}\text { Mass flow: } \\
\pm 0.035 \mathrm{lb} \mathrm{min}^{-1}\end{array}$ \\
\hline & $\begin{array}{l}\text { Density: } \\
(0 \text { to } 187) \mathrm{lb} \mathrm{ft}^{-3}\end{array}$ & $\begin{array}{l}\text { Density: } \\
\pm 0.062 \mathrm{lb} \mathrm{ft}^{-3}\end{array}$ & $\begin{array}{l}\text { Density: } \\
\pm 0.006 \mathrm{lb} \mathrm{ft}^{-3}\end{array}$ & $\begin{array}{l}\text { Density: } \\
\pm 0.062 \mathrm{lb} \mathrm{ft}^{-3}\end{array}$ \\
\hline \multirow[t]{2}{*}{ Coriolis meter (refrigerant) } & $\begin{array}{l}\text { Mass flow: } \\
\text { ( } 0 \text { to } 79.9) \mathrm{lb} \mathrm{min}^{-1}\end{array}$ & $\begin{array}{l}\text { Mass flow }{ }^{4} \text { : } \\
\pm 0.1 \% \text { rdg. }\end{array}$ & $\begin{array}{l}\text { Mass flow: } \\
\pm 0.0015 \mathrm{lb} \mathrm{min}^{-1}\end{array}$ & $\begin{array}{l}\text { Mass flow: } \\
\pm 0.002 \mathrm{lb} \mathrm{min}^{-1}\end{array}$ \\
\hline & $\begin{array}{l}\text { Density: } \\
(0 \text { to } 187) \mathrm{lb} \mathrm{ft}^{-3}\end{array}$ & $\begin{array}{l}\text { Density: } \\
\pm 0.062 \mathrm{lb} \mathrm{ft}^{-3}\end{array}$ & $\begin{array}{l}\text { Density: } \\
\pm 0.006 \mathrm{lb} \mathrm{ft}^{-3}\end{array}$ & $\begin{array}{l}\text { Density: } \\
\pm 0.062 \mathrm{lb} \mathrm{ft}^{-3}\end{array}$ \\
\hline Data acquisition system & $(-10$ to 10$) \mathrm{V}$ & $\pm 1 \mu \mathrm{V}$ & -- & $\pm 1 \mu \mathrm{V}$ \\
\hline Press. transducer (diff.) - condenser & (0 to 25$) \mathrm{psi}$ & $\pm 0.1 \mathrm{psi}$ & $\pm 0.1 \mathrm{psi}$ & $\pm 0.18 \mathrm{psi}$ \\
\hline Press. transducer (diff.) - evaporator & $(0$ to 50$)$ psi & $\pm 0.015 \mathrm{psi}$ & $\pm 0.1 \mathrm{psi}$ & $\pm 0.1 \mathrm{psi}$ \\
\hline Press. transducer (diff.) - suction & $(0$ to 10$)$ psi & $\pm 0.0015 \mathrm{psi}$ & $\pm 0.04 \mathrm{psi}$ & $\pm 0.04 \mathrm{psi}$ \\
\hline Press. transducer (high press.) & $(0$ to 500$)$ psia & $\pm 0.5 \mathrm{psi}$ & $\pm 0.1 \mathrm{psi}$ & $\pm 0.51 \mathrm{psi}$ \\
\hline Press. transducer (low press.) & (0 to 250$)$ psia & $\pm 0.5 \mathrm{psi}$ & $\pm 0.1 \mathrm{psi}$ & $\pm 0.51 \mathrm{psi}$ \\
\hline Tachometer & $\begin{array}{l}(0.17 \text { to } 1667) \mathrm{Hz} \\
\text { (10 to } 99999) \mathrm{RPM}\end{array}$ & $\begin{array}{l} \pm 0.0167 \mathrm{~Hz} \\
\pm 1 \mathrm{RPM}\end{array}$ & $\begin{array}{l} \pm 0.005 \mathrm{~Hz} \\
\pm 0.3 \mathrm{RPM}\end{array}$ & $\begin{array}{l} \pm 0.0173 \mathrm{~Hz} \\
\pm 1.04 \mathrm{RPM}\end{array}$ \\
\hline Thermocouple (in-stream probe, ice ref.) & $(14 \text { to } 212)^{\circ} \mathrm{F}$ & $\pm 0.15^{\circ} \mathrm{F}$ & $\pm 0.11^{\circ} \mathrm{F}$ & $\pm 0.18^{\circ} \mathrm{F}$ \\
\hline Thermocouple (surface-mount, CJC) & $(14 \text { to } 140)^{\circ} \mathrm{F}$ & $\pm 1.1^{\circ} \mathrm{F}$ & $\pm 0.08^{\circ} \mathrm{F}$ & $\pm 1.1^{\circ} \mathrm{F}$ \\
\hline Thermopile $^{5}$ & $(1.8 \text { to } 18)^{\circ} \mathrm{F}$ & $\pm 0.027^{\circ} \mathrm{F}$ & $\pm 0.023^{\circ} \mathrm{F}$ & $\pm 0.04^{\circ} \mathrm{F}$ \\
\hline Torque meter & ( 0 to 350$)$ in $\mathrm{lb}$ & \pm 2.9 in $\mathrm{lb}$ & $\pm 0.045 \mathrm{in} \mathrm{lb}$ & \pm 2.9 in $\mathrm{lb}$ \\
\hline
\end{tabular}

${ }^{1} 95 \%$ confidence interval $(k=2)$

$2 \%$ rdg values have been applied to nominal values

${ }^{3}$ Maximum of $0.1 \%$ and (z.s./flowrate) $* 100 \%$, where z.s. is zero stability $=0.0065 \mathrm{lb} \mathrm{min}^{-1}$

${ }^{4}$ Maximum of $0.1 \%$ and (z.s./flowrate) $* 100 \%$, where z.s. is zero stability $=0.001 \mathrm{lb} \mathrm{min}^{-1}$

${ }^{5}$ For temperature differences in $1.8^{\circ} \mathrm{F}$ to $18^{\circ} \mathrm{F}$ range. Outside range, uncertainty is higher. See Appendix A.5 for more detail. 


\subsection{Operation}

\subsubsection{Test Rig Control Parameters}

There are ten Control Parameters (i.e., settings of adjustable components) listed in Table 2-5 that the MBBHP operator sets to achieve a desired set of Operating Parameters. Each Control Parameter primarily governs one or two Operating Parameters; the correspondence is shown in the table.

Table 2-5: List of the Control Parameters and Operating Parameters

\begin{tabular}{|c|c|c|c|}
\hline \# & Operating Parameter & Operating Parameter Values & Control Parameter \\
\hline 1 & Evaporator saturation temperature & See Table 2-6 & Heater setpoint (HTF inlet temp.) \\
\hline 2 & Condenser saturation temperature & See Table 2-6 & Chiller setpoint (HTF inlet temp.) \\
\hline 3 & Capacity/heat flux & $\begin{array}{l}1760 \mathrm{~W} \text { to } 3520 \mathrm{~W} \\
(0.5 \text { ton to } 1 \text { ton })\end{array}$ & Compressor speed \\
\hline 4 & Evaporator heat flux & $\begin{array}{l}2000 \mathrm{~W} \mathrm{~m}^{-2} \text { to } 12000 \mathrm{~W} \mathrm{~m}^{-2} \\
\left(600 \mathrm{Btu} \mathrm{h}^{-1} \mathrm{ft}^{-2} \text { to } 3800 \mathrm{Btu} \mathrm{h}^{-1} \mathrm{ft}^{-2}\right)\end{array}$ & Number of evaporator tubes \\
\hline 5 & Condenser heat flux & $\begin{array}{l}2000 \mathrm{~W} \mathrm{~m}^{-2} \text { to } 12000 \mathrm{~W} \mathrm{~m}^{-2} \\
\left(600 \mathrm{Btu} \mathrm{h}^{-1} \mathrm{ft}^{-2} \text { to } 3800 \mathrm{Btu} \mathrm{h}^{-1} \mathrm{ft}^{-2}\right)\end{array}$ & Number of condenser tubes \\
\hline 6 & Condenser HTF-side resistance & $50 \%$ to $70 \%$ of overall resistance & Condenser HTF flowrate \\
\hline 7 & Evaporator HTF-side resistance & $70 \%$ to $85 \%$ of overall resistance & Evaporator HTF flowrate \\
\hline 8 & Subcool/ Superheat & $\leq 2$ tubes $^{1} / \leq 1$ tube $^{2}$ & Refrigerant needle valve setting \\
\hline 9 & Subcool/ Superheat & $\leq 2$ tubes $^{1} / \leq 1$ tube $^{2}$ & Refrigerant charge \\
\hline 10 & LLSL-HX included/bypassed & Included/bypassed & LLSL-HX valves \\
\hline
\end{tabular}

${ }^{1}$ achieved with subcooling of $2 \mathrm{~K}$ to $3 \mathrm{~K}\left(1.8^{\circ} \mathrm{F}\right.$ to $\left.3.6^{\circ} \mathrm{F}\right)$

${ }^{2}$ achieved with superheat of $3 \mathrm{~K}$ to $6 \mathrm{~K}\left(5.4^{\circ} \mathrm{F}\right.$ to $\left.10.8^{\circ} \mathrm{F}\right)$

\subsubsection{Test Rig Operating Parameters}

This section describes each of the target Operating Parameters, and how they are set using the Control Parameters. Note that the headings for Sections 2.3.2.1 through 2.3.2.5 include the Operating Parameters numbers (1 to 10) as listed in Table 2-5.

\subsubsection{Operating Parameters 1 \& 2: Evaporator and Condenser Saturation Temperature}

The U.S. Department of Energy (DOE) requires heat pumps and air conditioners to be rated at conditions prescribed in the ANSI/AHRI 210/240-2008 (AHRI, 2008) standard. The standard specifies temperatures of the HTF (air, in the standard) entering the evaporator and condenser. A somewhat different, but derivative, method is employed here; the HTF inlet temperatures are set to achieve refrigerant saturation temperatures expected under ANSI/AHRI Cooling A, Cooling B and Heating H1 Rating Tests for the baseline refrigerant R134a.

The target saturation temperatures are computed first for the Cooling A test where the assumed Coefficient of Performance $\left(\mathrm{COP}_{c o o l}\right)$ is 4.4 (energy efficiency ratio, EER, is 15). The 
ANSI/AHRI standard is not prescriptive about airflow, so typical values per unit evaporator capacity are used: for the evaporator $\left(\dot{V}_{\text {air,evap }} / \dot{Q}_{\text {evap }}\right), 0.189 \mathrm{~m}^{3} \mathrm{~s}^{-1} \mathrm{~kW}^{-1}\left(400 \mathrm{ft}^{3} \mathrm{~min}^{-1} \mathrm{ton}^{-1}\right)$, and for the condenser $\left(\dot{V}_{\text {air,cond }} / \dot{Q}_{\text {evap }}\right), 0.378 \mathrm{~m}^{3} \mathrm{~s}^{-1} \mathrm{~kW}^{-1}\left(800 \mathrm{ft}^{3} \mathrm{~min}^{-1}\right.$ ton $\left.^{-1}\right)$. Inlet air temperatures $\left(T_{\text {air, in }}\right)$ prescribed by the ANSI/AHRI standard are listed in Table 2-6; the temperature change across the evaporator and condenser $\left(\Delta T_{\text {air,evap }}, \Delta T_{\text {air,cond }}\right)$ is $12.6 \mathrm{~K}$ and $9.7 \mathrm{~K}\left(22.8^{\circ} \mathrm{F}\right.$ and 17.5 ${ }^{\circ} \mathrm{F}$ ), respectively, as computed using an energy balance on the airstream, where the condenser energy is larger by an amount that reflects the compressor power (in the COP term):

$$
\begin{gathered}
\Delta T_{\text {air,evap }}=\left(\dot{V}_{\text {air }, \text { evap }} / \dot{Q}_{\text {evap }}\right)^{-1} \frac{1}{\rho_{\text {air }} C_{p, \text { air }}} \\
\Delta T_{\text {air, cond }}=\left(\dot{V}_{\text {air, cond }} / \dot{Q}_{\text {evap }}\right)^{-1}\left(1+\frac{1}{\mathrm{COP}_{\text {cool }}}\right) \frac{1}{\rho_{\text {air }} C_{p, \text { air }}}
\end{gathered}
$$

where the variables represent:

$$
\begin{array}{cl}
C_{p, \text { air }} & =\text { specific heat of air at constant pressure } \\
\dot{V}_{\text {air, cond }} / \dot{Q}_{\text {evap }} & =\text { condenser airflow per unit evaporator capacity } \\
\dot{V}_{\text {air,evap }} / \dot{Q}_{\text {evap }} & =\text { evaporator airflow per unit evaporator capacity } \\
\rho_{\text {air }} & =\text { density of air }
\end{array}
$$

The air outlet temperatures $\left(T_{\text {air,out }}\right)$ are then computed by respectively subtracting or adding the $\Delta T_{\text {air,evap }}, \Delta T_{\text {air,cond, }}$ from the $T_{\text {air, in }}$ values.

The average temperature difference between the refrigerant and the air $\left(\Delta T_{\text {air,ref }}\right)$ for Cooling $\mathrm{A}$ is specified as $10 \mathrm{~K}$ and $3.3 \mathrm{~K}\left(18^{\circ} \mathrm{F}\right.$ and $\left.6^{\circ} \mathrm{F}\right)$ in the evaporator and condenser, respectively, based on experience and measurements at NIST for air-source heat pumps with comparable COPs. Table 2-6 shows the average air $\left(T_{\text {air }, \text { avg }}\right)$ and average refrigerant saturation temperatures $\left(T_{\text {ref,avg }}\right)$ computed using this method. The Cooling B refrigerant saturation temperatures are computed using the same $\Delta T_{\text {air }}$ and $\Delta T_{\text {air,ref. }}$. In heating, the heat exchangers operating as the evaporator/condenser swap, so the values of $\Delta T_{\text {air }}$ and $\Delta T_{\text {air, ref }}$ for the evaporator (in cooling) are used for the condenser, and vice versa. The resulting refrigerant saturation temperatures are nominally aligned with values observed in heat pump measurements at NIST. The HTF inlet temperatures $\left(T_{H T F, i n}\right)$ are adjusted to achieve the target refrigeration saturation temperature at a compressor speed of $30 \mathrm{~Hz}$ (1800 RPM) with R134a, and then held constant for all other speeds. The corresponding HTF outlet temperatures $\left(T_{H T F, \text { out }}\right)$ are defined as:

$$
\begin{aligned}
& T_{H T F, e, \text { out }}=T_{H T F, e, \text { in }}+\Delta T_{e} \\
& T_{H T F, \text {, out }}=T_{H T F, \text {, in }}+\Delta T_{c}
\end{aligned}
$$

where $\Delta T_{e}$ and $\Delta T_{c}$ are the HTF temperature differences across the evaporator/condenser measured by the thermopiles. The $T_{H T F, \text { out }}$ values differ for each speed; Table 2-6 shows the values at $30 \mathrm{~Hz}$ (1800 RPM) as a nominal example. As discussed in Section 1, a completely fair comparison of refrigerants requires the same HTF inlet and outlet temperatures (McLinden et al., 1987). However, it is only possible to match either the evaporator or condenser (but not both) $T_{H T \text {,out }}$ by adjusting the heat pump capacity (via compressor speed); the other $T_{H T F, \text { out }}$ will be an 
uncontrolled value, which will vary somewhat from the R134a value, depending on the COP of each fluid (note the HTF mass flow rate is fixed as described in Section 2.3.2.3, so it cannot be adjusted to control the other $\left.T_{H T F, o u t}\right)$. Tests with future refrigerants will be carried out with an evaporator or condenser $T_{H T F, \text { out }}$ equal to the measurements for R134a in cooling or heating, respectively, and the other $T_{H T F, \text { out }}$ will vary for each fluid.

Table 2-6: Evaporator and condenser fluid temperatures for standard rating tests

\begin{tabular}{|c|c|c|c|c|c|c|c|c|c|c|}
\hline & Rating Test & $\begin{array}{c}\boldsymbol{T}_{\text {air,in }} \\
{ }^{\circ} \mathrm{C} \\
\left({ }^{\circ} \mathrm{F}\right)\end{array}$ & $\begin{array}{c}\Delta \boldsymbol{T}_{\text {air }} \\
\mathrm{K} \\
\left({ }^{\circ} \mathrm{F}\right)\end{array}$ & $\begin{array}{c}\boldsymbol{T}_{\text {air }, \text { out }} \\
{ }^{\circ} \mathrm{C} \\
\left({ }^{\circ} \mathrm{F}\right)\end{array}$ & $\begin{array}{c}T_{\text {air }, \boldsymbol{a v g}} \\
{ }^{\circ} \mathrm{C} \\
\left({ }^{\circ} \mathrm{F}\right)\end{array}$ & $\begin{array}{c}\Delta \boldsymbol{T}_{\text {air }, \text { ref }} \\
\mathrm{K} \\
\left({ }^{\circ} \mathrm{F}\right)\end{array}$ & $\begin{array}{c}\boldsymbol{T}_{\text {reffavg }} \\
{ }^{\circ} \mathrm{C} \\
\left({ }^{\circ} \mathrm{F}\right)\end{array}$ & $\begin{array}{c}\boldsymbol{T}_{\boldsymbol{H} T \boldsymbol{\text { in }} \text { 促 }} \\
{ }^{\circ} \mathrm{C} \\
\left({ }^{\circ} \mathrm{F}\right)\end{array}$ & $\begin{array}{c}\boldsymbol{T}_{\boldsymbol{H} T \boldsymbol{\text { out }}}{ }^{\mathrm{I}} \\
{ }^{\circ} \mathrm{C} \\
\left({ }^{\circ} \mathrm{F}\right)\end{array}$ & $\begin{array}{c}\dot{m}_{H T F} \\
\mathrm{~kg} \mathrm{~s}^{-1} \\
\mathrm{lb} \mathrm{min}^{-1}\end{array}$ \\
\hline \multirow{3}{*}{ Condenser } & Cooling A & $\begin{array}{c}35.0 \\
(95.0)\end{array}$ & $\begin{array}{c}9.7 \\
(17.5)\end{array}$ & $\begin{array}{c}44.7 \\
(112.5)\end{array}$ & $\begin{array}{c}39.9 \\
(103.8)\end{array}$ & $\begin{array}{c}3.3 \\
(6.0)\end{array}$ & $\begin{array}{c}43.2 \\
(109.8)\end{array}$ & $\begin{array}{c}33.9 \\
(93.0)\end{array}$ & $\begin{array}{c}39.1 \\
(102.4)\end{array}$ & $\begin{array}{c}0.098 \\
(13)\end{array}$ \\
\hline & Cooling B & $\begin{array}{c}27.8 \\
(82.0)\end{array}$ & $\begin{array}{c}9.7 \\
(17.5)\end{array}$ & $\begin{array}{c}37.5 \\
(99.5)\end{array}$ & $\begin{array}{c}32.6 \\
(90.8)\end{array}$ & $\begin{array}{c}3.3 \\
(6.0)\end{array}$ & $\begin{array}{c}36.0 \\
(96.8)\end{array}$ & $\begin{array}{c}24.9 \\
(76.7)\end{array}$ & $\begin{array}{c}30.9 \\
(87.6)\end{array}$ & $\begin{array}{c}0.098 \\
(13)\end{array}$ \\
\hline & Heating H1 & $\begin{array}{c}21.1 \\
(70.0)\end{array}$ & $\begin{array}{c}12.6 \\
(22.8)\end{array}$ & $\begin{array}{c}33.8 \\
(92.8)\end{array}$ & $\begin{array}{c}27.4 \\
(81.4)\end{array}$ & $\begin{array}{c}10.0 \\
(18.0)\end{array}$ & $\begin{array}{c}37.4 \\
(99.4)\end{array}$ & $\begin{array}{c}32.0 \\
(89.5)\end{array}$ & $\begin{array}{c}36.3 \\
(97.3)\end{array}$ & $\begin{array}{c}0.098 \\
(13)\end{array}$ \\
\hline \multirow{3}{*}{ Evaporator } & Cooling A & $\begin{array}{c}26.7 \\
(80.0)\end{array}$ & $\begin{array}{c}12.6 \\
(22.8)\end{array}$ & $\begin{array}{c}14.0 \\
(57.3)\end{array}$ & $\begin{array}{c}20.3 \\
(68.6)\end{array}$ & $\begin{array}{c}10.0 \\
(18.0)\end{array}$ & $\begin{array}{c}10.3 \\
(50.6)\end{array}$ & $\begin{array}{c}20.2 \\
(68.5)\end{array}$ & $\begin{array}{c}15.4 \\
(59.7)\end{array}$ & $\begin{array}{l}0.131 \\
(17.3)\end{array}$ \\
\hline & Cooling B & $\begin{array}{c}26.7 \\
(80.0)\end{array}$ & $\begin{array}{c}12.6 \\
(22.8)\end{array}$ & $\begin{array}{c}14.0 \\
(57.3)\end{array}$ & $\begin{array}{c}20.3 \\
(68.6)\end{array}$ & $\begin{array}{c}10.0 \\
(18.0)\end{array}$ & $\begin{array}{c}10.3 \\
(50.6)\end{array}$ & $\begin{array}{c}19.9 \\
(67.8)\end{array}$ & $\begin{array}{c}14.2 \\
(57.6)\end{array}$ & $\begin{array}{l}0.131 \\
(17.3)\end{array}$ \\
\hline & Heating H1 & $\begin{array}{c}8.3 \\
(47.0)\end{array}$ & $\begin{array}{c}9.7 \\
(17.5)\end{array}$ & $\begin{array}{c}-1.4 \\
(29.5)\end{array}$ & $\begin{array}{c}3.5 \\
(38.3)\end{array}$ & $\begin{array}{c}3.3 \\
(6.0)\end{array}$ & $\begin{array}{c}0.1 \\
(32.3)\end{array}$ & $\begin{array}{c}10.3 \\
(50.5)\end{array}$ & $\begin{array}{c}6.5 \\
(43.7)\end{array}$ & $\begin{array}{l}0.131 \\
(17.3)\end{array}$ \\
\hline
\end{tabular}

${ }^{1}$ Values for R134a at a compressor speed of $30 \mathrm{~Hz}(1800 \mathrm{RPM})$

\subsubsection{Operating Parameters 3, 4, \& 5: Capacity and Heat Flux}

Baseline capacities were established for R134a at speeds of $23.3 \mathrm{~Hz}$ to $36.7 \mathrm{~Hz}$ (1400 RPM to 2200 RPM), in $3.3 \mathrm{~Hz}$ (200 RPM) increments, for each Rating Test. Tests with subsequent refrigerants will be carried out with compressor speeds that match the capacities from the baseline tests; this ensures the refrigerants are tested at the same $\dot{Q} / A_{\text {total }}$. The target refrigerantside heat flux range was $2 \mathrm{~kW} \mathrm{~m}^{-2}$ to $12 \mathrm{~kW} \mathrm{~m}^{-2}\left(600 \mathrm{Btu} \mathrm{h}^{-1} \mathrm{ft}^{-2}\right.$ to $\left.3800 \mathrm{Btuh}^{-1} \mathrm{ft}^{-2}\right)$ to coincide with values from typical HVAC\&R equipment. The average heat flux in the evaporator and condenser was controlled by setting the number of active tubes to 10 and 12, respectively. Figure 2-6 summarizes the capacity for the baseline tests, where the evaporator capacity varies from $1.2 \mathrm{~kW}$ to $2.1 \mathrm{~kW}(0.34$ ton to $0.60 \mathrm{ton})$ and condenser capacity ranges from $1.6 \mathrm{~kW}$ to 2.8 $\mathrm{kW}\left(0.45\right.$ ton to 0.80 ton). The heat flux in the evaporator varies from $5 \mathrm{~kW} \mathrm{~m}^{-2}$ to $9 \mathrm{~kW} \mathrm{~m}^{-2}$ $\left(1600 \mathrm{Btuh}^{-1} \mathrm{ft}^{-2}\right.$ to $\left.2900 \mathrm{Btuh}^{-1} \mathrm{ft}^{-2}\right)$ and in the condenser from $5 \mathrm{~kW} \mathrm{~m}^{-2}$ to $10 \mathrm{~kW} \mathrm{~m}^{-2}(1700$ $\mathrm{Btuh}^{-1} \mathrm{ft}^{-2}$ to $3200 \mathrm{Btuh}^{-1} \mathrm{ft}^{-2}$ ), meeting the target heat flux range. 


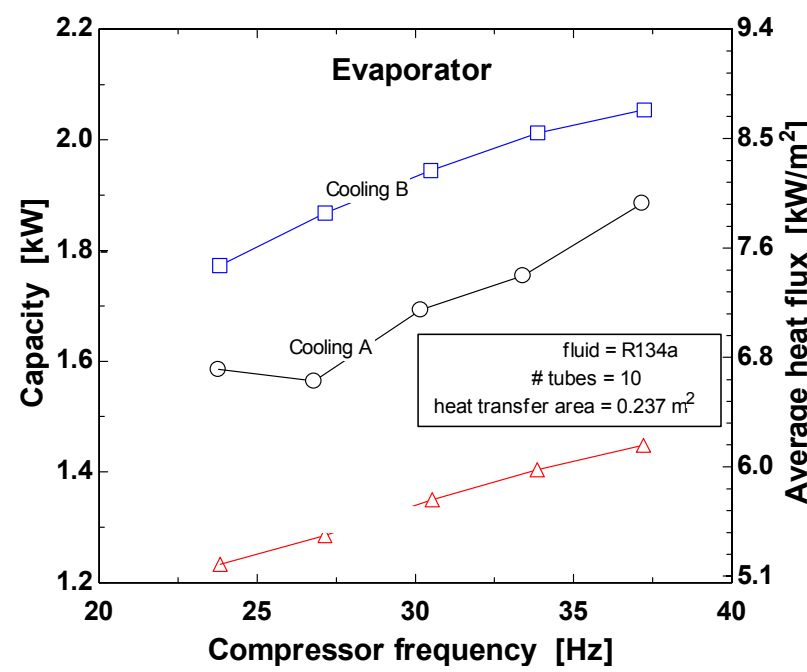

(a)

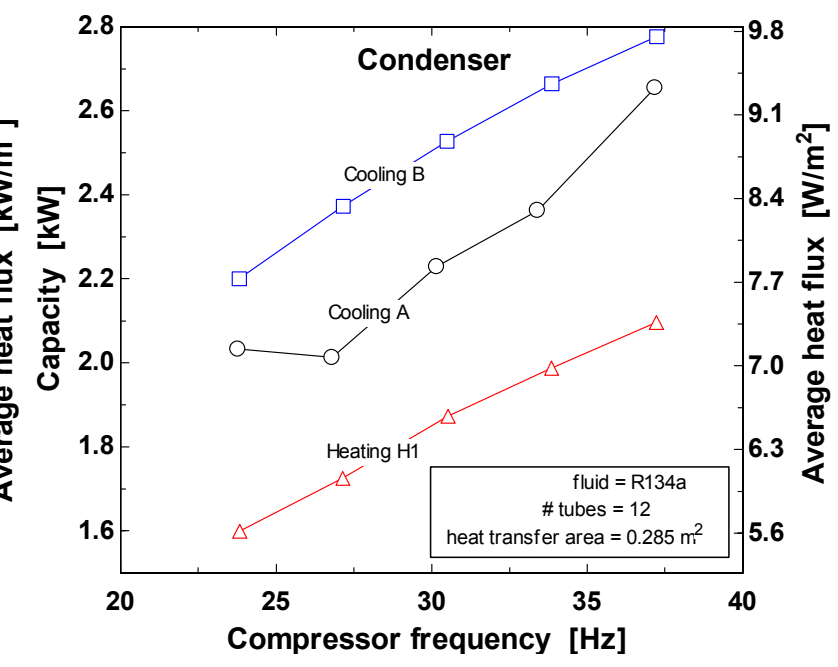

(b)

Figure 2-6: - Capacity and heat flux for baseline R134a tests for (a) evaporator and (b) condenser

\subsubsection{Operating Parameters 6 \& 7: HTF-side Thermal Resistance Ratio}

In typical air-to-air heat pumps the air-side convection provides the majority of the resistance to heat transfer. Evaporation heat transfer coefficients are generally larger than those for condensation, so the HTF-side resistance ratio $\left(R_{H T F} / R_{\text {total }}\right)$ is selected in the range of $50 \%$ to $70 \%$ for the condenser and $70 \%$ to $85 \%$ in the evaporator. The CYCLE_D-HX model reports heat exchanger thermal resistances for both the evaporator and condenser when given measurements of HTF in/out temperatures, capacity, compressor efficiency, and heat exchanger geometry, pressure drop, and log-mean temperature difference. These resistances include the heat exchanger total conductance $(U A)$ (the total resistance, $R_{\text {total }}$, is the inverse of $U A$ ), the heat transfer-side resistance $\left(R_{H T F}\right)$ in the evaporator/condenser, and the refrigerant-side thermal resistance $\left(R_{r e f}\right)$ in the evaporator/condenser. Note that the tube wall thermal resistance is neglected.

The MBBHP was operated under varied HTF flowrates $\left(\dot{m}_{H T F}\right)$, and the resulting data were processed using the CYCLE_D-HX model to determine $R_{H T F} / R_{\text {total }}$ for each flowrate. The evaporator and condenser HTF flowrates used for the tests are $0.131 \mathrm{~kg} \mathrm{~s}^{-1}$ and $0.098 \mathrm{~kg} \mathrm{~s}^{-1}(17.3$ $\mathrm{lb} \mathrm{min}^{-1}$ and $13 \mathrm{lb} \mathrm{min}^{-1}$ ) as shown in Table 2-6, which yield $R_{H T F} / R_{\text {total }}$ of $80 \%$ and $60 \%$ for the baseline Cooling A test with R134a at $30 \mathrm{~Hz}$ (1800 RPM). The flowrates are kept constant for all other speeds, test conditions, and refrigerants. Maintaining a constant flowrate is important for verifying the CYCLE_D-HX model; the model evaluates the HTF-side thermal resistance for a reference data set, and then holds this resistance constant as other operating parameters, refrigerants, and tube circuit configurations are computationally explored.

\subsubsection{Operating Parameters 8 \& 9: Subcool and Superheat}

The number of evaporator tubes containing superheated-vapor and condenser tubes with subcooled-liquid are controlled to one and two, respectively. It is important to limit the number of tubes in superheat and subcooling for comparison with the CYCLE_D-HX model because the 
model does not consider the pressure drop or area required for heat transfer in these sections, rather, it only accounts for transport phenomena in the two-phase section. (Note that the superheat and subcooling are included as an input to the model to determine the thermodynamic states at the heat exchanger outlets.) The superheat and subcooling are also limited because of performance considerations; the single phase fluid exhibits a lower heat transfer coefficient compared to a two-phase fluid. The superheat is bound at the low end by the need to prevent liquid from entering the compressor. The lower limit for subcooling is governed by a requirement of fully subcooled liquid entering the expansion valve; vapor bubbles entering the expansion valve cause oscillations in the flow that make it difficult to achieve steady state. In general, a superheat range of $3 \mathrm{~K}$ to $6 \mathrm{~K}$ and a subcooling range of $2 \mathrm{~K}$ to $3 \mathrm{~K}$ satisfies this Operating Parameter requirement.

Closing the refrigerant needle valve increases the superheat and the subcooling, whereas adding refrigerant increases the subcooling and reduces the superheat. The combination of these two controls allows for independent regulation of superheat and subcooling.

\subsubsection{Operating Parameter 10: LLSL-HX included or bypassed}

The LLSL-HX heat exchanger is included or bypassed using the six valves shown in Figure 2-1. When the LLSL-HX is bypassed, only one (rather than both) of the valves that stops flow through the heat exchanger is closed; this prevents the possibility of trapping subcooled liquid between the valves (and presenting the same pressure hazard discussed in Section 2.1. 


\section{Data Analysis -}

\subsection{Thermodynamic States}

The thermodynamic states numbered 1 through 11 in Figure 2-1 are fixed with two intensive properties defined by the measurements and equations presented in Table 3-1. Thermodynamic property data for R134a are computed using the Engineering Equation Solver (EES) software (Klein, 2015); the software uses the equation of state developed by Tilner-Roth et al. (1994) for R134a. Note that property data for mixtures and for fluids not directly available in EES will be computed using the NIST REFPROP database (Lemmon et al., 2013).

Table 3-1: Measurements and equations used to define the thermodynamic states

\begin{tabular}{clcll} 
State & Description & Measurement & \multicolumn{2}{c}{ Equations } \\
\hline 1 & Compressor inlet, LLSL-HX vapor outlet & $T_{1}$ & $P_{1}=P_{11}-\Delta P_{s}$ & \\
\hline 2 & Compressor cylinder before compression & & $T_{2}=T_{1}$ & $P_{2}=P_{1}$ \\
\hline 3 & Compressor outlet & $T_{3}$ & $P_{3}=P_{4}$ & \\
\hline 4 & Condenser inlet & $T_{4}$ & $P_{4}=P_{7}+\Delta P_{c}$ & \\
\hline 5 & Condenser saturated vapor & & $P_{5}=P_{4}$ & $x_{5}=1$ \\
\hline 6 & Condenser saturated liquid & & $P_{6}=P_{7}$ & $x_{6}=0$ \\
7 & Condenser outlet, LLSL-HX liquid inlet & $T_{7}, P_{7}$ & & \\
\hline 8 & Expansion valve inlet, LLSL-HX liquid outlet & $T_{8}$ & $P_{8}=P_{7}$ & \\
\hline 9 & Evaporator inlet, Expansion valve outlet & $P_{9}$ & $h_{9}=h_{8}$ & \\
\hline 10 & Evaporator saturated vapor & & $P_{10}=P_{11}$ & $x_{10}=1$ \\
\hline 11 & Evaporator outlet, LLSL-HX vapor inlet & $T_{11}$ & $P_{11}=P_{9}-\Delta P_{e}$ & \\
\hline
\end{tabular}

$T=$ temperature, $P=$ pressure, $h=$ enthalpy, $x=$ thermodynamic quality

\subsection{Thermodynamic Performance}

Given the fixed state points identified in Table 3-1 (and all associated intensive properties), the key thermodynamic performance metrics are calculated according to the equations in Sections 3.2.1 through 3.2.7. Nominal values and uncertainties of the metrics are shown in Section 4, and Appendix A, respectively.

\subsubsection{Capacity}

The evaporator and condenser capacities are computed on the refrigerant/HTF-sides according to:

$$
\begin{gathered}
\dot{Q}_{c, r e f}=\dot{m}_{r e f}\left(h_{4}-h_{7}\right) \\
\dot{Q}_{e, r e f}=\dot{m}_{r e f}\left(h_{9}-h_{11}\right) \\
\dot{Q}_{\mathrm{c}, H T F}=\dot{m}_{H T F, \mathrm{c}} C_{p, H T F, c} \Delta T_{c}-\dot{Q}_{i n s, c}
\end{gathered}
$$




$$
\dot{Q}_{e, H T F}=\dot{m}_{H T F, e} C_{p, H T F, e} \Delta T_{e}-\dot{Q}_{i n s, e}
$$

where the variables represent:

$$
\begin{aligned}
& \dot{m}_{r e f} \quad=\text { mass flow of refrigerant } \\
& \dot{m}_{H T F, \mathrm{e}} \quad \dot{m}_{H T F, c}=\text { mass flow of HTF in evaporator/condenser } \\
& C_{p, H T F, e} C_{p, H T F, c}=\text { specific heats (average) of HTF in evaporator/condenser } \\
& \dot{Q}_{i n s, e} \quad \dot{Q}_{i n s, c}=\text { insulation heat leak in evaporator/condenser } \\
& \Delta T_{e} \quad \Delta T_{c}=\text { temperature change of HTF in evaporator/condenser }
\end{aligned}
$$

The insulation heat leak is a non-trivial $30 \mathrm{~W}$ to $50 \mathrm{~W}$, and therefore must be accounted for in the heat exchanger capacity. The heat leak is debited from the HTF-side capacity because the HTF is the annulus, and therefore thermally interacts with the surrounding ambient air. The heat exchangers are divided into active and inactive sections (i.e., tubes where the HTF flows, but the refrigerant does and does not, respectively) to compute the heat leak according to:

$$
\begin{aligned}
& \dot{Q}_{i n s, e}=U A_{\text {ins }, e}\left(\frac{N T_{e, a c t i v e}}{N T_{e, \text { total }}}\left(T_{H T F, e, a c t i v e, a v g}-T_{\text {amb }, e}\right)+\frac{N T_{\mathrm{e}, \text { inactive }}}{N T_{\mathrm{e}, \text { total }}}\left(T_{H T F, e, \text { inactive, avg }}-T_{\text {amb }, e}\right)\right) \\
& \dot{Q}_{i n s, c}=U A_{\text {ins }, c}\left(\frac{N T_{c, a c t i v e}}{N T_{c, \text { total }}}\left(T_{H T F, c, \text { active, avg }}-T_{\text {amb }, c}\right)+\frac{N T_{c, \text { inactive }}}{N T_{c, \text { total }}}\left(T_{H T F, c, \text { inactive, avg }}-T_{\text {amb }, c}\right)\right)
\end{aligned}
$$

where:

$$
\begin{aligned}
& U A_{\text {ins }, e} \quad U A_{\text {ins, },} \quad=\text { insulation conductance for evaporator/condenser } \\
& N T_{e, \text { total }} \quad N T_{e, \text { total }} \quad=\text { number of tubes in evaporator/condenser total (20) } \\
& N T_{e, \text { active }} \quad N T_{c, \text { active }} \quad=\text { number of active tubes in evaporator/condenser } \\
& N T_{\text {, inactive }} \quad N T_{\text {, inactive }} \quad=\text { number of inactive tubes in evaporator/condenser } \\
& T_{H T F, e, a c t i v e, a v g} T_{H T F, \text {,active, avg }}=\text { avg. HTF temp. in the active evaporator/condenser tubes } \\
& T_{H T F, \text {,inactive, avg }} T_{H T F, \text {, inactive, avg }}=\text { avg. HTF temp. in the inactive evaporator/condenser tubes } \\
& T_{a m b, e} \quad T_{a m b, c} \quad=\text { temp. of ambient air surrounding evaporator/condenser }
\end{aligned}
$$

The HTF temperatures are taken from the surface-mounted thermocouples, and the ambient air temperature is taken from a thermocouple near each of the heat exchangers. The heat exchangers are split into active/inactive sections because the slope of the HTF temperature profile is different in each section; the heat transfer is only governed by the average temperature difference

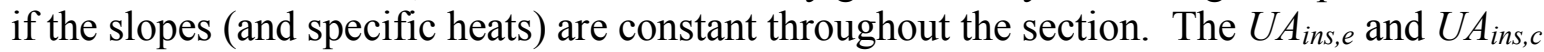
values for all 20 tubes are $5.48 \mathrm{~W} \mathrm{~K}^{-1} \pm 0.31 \mathrm{~W} \mathrm{~K}^{-1}$ and $6.52 \mathrm{~W} \mathrm{~K}^{-1} \pm 0.41 \mathrm{~W} \mathrm{~K}^{-1}\left(10.4 \mathrm{Btuh}^{-1}{ }^{\circ} \mathrm{F}^{-1}\right.$ $\pm 0.59 \mathrm{Btuh}^{-1}{ }^{\circ} \mathrm{F}^{-1}$ and $\left.12.4 \mathrm{Btuh}^{-1}{ }^{\circ} \mathrm{F}^{-1} \pm 0.78 \mathrm{Btuh}^{-1} \mathrm{o}^{-1}\right)$. The method used to compute the conductance values and their uncertainties is described in Appendix A.8.

\subsubsection{Compressor Power}

The compressor power is computed using the change in enthalpy across the compressor: 


$$
\dot{W}_{\text {comp }}=\dot{m}_{r e f}\left(h_{3}-h_{1}\right)
$$

The shaft power is computed for comparison with the compressor power:

$$
\dot{W}_{\text {shaft }}=2 \pi \tau N
$$

where the variables represent:

$$
\begin{aligned}
N & =\text { compressor shaft speed } \\
\tau & =\text { compressor shaft torque }
\end{aligned}
$$

\subsubsection{Coefficient of Performance}

The cooling and heating COP are computed using the refrigerant-side capacity and the compressor power applied to the refrigerant:

$$
\begin{aligned}
& \mathrm{COP}_{\text {cool }}=\dot{Q}_{e, r e f} / \dot{W}_{\text {comp }} \\
& \mathrm{COP}_{\text {heat }}=\dot{Q}_{c, \text { ref }} / \dot{W}_{\text {comp }}
\end{aligned}
$$

\subsubsection{Volumetric Capacity}

The volumetric cooling and heating capacity (VCC and VHC) are:

$$
\begin{gathered}
V C C=\dot{Q}_{e, r e f} /\left(\dot{m}_{r e f} v_{1}\right) \\
V H C=\dot{Q}_{c, r e f} /\left(\dot{m}_{r e f} v_{1}\right)
\end{gathered}
$$

where:

$$
v_{1}=\text { compressor suction specific volume }
$$

\subsubsection{Compressor Efficiency}

The compressor isentropic efficiency is calculated as: -

$$
\eta_{s}=\frac{h\left(P_{3}, s_{1}\right)-h_{1}}{h_{3}-h_{1}}
$$

where:

$$
h\left(P_{3, S_{1}}\right)=\text { compressor discharge enthalpy under isentropic compression }
$$

The volumetric efficiency is quantified by the refrigerant displacement normalized by the compressor swept volume displacement:

$$
\eta_{v}=\frac{\dot{m}_{r e f} v_{1}}{D_{\text {comp }} N}
$$

where: 


$$
D_{\text {comp }}=\text { compressor displacement (listed in Table 2-1) }
$$

\subsubsection{Superheat and Subcooling}

The evaporator superheat is:

$$
S H=T_{11}-T\left(P_{11}, x=1\right)
$$

and the condenser subcooling is:

$$
S C=T\left(P_{7}, x=0\right)-T_{7}
$$

where:

$$
\begin{aligned}
T\left(P_{11}, x=1\right) & =\text { saturated vapor temperature at the evaporator exit pressure - } \\
T\left(P_{7}, x=0\right) & =\text { saturated liquid temperature at the condenser exit pressure - }
\end{aligned}
$$

The number of refrigerant tubes containing superheated/subcooled fluid in the evaporator/condenser is controlled to one and two, respectively, during experimental tests. Visual inspection of the temperature profile, such as the one shown in Figure 3-1, is used to determine the locations of the various phase transitions. The tube number on the $\mathrm{x}$-axis reflects the convention established in Figure 2-5.

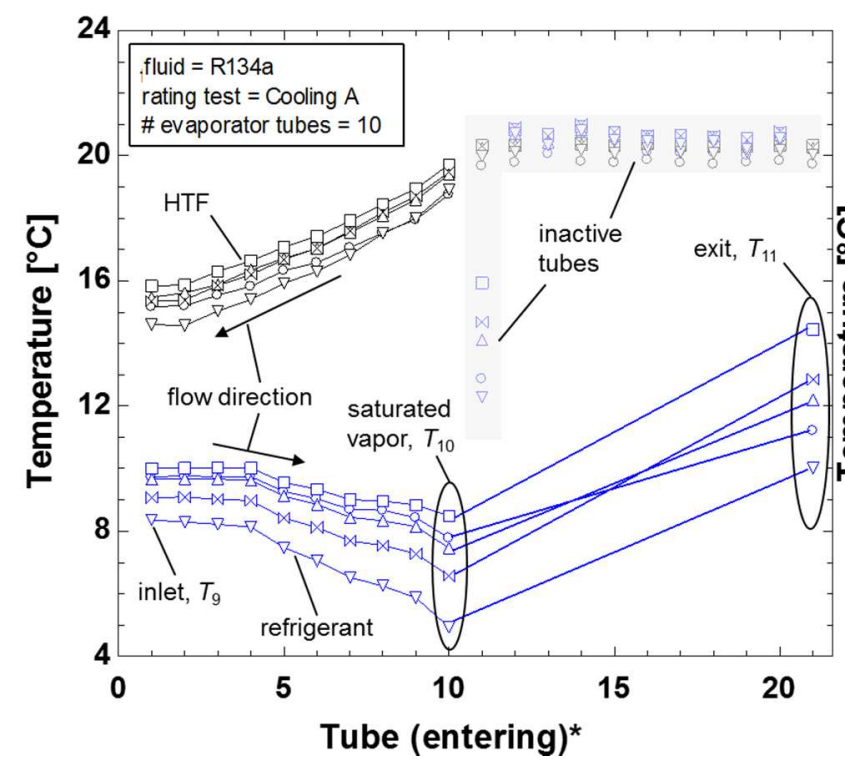

(a) -

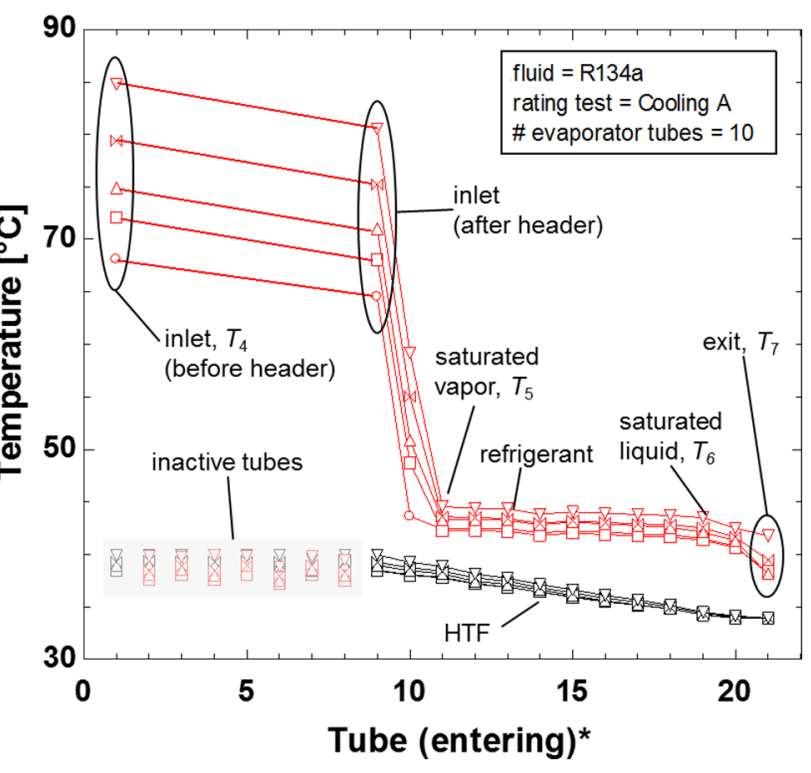

(b)

Figure 3-1: - Temperature profile in (a) evaporator, showing superheat and (b) condenser, showing subcooling

$\rightarrow-1400$ RPM $\square-1600$ RPM $\triangle-1800$ RPM $\rightarrow-2000$ RPM $\rightarrow-2200$ RPM

*The location 21 is the exit of the $20^{\text {th }}$ tube

\subsubsection{LLSL-HX Effectiveness}

The LLSL-HX effectiveness is computed as the ratio of the heat transferred on the vapor 
side $\left(\dot{Q}_{L L S L, v}\right)$ to the maximum possible heat transfer:

$$
\varepsilon_{L L S L}=\frac{\dot{Q}_{L L S L, v}}{\dot{Q}_{L L S L, \max }}=\frac{C_{p, a v g, 1,11}\left(T_{1}-T_{11}\right)}{\operatorname{MIN}\left(C_{p, \text { vvg }, 1,11}, C_{p, a v g, 7,8}\right)\left(T_{7}-T_{11}\right)}
$$

where:

$$
\begin{aligned}
C_{p, \text { avg }, 1,11} & =\text { average specific heats of the refrigerant on the vapor side - } \\
C_{p, \text { avg, }, 7,8} & =\text { average specific heats of the refrigerant on the liquid side - }
\end{aligned}
$$

The heat transfer on the vapor side, rather than liquid side, is chosen for the numerator because the larger temperature difference exhibited on the vapor side (due to lower specific heat) results in a smaller uncertainty in the effectiveness. 


\section{Validation and Baseline Tests with R134a -}

An initial set of tests were carried out with R134a to provide verification of the instrumentation and show the nominal uncertainties of the measurements. One of the most important validations is to show an energy balance between the refrigerant and the HTF in the heat exchangers. The energy imbalance, defined as $\dot{Q}_{r e f} /\left(\dot{Q}_{r e f}-\dot{Q}_{H T F}\right)$, for the initial tests is shown in Figure 4-1; the imbalance is generally around $1 \%$ to $1.5 \%$ or better in both the evaporator and condenser. The imbalance falls well within its uncertainty at the $95 \%$ confidence interval, indicating that the estimation of the uncertainty in HTF capacity $(3 \%)$ is likely too conservative; note that the HTF capacity accounts for more than $90 \%$ of the relative uncertainty in the imbalance metric.

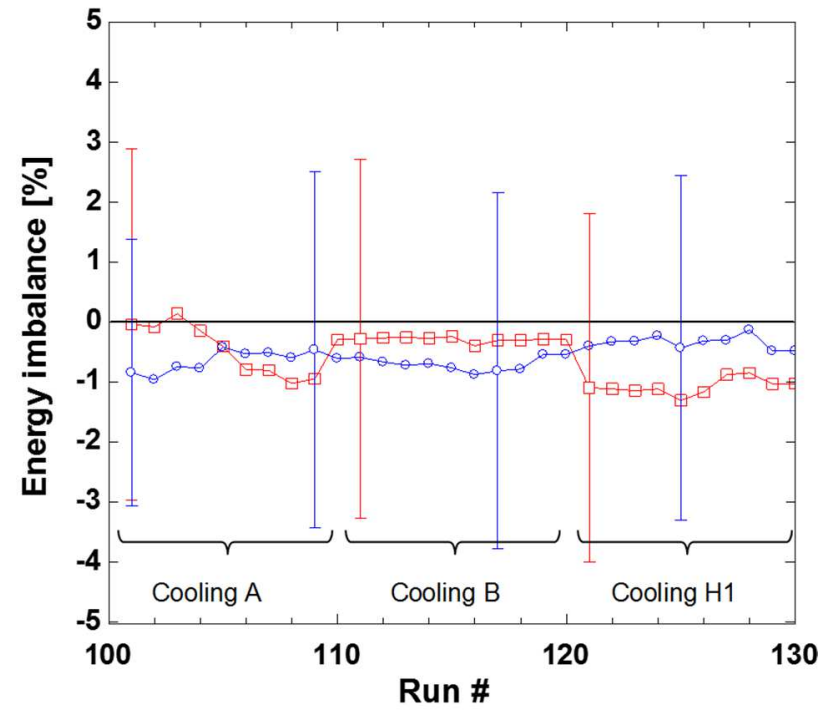

Figure 4-1: Energy imbalance in the evaporator and condenser

The performance of R134a in the MBBHP, as described by the metrics defined in Section 3.2, are presented in Figure 4-2 through Figure 4-4. Figure 4-2 (a) and (b) show nominal pressure profiles on the low/high pressure sides of the cycle, where the error bars represent measurement uncertainty listed in Table 2-3. The compressor power measured both by the shaft power and change of enthalpy of the working fluid are shown in Figure 4-3(a), where the conversion from mechanical to fluid power is about $65 \%$ efficient. The error bars represent the uncertainty calculated by propagating measurement uncertainty through Eqs. (3.7) and (3.8). The mass flow ranges from $8 \mathrm{~g} \mathrm{~s}^{-1}$ to $13 \mathrm{~g} \mathrm{~s}^{-1}\left(1.1 \mathrm{lb} \mathrm{min}^{-1}\right.$ to $\left.1.7 \mathrm{lb} \mathrm{min}^{-1}\right)$. Figure $4-4$ shows the COP ranges from 2.4 to 4 , and the capacity ranges from $1.6 \mathrm{~kW}$ to $2.1 \mathrm{~kW}$ ( 0.45 ton to 0.60 ton). The figure shows the uncertainties of the COP and capacity, where the computation and tabulation of uncertainty is described further in Appendix A.10 and A.11. The volumetric capacity ranges from $2100 \mathrm{~kJ} \mathrm{~m}^{-3}$ to $2800 \mathrm{~kJ} \mathrm{~m}^{-3}$ (56 Btu ft' $\mathrm{t}^{-3}$ to $75 \mathrm{Btu} \mathrm{ft}^{-3}$ ), and the compressor isentropic and volumetric efficiencies are nominally 0.46 and 0.55 ; uncertainties in all three of these metrics are shown in the figures and are computed using a similar method as the capacity/COP, but the computation is not discussed in detail in this report.

Figure 4-3 (b) also shows the mass flux, which is used to determine the two-phase flow regimes indicated in Figure 4-5. The refrigerant generally entered the annular flow regime in the evaporator and condenser, though for some tests with low mass flux the refrigerant never left the stratified-wavy regime. 


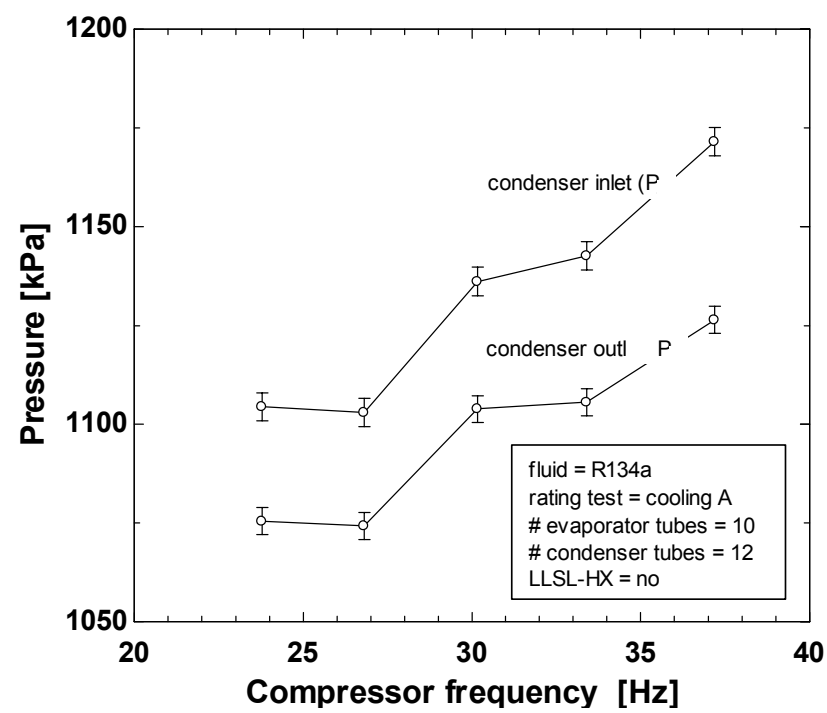

(a) -

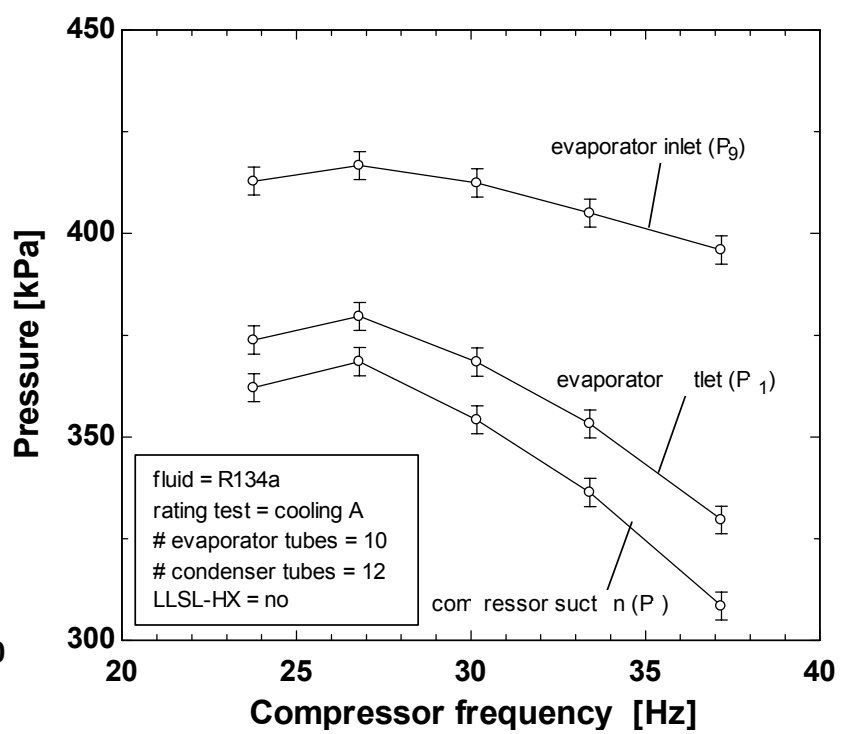

(b)

Figure 4-2: - Heat pump cycle pressures on the (a) low pressure side and (b) high pressure side -

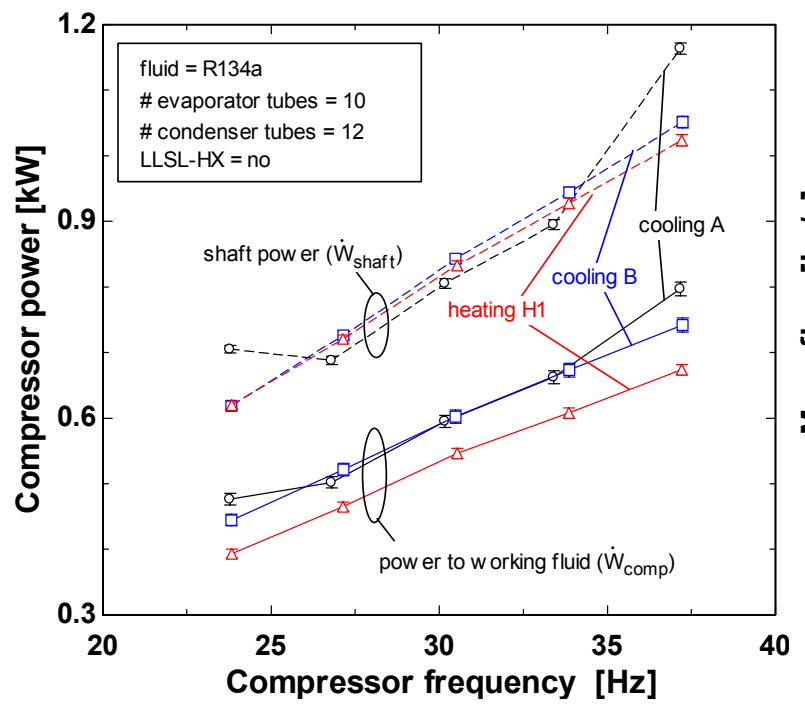

(a) -

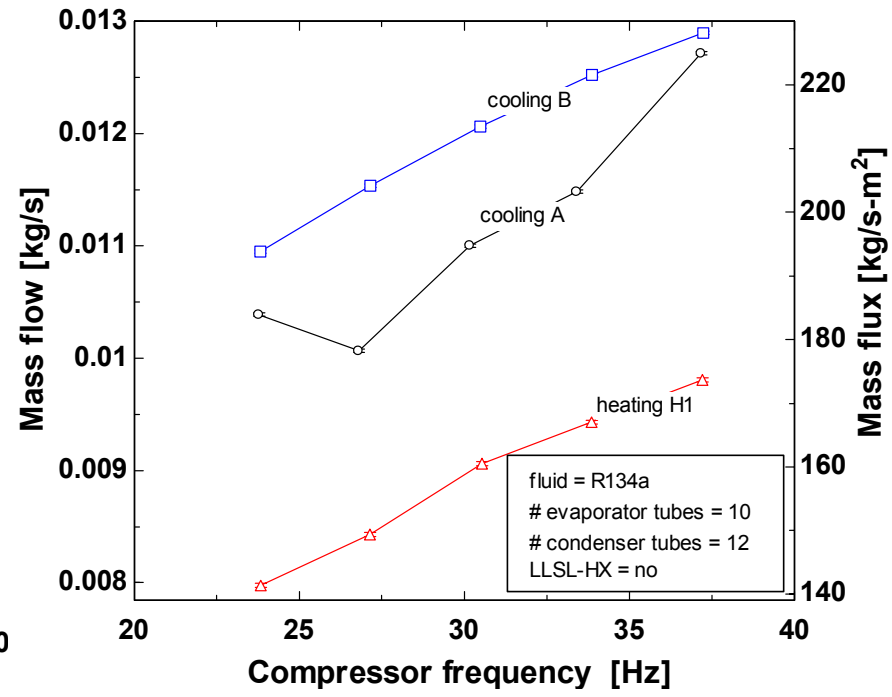

(b)

Figure 4-3: - Performance metrics including (a) compressor power and (b) mass flow and mass flux 


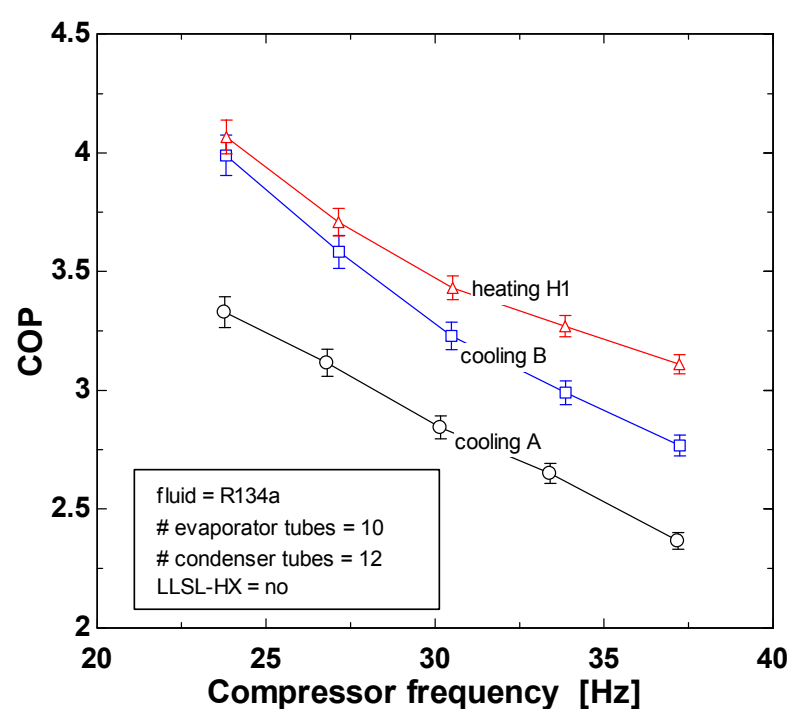

(a)

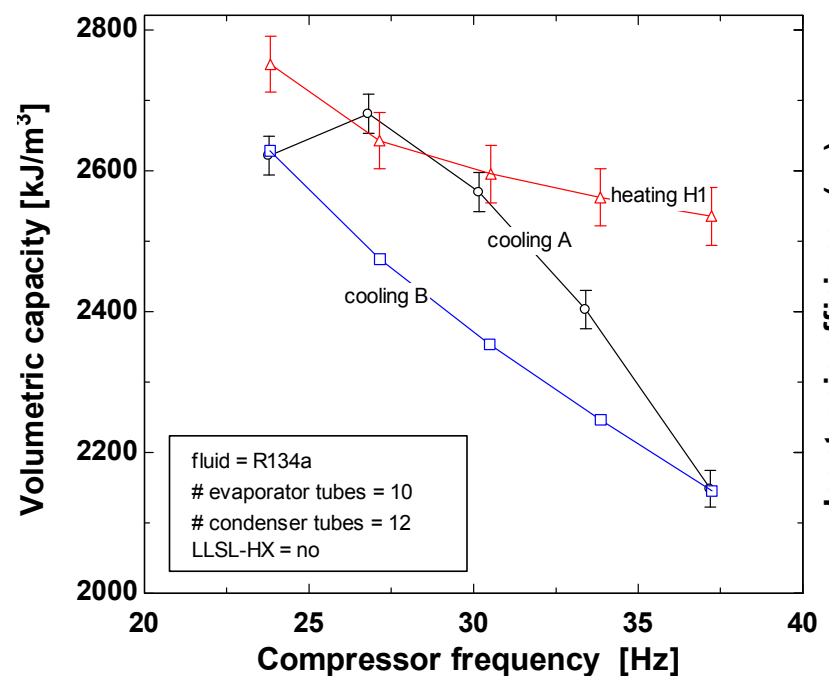

(c)

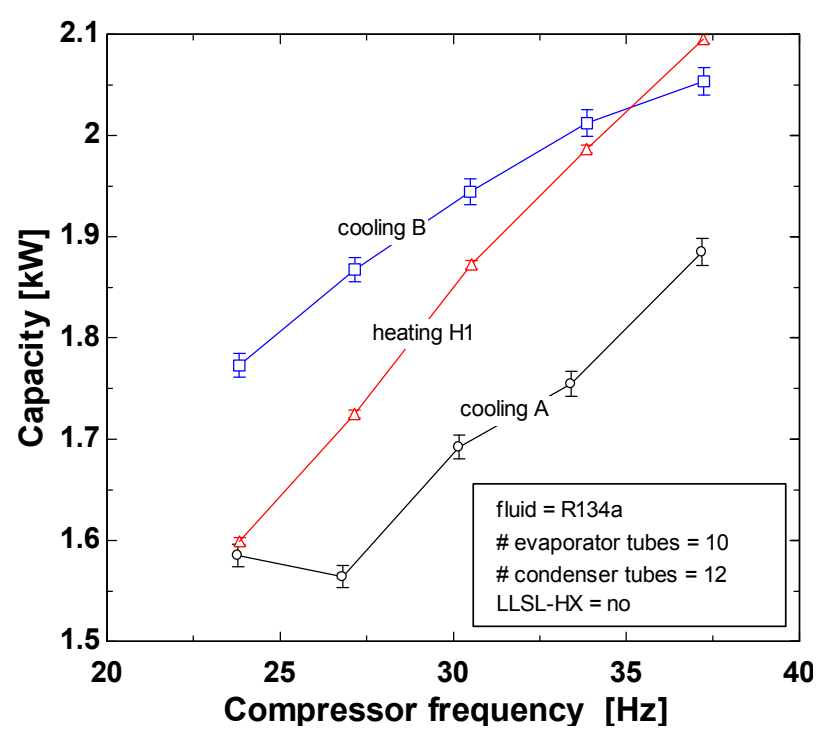

(b)

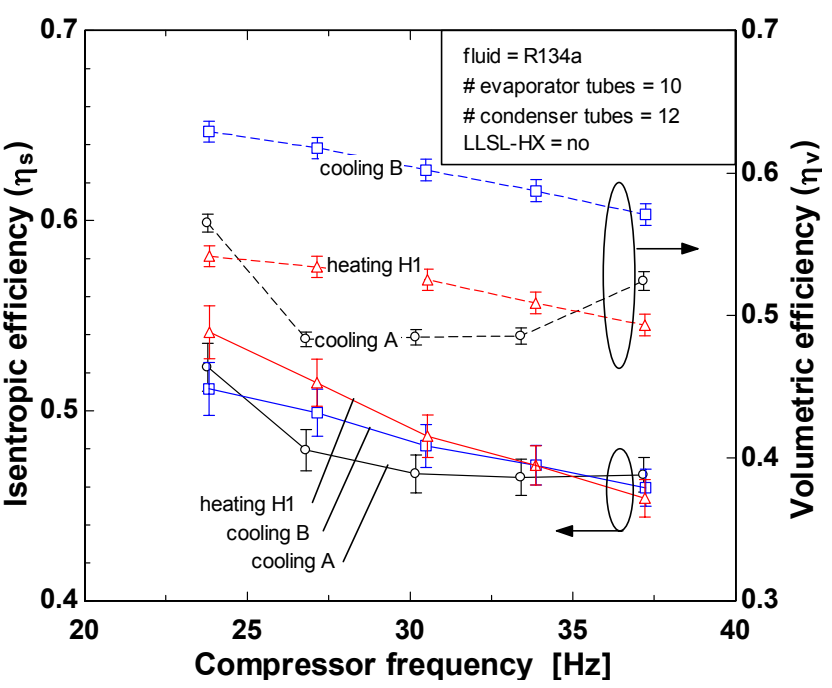

(d)

Figure 4-4: Performance metrics including (a) COP, (b) capacity, (c) volumetric capacity, and (d) compressor isentropic and volumetric efficiency 


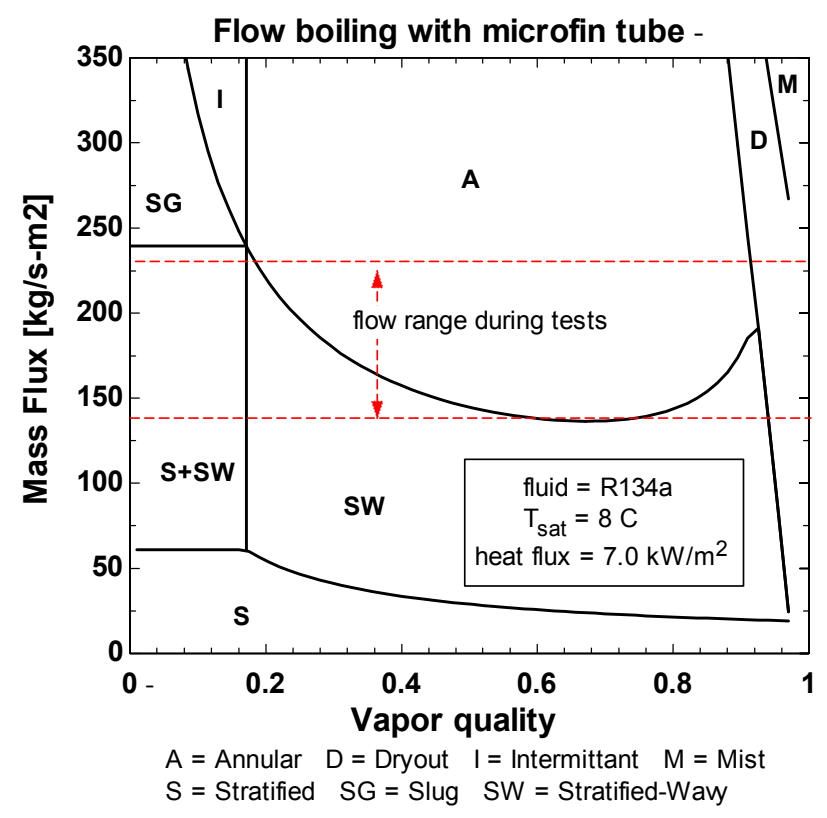

(a) ${ }^{1,3}$

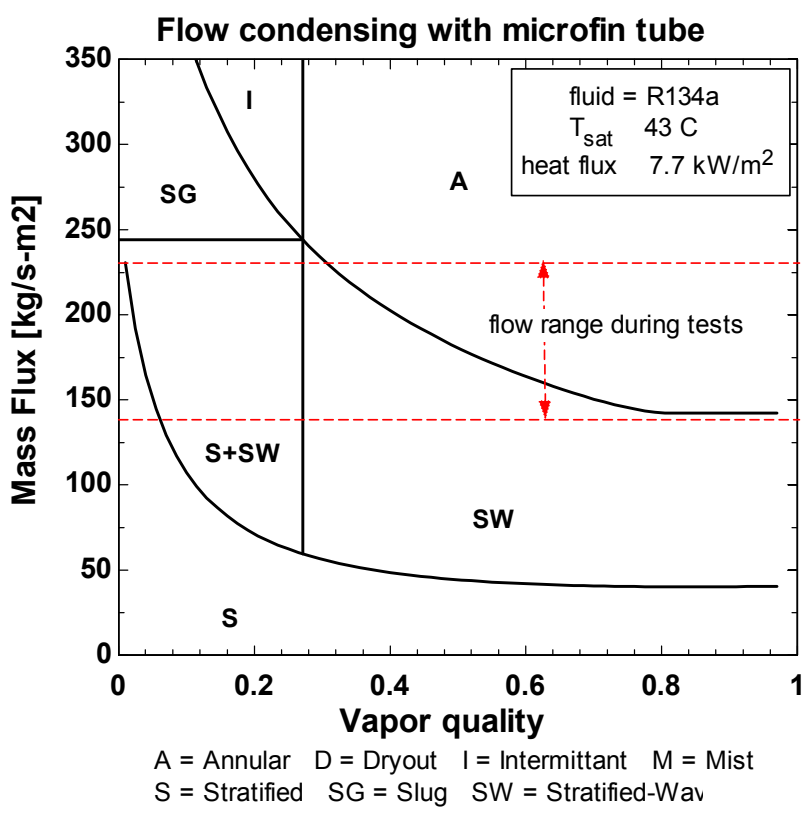

(b) ${ }^{2,3}$

Figure 4-5: - Flow regime map for microfin tube (a) evaporation and (b) condensation

${ }^{1}$ Flow boiling regime map from (Wojtan et al., 2005) -

${ }^{2}$ Flow condensation regime map from (Hajal et al., 2003) -

${ }^{3}$ Boundary between Intermittent/Annular regimes from (Thome, 2007), using equation 12.6 .1 with a coefficient of 0.678 , for helical microfins

\section{Conclusions and Future Work}

This report shows that the test apparatus is capable of measuring the performance of low-GWP refrigerants with high fidelity, including less than $0.5 \%$ uncertainty in both capacity and COP. The energy balance closure on the evaporator and condenser was better than $1.5 \%$ and will be continually tracked to ensure continued high quality data are collected.

Future tests will include a second baseline refrigerant R410A, followed by a series of comparative tests with low-GWP refrigerants and refrigerant mixtures. The HTF flowrates will remain fixed from the R134a baseline tests, so that the CYCLE_D-HX simulations of the test data can be carried out for all test data based on a single reference data set. After the model results are verified, the model will be used to identify additional candidate refrigerants to test in the MBBHP test apparatus. 


\section{References -}

AHRI. (2008). 2008 Standard for Performance Rating of Unitary Air-Conditioning \& AirSource Heat Pump Equipment. Air-Conditioning, Heating, and Refrigeration Institute, Arlington, VA, United States. Retrieved from www.ahrinet.org

AHRI. (2015). Participants' Handbook: AHRI Low-GWP Alternative Refrigerants Evaluation Program (Low-GWP AREP). Arlington, VA, United States: Air-Conditioning, Heating, and Refrigeration Institute. Retrieved from http://www.ahrinet.org/site/514/Resources/Research/AHRI-Low-GWP-AlternativeRefrigerants-Evaluation

Brown, J. S., Domanski, P. A., \& Lemmon, E. (2011). Standard Reference Database 49, CYCLE_D: NIST Vapor Compression Cycle Design Program, Version 5.0. Retrieved from http://www.nist.gov/srd/nist49.cfm

Domanski, P. A., Brown, S. J., Heo, J., Wojtusiak, J., \& McLinden, M. O. (2014). A thermodynamic analysis of refrigerants: Performance limits of the vapor compression cycle. International Journal of Refrigeration, 38, 71-79. doi:10.1016/j.ijrefrig.2013.09.036

EPA. (2015). 2015 North American Amendment Proposal to Address HFCs under the Montreal Protocol. Retrieved from http://www.epa.gov/ozone/intpol/mpagreement.html and http://www.epa.gov/ozone/intpol/HFC_Amendment_2015_Summary.pdf

EU. (2014, April 16). Regulation (EU) No 517/2014 of the European Parliament and of the Council of 16 April 2014 on fluorinated greenhouse gases and repealing Regulation (EC) No 842/2006. Journal of the European Union. Retrieved from http://eurlex.europa.eu/legal-content/EN/TXT/?uri=uriserv:OJ.L_.2014.150.01.0195.01.ENG

Fortin, T. J. (2015). Personal communication.

Hajal, J. E., Thome, J. R., \& Cavallini, A. (2003). Condensation in horizontal tubes, part 1: twophase flow pattern map. International Journal of Heat and Mass Transfer, 3349-3363. doi:10.1016/S0017-9310(03)00139-X

Harr, L., Gallagher, J. S., \& Kell, G. S. (1984). NBS/NRC Steam Tables. Hemisphere Publishing Co.

Kazakov, A., McLinden, M. O., \& Frenkel, M. (2012). Computational Design of New Refrigerant Fluids Based on Environmental, Safety, and Thermodynamic Characteristics. Industrial \& Engineering Chemistry Research, 51, 12537-12548. doi:10.1021/ie3016126

Kim, Y., Payne, V., Choi, J., \& Domanski, P. A. (2005). Mass flow rate of R-410A through short tubes working near the critical point. International Journal of Refrigeration, 28, 547-553. doi:10.1016/j.ijrefrig.2004.10.007

Klein, S. A. (2015). Engineering Equation Solver, v 9.908. Retrieved from http://www.fchart.com/ees/

Lemmon, E. W., Huber, M. L., \& McLinden, M. O. (2013). NIST Standard Reference Database 23, Reference Fluid Thermodynamic and Transport Properties (REFPROP), Version 9.1. 
National Institute of Standards and Technology. Retrieved from http://www.nist.gov/srd/nist23.cfm -

McLinden, M. O., \& Radermacher., R. (1987). Methods for Comparing the Performance of Pure and Mixed Refrigerants in the Vapour Compression Cycle. International Journal of Refrigeration, 10(6), 318-325. doi:10.1016/0140-7007(87)90117-4

McLinden, M. O., Kazakov, A., Heo, J., Brown, J. S., \& Domanski, P. A. (2014). A thermodynamic analysis of refrigerants: Possibilities and tradeoffs for Low-GWP refrigerants. International Journal of Refrigeration, 38, 80-92.

doi:10.1016/j.ijrefrig.2013.09.032

Pannock, J., \& Didion, D. A. (1991). The Performance of Chlorine-Free Binary Zeotropic Refrigerant Mixtures in a Heat Pump, NISTIR 4748. Internal Report, National Institute of Standards and Technology, U.S. Department of Commerce, Gaithersburg. Retrieved from http://fire.nist.gov/bfrlpubs/build91/art002.html

Solomon, S., Qin, D., Manning, M., Chen, Z., Marquis, M., Averyt, K. B., . . Miller, H. L. (2007). Contribution of Working Group I to the Fourth Assessment Report of the Intergovernmental Panel on Climate Change. New York, NY, USA: Cambridge University Press. Retrieved July 29, 2015, from

http://www.ipcc.ch/publications_and_data/publications_ipcc_fourth_assessment_report wg1_report_the_physical_science_basis.htm

Taylor, B. N., \& Kuyatt, C. E. (1994). Guidelines for Evaluating and Expressing the Uncertainty of NIST Measurement Results, National Institute of Standards and Technology Technical Note 1297.

Thome, J. R. (Updated in 2007). Wolverine Heat Transfer Engineering Data book III. Germany: Weiland-Werke AG. Retrieved from http://www.wlv.com/heat-transfer-databook/

Tilner-Roth, R., \& Baehr, H. D. (1994). An International Standard Formulation for the Thermodynamic Properties of 1,1,1,2-Tetrafluoroethane (HFC-134a) for Temperatures from $170 \mathrm{~K}$ to $455 \mathrm{~K}$ and Pressures up to $70 \mathrm{MPa}$. J. Phys. Chem, Ref. Data, 23(5).

Wojtan, L., Ursenbacher, T., \& Thome, J. R. (2005). Investigation of flow boiling in horizontal tubes: Part I-A new diabatic two-phase flow pattern map. International Journal of Heat and Mass Transfer, 2955-2969. doi:10.1016/j.ijheatmasstransfer.2004.12.012 


\section{Appendix A: Uncertainty Analysis -}

\section{A.1 Symbols Used in Uncertainty Analysis -}

\begin{tabular}{|c|c|c|}
\hline Symbol & $\underline{\text { Units }}$ & $\underline{\text { Definition }}$ \\
\hline$k$ & -- & Expanded uncertainty coverage factor \\
\hline$n$ & -- & Number of data points \\
\hline$\dot{Q}$ & $\mathrm{~kW}$ & Energy transfer \\
\hline$S_{U A, i n s, e}$ & $\mathrm{~W} \mathrm{~K}^{-1}$ & Standard deviation of evaporator insulation conductance \\
\hline$S_{X}$ & -- & Standard deviation of measured quantity " $\mathrm{X}$ " \\
\hline$T$ & ${ }^{\circ} \mathrm{C}$ & Temperature \\
\hline$T_{1}$ & ${ }^{\circ} \mathrm{C}$ & Temperature at cold end of thermopile \\
\hline$T_{\text {cal }}$ & ${ }^{\circ} \mathrm{C}$ & Temperature of RTD used for calibrations \\
\hline$T_{T C, c a l}$ & ${ }^{\circ} \mathrm{C}$ & Calibrated thermocouple measurement \\
\hline$T_{T C, C J C}$ & ${ }^{\circ} \mathrm{C}$ & Thermocouple measurement with Cold Junction Compensation \\
\hline$\Delta T_{l m}$ & $\mathrm{~K}$ & Log-mean temperature difference \\
\hline$\Delta T_{T C, c a l}$ & $\mathrm{~K}$ & Thermocouple calibration temperature difference \\
\hline$\Delta T_{T P}$ & $\mathrm{~K}$ & Temperature difference of thermopile \\
\hline$U A$ & $\mathrm{~W} \mathrm{~K}^{-1}$ & Thermal conductance \\
\hline$U_{\overline{U A}, i n s, e}$ & $\mathrm{~W} \mathrm{~K}^{-1}$ & Uncertainty of average of evaporator insulation conductance \\
\hline$U_{T C}$ & ${ }^{\circ} \mathrm{C}$ & Total instrument uncertainty of thermocouple \\
\hline$U_{T C, c a l}$ & ${ }^{\circ} \mathrm{C}$ & Thermocouple instrument uncertainty from calibrating device uncertainty \\
\hline$U_{T C, f i t}$ & ${ }^{\circ} \mathrm{C}$ & Instrument uncertainty of thermocouple due to fit of calibration regression \\
\hline$U_{X}$ & -- & Uncertainty of measured quantity " $\mathrm{X}$ " \\
\hline$U_{\bar{X}}$ & -- & Uncertainty of average of measured quantity " $\mathrm{X}$ " \\
\hline$U_{Y}$ & & Uncertainty of calculated quantity "Y" \\
\hline$V$ & $\mathrm{~V}$ & Voltage \\
\hline$V_{1}$ & $\mathrm{~V}$ & Thermopile voltage of cold end of thermopile (referenced to ice-point) \\
\hline$V C C$ & $\mathrm{~kJ} \mathrm{~m}^{-3}$ & Volumetric Cooling Capacity \\
\hline$V H C$ & $\mathrm{~kJ} \mathrm{~m}^{-3}$ & Volumetric Heating Capacity \\
\hline$V_{T C}$ & $\mathrm{~V}$ & Thermocouple voltage \\
\hline$\Delta V_{T P}$ & $\mathrm{~V}$ & Thermopile voltage \\
\hline$X$ & -- & Measured quantity \\
\hline$Y$ & -- & Calculated quantity \\
\hline
\end{tabular}




\begin{tabular}{|c|c|}
\hline$\underline{\text { Subscript }}$ & Definition \\
\hline$a m b$ & Ambient air - \\
\hline$c$ & Condenser - \\
\hline$e$ & Evaporator - \\
\hline$H T F$ & Heat Transfer Fluid - \\
\hline in & Inlet - \\
\hline ins & Insulation - \\
\hline out & Outlet - \\
\hline 1 to 11 & Refrigerant thermodynamic states as defined by Figure 2-1 - \\
\hline
\end{tabular}

\begin{tabular}{|c|c|}
\hline Abbreviation & Definition \\
\hline $\mathrm{COP}$ & Coefficient of Performance (W capacity per W of input power) - \\
\hline CJC & Cold Junction Compensation (for thermocouples) - \\
\hline DAQ & Data Acquisition - \\
\hline DSC & Differential Scanning Calorimeter (used to measure fluid specific heat) - \\
\hline EES & Engineering Equation Solver (software used to reduce data) - \\
\hline HTF & Heat Transfer Fluid - \\
\hline MBBHP & Mini Breadboard Heat Pump - \\
\hline RPM & Revolutions per Minute (compressor shaft) - \\
\hline RTD & Resistance Temperature Detector - \\
\hline
\end{tabular}

\section{A.2 General Remarks}

The uncertainty analyses for key performance metrics are presented in this section. All uncertainties are estimated based on instrument uncertainties computed at a $95 \%$ confidence interval.

\section{A.3 Thermocouples with CJC Compensation}

The surface-mounted thermocouples, as well as the thermocouples measuring the air temperature near the evaporator/condenser, are compensated at the DAQ using a thermistorbased Cold Junction Compensation (CJC). A calibration $\left(\Delta T_{c a l}\right)$ is applied to the resulting temperature reading $\left(T_{T C, C J C}\right)$ to compute the calibrated temperature $\left(T_{T C, c a l}\right)$ according to:

$$
T_{T C, \text { al }}=T_{T C, C J C}+\Delta T_{T C, \text { cal }}
$$

where the calibration is fit to a $2^{\text {nd }}$ order polynomial (the order of this curve fit, and others presented in Appendix A, were selected based on t-test of polynomial coefficients):

$$
\Delta T_{T C, c a l}=T_{c a l}-T_{T C, C J C}=a_{0}+a_{1} T_{T C, C J C}+a_{2} T_{T C, C J C}^{2}
$$

The polynomial coefficients $\left(a_{0}, a_{1}, a_{2}\right)$ are fit using the least square error method, and $T_{c a l}$ is the temperature measured by the calibrating instrument (two calibrated RTDs read by a precision digital thermometer, expanded uncertainty of $\pm 0.02^{\circ} \mathrm{C}$ ). The thermocouples were calibrated over a temperature range of $-10^{\circ} \mathrm{C}$ to $60^{\circ} \mathrm{C}$, and this calibration was repeated five times over the 
course of two weeks; Figure A-1 (a) shows the calibration data and polynomial curve fits for a representative thermocouple. Each calibration shows a significant offset from the others; this is likely a manifestation of the repeatability error of the CJC, which has an overall uncertainty of $\pm 0.5^{\circ} \mathrm{C}$. Figure A-1 (b) shows the aggregation of the five data sets and the resulting curve fit and $95 \%$ confidence interval $\left( \pm 0.6^{\circ} \mathrm{C}\right)$. The uncertainty of the calibrated RTDs is more than an order of magnitude smaller than the curve fit confidence interval, and is therefore neglected. The CJC thermocouple instrument uncertainty listed in Table $2-3$ is therefore $\pm 0.6{ }^{\circ} \mathrm{C}$.

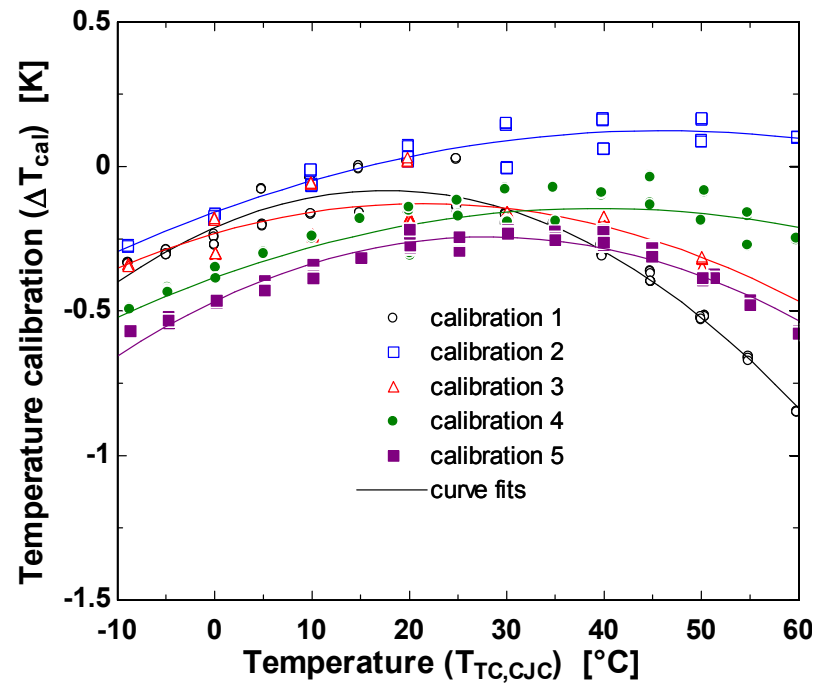

(a)

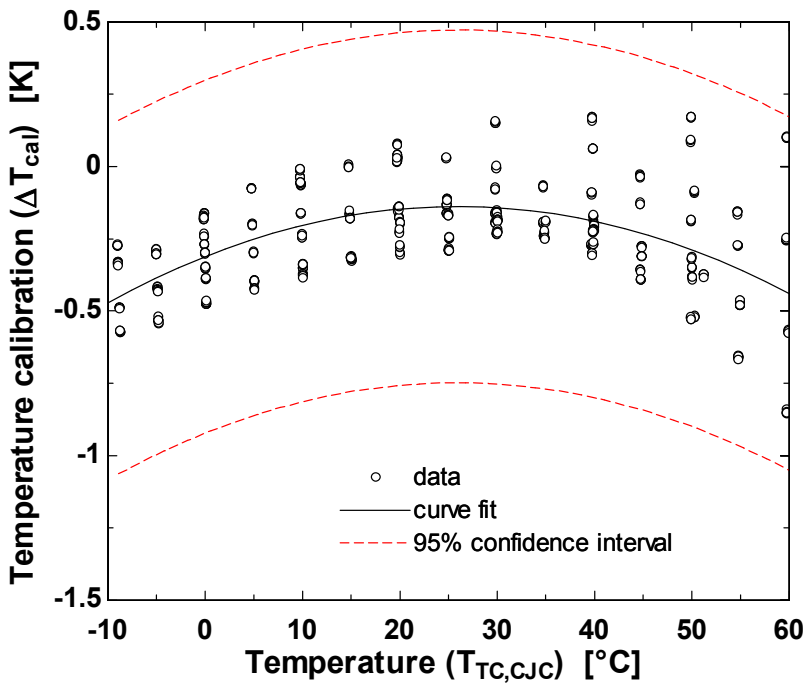

(b)

Figure A-1: Temperature calibration for CJC compensated thermocouples where (a) data are divided by each of the 5 calibrations and (b) all data are combined.

\section{A.4 Thermocouples with Ice-Water Bath Compensation}

A lower level of uncertainty is achieved for the in-stream probe thermocouples, which measure the refrigerant temperatures at key thermodynamic states, by utilizing an ice-water bath reference junction. The ice-water bath consists of a vacuum insulated Dewar filled with crushed ice and water; the reference junction is submerged in the bath inside of a water-filled test tube. Using the ice-water bath removes the large uncertainty associated with the electronic CJC on the DAQ system. The thermocouples were calibrated against the RTDs (same ones used to calibrate thermocouples with CJC), where the resulting data and curve fit are shown for a representative thermocouple in Figure A-2. The data were fit to $5^{\text {th }}$ order polynomials according to:

$$
T_{T C, c a l}=\sum_{i=0}^{5} a_{i} V_{T C}^{i}
$$

where $V_{T C}$ is the thermocouple voltage. The resulting instrument uncertainty $\left( \pm 0.08{ }^{\circ} \mathrm{C}\right)$ listed in Table 2-3 is the combination of the curve fit standard error $\left(U_{T C, f i t}, k=2\right)$ and the calibrating RTD error $\left(U_{T, c a l}\right)$ :

$$
U_{T C}= \pm \sqrt{U_{T C, f i t}^{2}+U_{T, c a l}^{2}}= \pm \sqrt{0.079^{2}+0.02^{2}}= \pm 0.08^{\circ} \mathrm{C}
$$




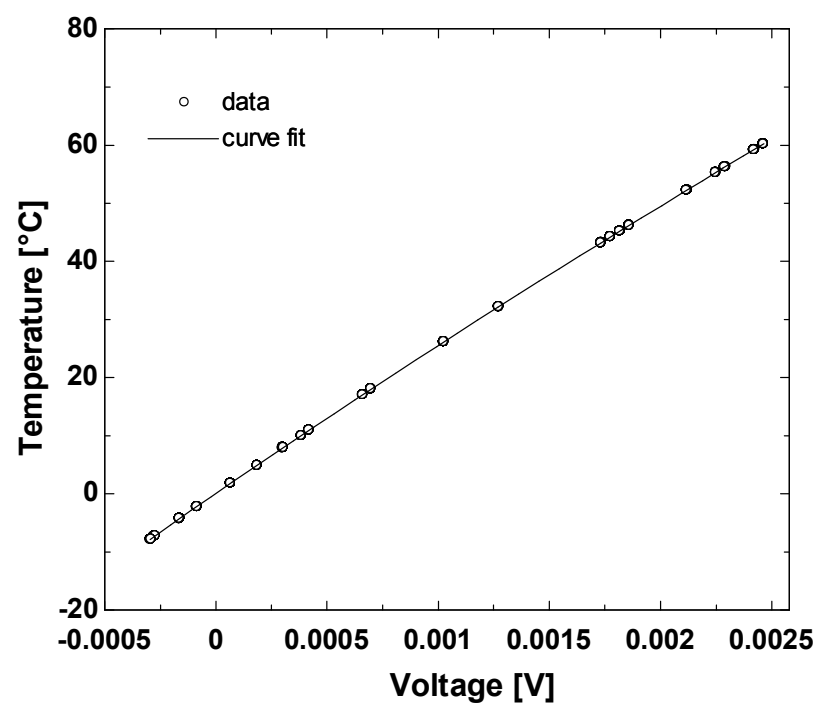

Figure A-2: Ice-water bath referenced thermocouple calibration data

\section{A.5 Thermopiles in Heat Transfer Fluid}

The 13-junction thermopiles were calibrated by immersing one end in an ice-water bath (inside a water-filled test tube) and the other end in a temperature controlled bath. The temperature in the controlled bath was measured using the two calibrated RTDs. A thermopile voltage-temperature dataset was generated and fit to a $4^{\text {th }}$ order polynomial. Figure A-3 shows the calibration data and the curve fit, and Table A-1 shows the polynomial coefficients. The calibration data are fit to the equation:

$$
T=\sum_{i=0}^{N=4} a_{T P, i} V^{i}
$$

The temperature difference for a thermopile is computed according to:

$$
\Delta T_{T P}=T\left(V_{1}+\Delta V_{T P}\right)-T_{1}
$$

where $\Delta V_{T P}$ is the measured thermopile voltage and $T_{1}$ is the temperature measured at the cold end of the thermopile by a CJC-corrected thermocouple. Eq. (A.5) is substituted into Eq. (A.6) to calculate the thermopile temperature difference:

$$
\Delta T_{T P}=\sum_{i=0}^{N=4} a_{T P, i}\left(V_{1}+\Delta V_{T P}\right)-T_{1}
$$

where $V_{1}$ (cold-end voltage) is computed by numerically solving Eq. (A.5) where $T$ is set to $\left(T_{1}\right)$ :

$$
V_{1}=\operatorname{root}\left(T_{1}-\sum_{i=0}^{N=4} a_{T P, \mathrm{i}} V_{1}^{i}=0\right)
$$

The thermopile uncertainties are computed with respect to the curve fit, voltage measurement, and temperature measurement at the cold end of the thermopile (characterized respectively by the coefficient uncertainties in Table A-1, the thermopile voltage uncertainty in Table 2-3, and the CJC corrected thermocouple in Table 2-3). The EES (Klein, 2015) software 
is used to numerically compute the partial derivatives and subsequent thermopile uncertainties. Figure A-4(a) shows the contours of uncertainty in the temperature difference measured by the evaporator/condenser HTF thermopiles.

Figure A-4(b) shows the contours of relative contribution to uncertainty in the thermopile measurement. Each of the uncertainty sources is dominant in different regions:

- voltage measurement: dominant at low temperature differences (less than $1 \mathrm{~K}$ )

- curve fit error: dominant at high cold end temperatures (greater than $50{ }^{\circ} \mathrm{C}$ )

- cold end temperature: dominant at moderate cold end temperatures $-5{ }^{\circ} \mathrm{C}$ to $20{ }^{\circ} \mathrm{C}$ and temperature differences $2.5 \mathrm{~K}$ to $20 \mathrm{~K}$

As noted in this discussion, the thermopile uncertainty is a complex function of the curve fit, voltage measurement, and cold end temperature measurement. For the temperature difference range expected for this application, $1 \mathrm{~K}$ to $10 \mathrm{~K}\left(1.8^{\circ} \mathrm{F}\right.$ to $\left.18^{\circ} \mathrm{F}\right)$, the upper bound of uncertainty is about $0.015 \mathrm{~K}\left(0.027^{\circ} \mathrm{F}\right)$; for simplicity, this is the value listed in Table 2-3. Note that the contribution to the uncertainty by the calibrating instrument (two calibrated RTDs) is negligible here as the error in slope (which is the error that propagates into the thermopile temperature difference) is less than $0.000248 \mathrm{~K}$ per $\mathrm{K}$ of temperature difference (e.g. $0.00248 \mathrm{~K}$ for a $10 \mathrm{~K}$ temperature difference).

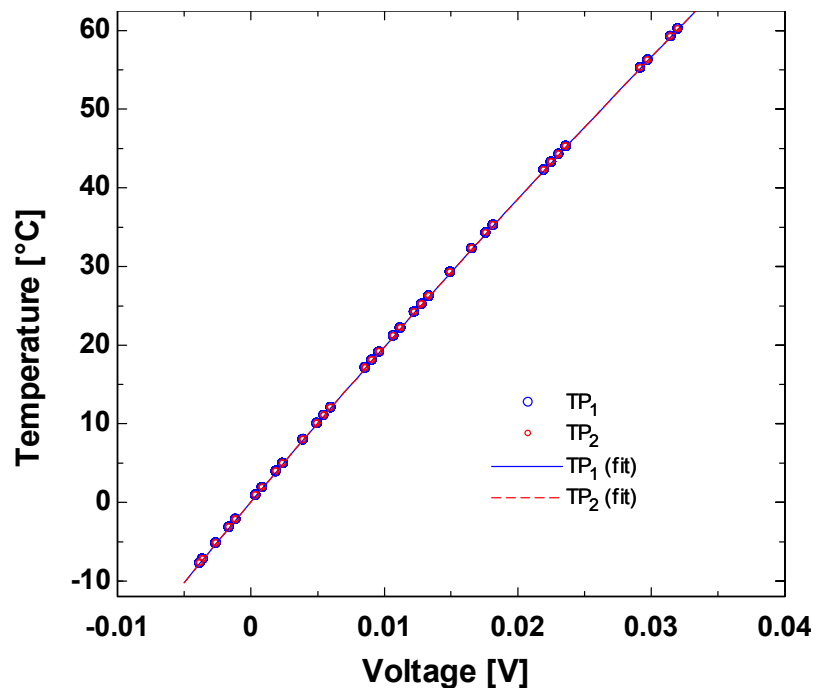

Figure A-3: Thermopile calibration data
Table A-1: Condenser \& evaporator thermopile polynomial coefficients

\begin{tabular}{ccc} 
Coeff. & Value & $\begin{array}{c}\text { Uncertainty } \\
(\mathbf{k}=\mathbf{2}), \mathbf{9 5} \%\end{array}$ \\
\hline$a_{T P, e, 0}$ & $3.9243 \mathrm{E}-02$ & $\pm 4.1 \mathrm{E}-04$ \\
\hline$a_{T P, e, 1}$ & $2.0243 \mathrm{E}+03$ & $\pm 1.2 \mathrm{E}-01$ \\
\hline$a_{T P, e, 2}$ & $-5.5466 \mathrm{E}+03$ & $\pm 2.2 \mathrm{E}+01$ \\
\hline$a_{T P, e, 3}$ & $3.9023 \mathrm{E}+04$ & $\pm 1.3 \mathrm{E}+03$ \\
\hline$a_{T P, e, 4}$ & $-2.6229 \mathrm{E}+05$ & $\pm 2.2 \mathrm{E}+04$ \\
\hline & & \\
\hline$a_{T P, c, 0}$ & $3.8494 \mathrm{E}-02$ & $\pm 5.3 \mathrm{E}-04$ \\
\hline$a_{T P, c, 1}$ & $2.0241 \mathrm{E}+03$ & $\pm 1.5 \mathrm{E}-01$ \\
\hline$a_{T P, c, 2}$ & $-5.5190 \mathrm{E}+03$ & $\pm 2.8 \mathrm{E}+01$ \\
\hline$a_{T P, c, 3}$ & $3.8551 \mathrm{E}+04$ & $\pm 1.6 \mathrm{E}+03$ \\
\hline$a_{T P, c, 4}$ & $-2.5440 \mathrm{E}+05$ & $\pm 2.9 \mathrm{E}+04$
\end{tabular}




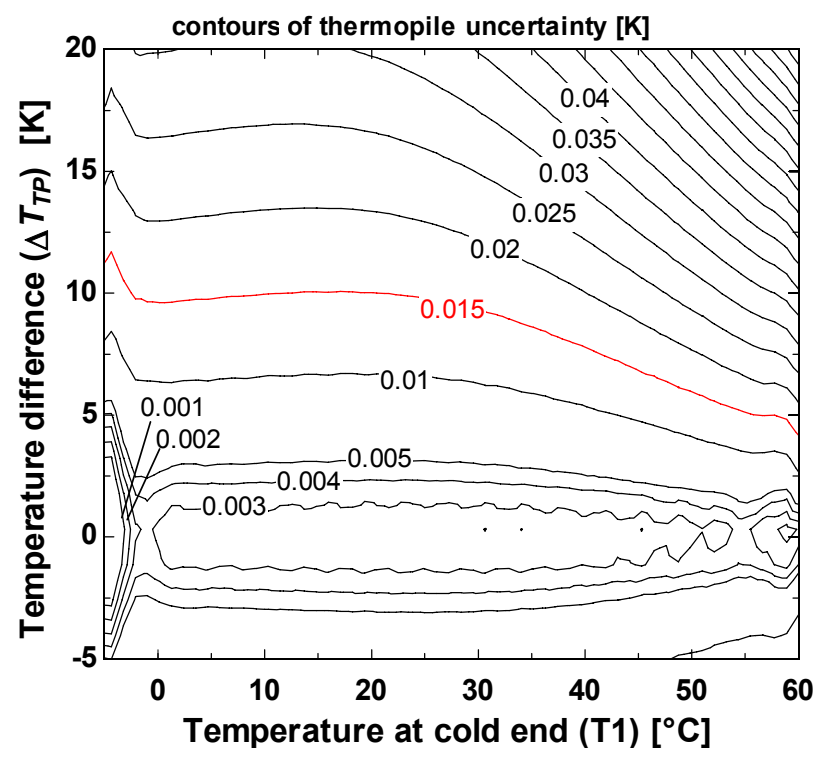

(a)

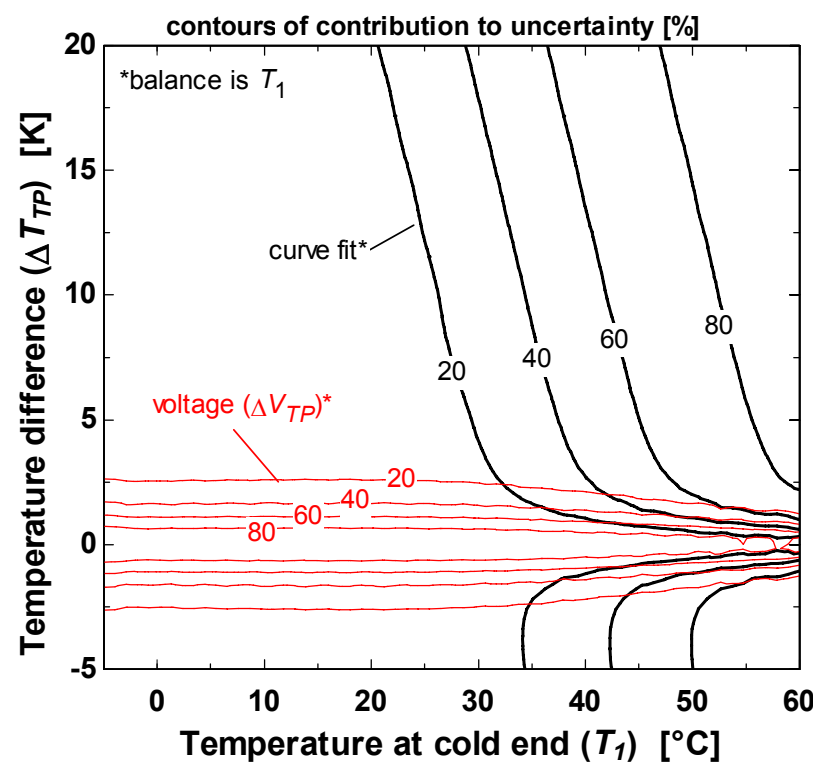

(b)

Figure A-4: Contours of thermopile (a) uncertainty and (b) relative contribution to uncertainty

\section{A.6 Evaporator Heat Transfer Fluid Specific Heat}

The evaporator HTF is a potassium formate and water heat transfer fluid that is freeze protected to $-40{ }^{\circ} \mathrm{C}$. The manufacturer's specific heat data were found to have error of at least $10 \%$, so a sample of the fluid was analyzed in a Differential Scanning Calorimeter (DSC) by the NIST-Boulder Applied Chemicals and Materials Division. The temperature dependent specific heat and the $2^{\text {nd }}$ order curve fit to the data are shown in Figure A-5; the curve fit coefficients and their uncertainties are listed in Table A-2. Figure A-5 also shows the manufacturer's reported specific heat data for comparison. The exact uncertainty of the DSC measurement was not available at the time of writing, but was estimated to be about $2 \%$ to $3 \%$ of reading based on the experience of the DSC operator (Fortin, 2015). An uncertainty of $3 \%$ of reading is therefore assigned as a conservative estimate. Both the curve fit and DSC calibration uncertainties are included in the calculation of overall uncertainties. 


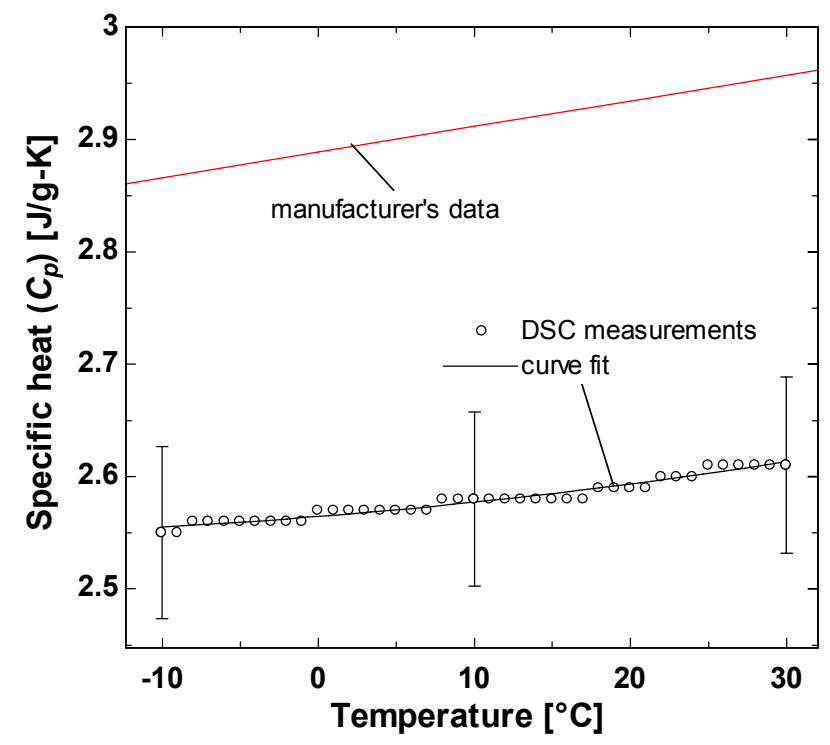

Table A-2: Evaporator HTF specific heat polynomial coefficients

\begin{tabular}{ccc} 
Coeff. & Value & $\begin{array}{c}\text { Uncertainty } \\
(\mathbf{k}=\mathbf{2}), \mathbf{9 5} \%\end{array}$ \\
\hline$a_{C p, e, 0}$ & $2.5643 \mathrm{E}+00$ & $\pm 1.6 \mathrm{E}-03$ \\
\hline$a_{C p, e, 1}$ & $1.1015 \mathrm{E}-03$ & $\pm 2.1 \mathrm{E}-04$ \\
\hline$a_{C p, e, 2}$ & $1.7422 \mathrm{E}-05$ & $\pm 9.5 \mathrm{E}-06$
\end{tabular}

Figure A-5: Specific heat measurements for evaporator HTF

\section{A.7 Condenser Heat Transfer Fluid Specific Heat}

The condenser HTF is water; the specific heat data are computed in EES using the data from (Harr et al., 1984) and are shown in Figure A-6. A conservative estimate of $\pm 3 \%$ is used for the uncertainty in the specific heat.

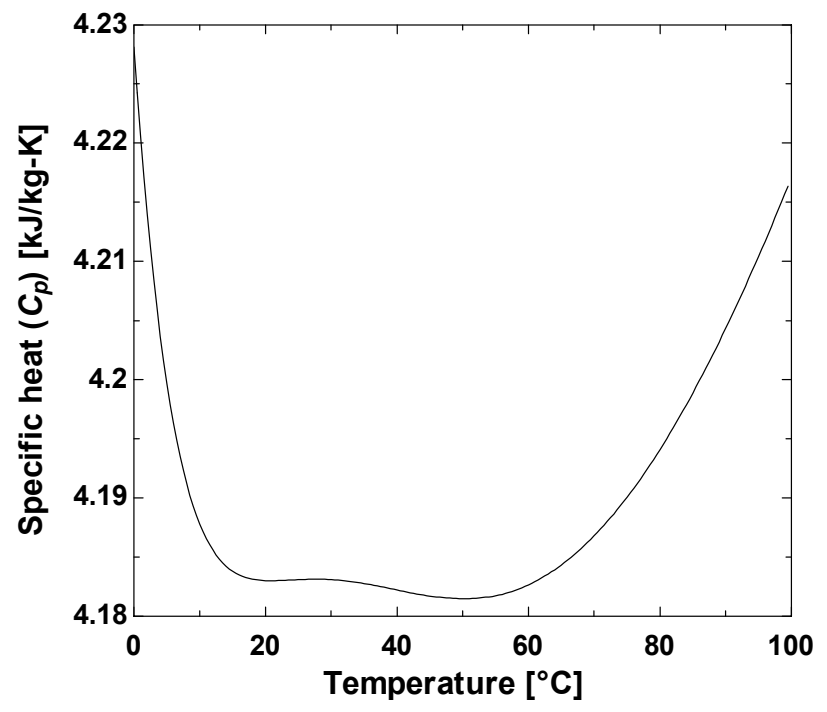

Figure A-6: Specific heat of condenser HTF (water)

\section{A.8 Evaporator and Condenser Insulation Conductance}

The total evaporator and condenser insulation conductances $\left(U A_{\text {ins,e }}\right.$ and $\left.U A_{\text {ins,c }}\right)$ for thermal interaction with the ambient air were measured during an initial test where the HTFs were circulated at various flow rates through the apparatus at an elevated temperature, while the refrigerant tubes were under vacuum. The temperature change of the HTF across the heat 
exchanger was assumed to be entirely attributed to insulation heat leak, and therefore an effective insulation conductance could be computed. The resulting $U A_{\text {ins,e }}$ and $U A_{\text {ins, }, \text { values for }}$ all 20 tubes are shown in Figure A-7. Average values of conductances for the evaporator and condenser were calculated as $5.48 \mathrm{~W} \mathrm{~K}^{-1} \pm 0.31 \mathrm{~W} \mathrm{~K}^{-1}$ and $6.52 \mathrm{~W} \mathrm{~K}^{-1} \pm 0.41 \mathrm{~W} \mathrm{~K}^{-1}$

(10.4 $\mathrm{Btuh}^{-1}{ }^{\circ} \mathrm{F}^{-1} \pm 0.59 \mathrm{Btu} \mathrm{h}^{-1}{ }^{\circ} \mathrm{F}^{-1}$ and $12.4 \mathrm{Btuh}^{-1}{ }^{\circ} \mathrm{F}^{-1} \pm 0.78 \mathrm{Btuh}^{-1}{ }^{\circ} \mathrm{F}^{-1}$ ), respectively, where the uncertainty accounts for both instrumentation error and test variance. The evaporator insulation conductance for these tests is computed according to:

$$
U A_{i n s, e}=\frac{\dot{Q}_{i n s, e}}{\Delta T_{l m, H T F, e}}=\frac{\dot{m}_{H T F, e} C_{p, H T F, e}\left(T_{H T F, \text { in }, e}-T_{H T F, o u t, e}\right)}{\frac{\left(T_{H T F, i n, e}-T_{a m b, e}\right)-\left(T_{H T F, \text { out }, e}-T_{a m b, e}\right)}{\ln \left(\frac{\left(T_{H T F, i n, e}-T_{a m b, e}\right)}{\left(T_{H T F, o u t, e}-T_{a m b, e}\right)}\right)}}
$$

where the variables represent:

$$
\begin{aligned}
C_{p, H T F, e} & =\text { evaporator HTF specific heat } \\
\dot{m}_{H T F, e} & =\text { evaporator HTF mass flow } \\
\dot{Q}_{i n s, e} & =\text { evaporator insulation heat leak } \\
T_{a m b, e} & =\text { ambient air temperature surrounding evaporator } \\
T_{H T F, \text { in }, e} & =\text { evaporator HTF inlet temperature } \\
T_{H T F, o u t, e} & =\text { evaporator HTF outlet temperature } \\
\Delta T_{l m, H T F, e} & =\text { evaporator log-mean temperature difference }
\end{aligned}
$$

and the uncertainty of the average value is calculated according to:

$$
U_{\overline{U A}, i n s, e}=k S_{U A, i n s, e} / \sqrt{n}
$$

where the variables represent:

$$
\begin{array}{cl}
k & =\text { expanded uncertainty coverage factor }(k=2) \text { for } 95 \% \text { confidence interval } \\
S_{U A, i n s, e} & =\text { standard deviation of conductances } \\
n & =\text { number of conductance data points }
\end{array}
$$

The condenser conductance is computed using the same method with the corresponding measurements from that heat exchanger. 


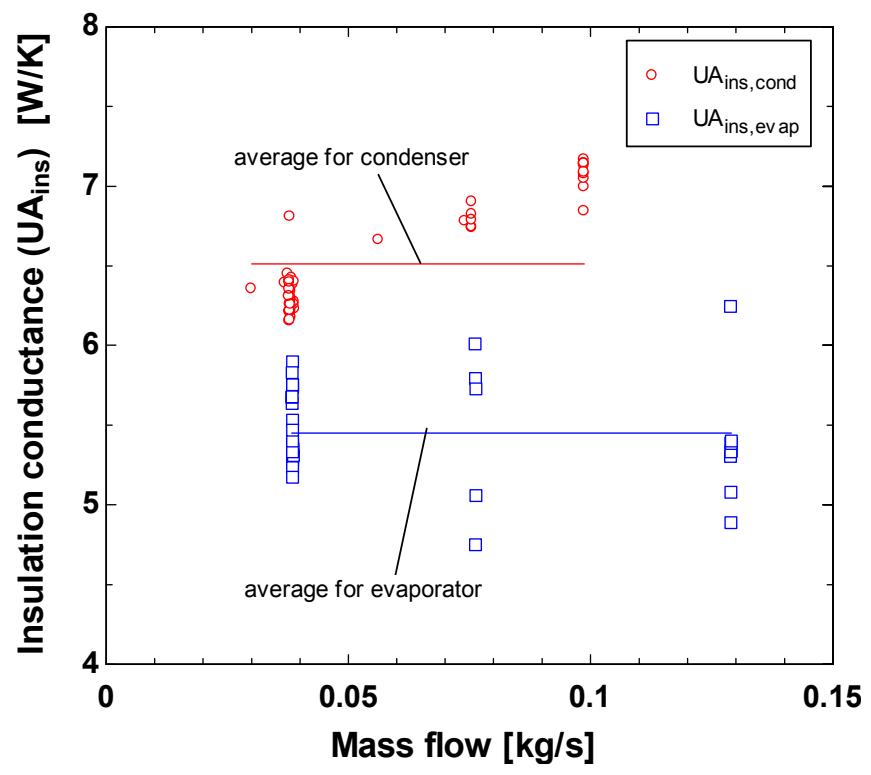

Figure A-7: Insulation conductance for evaporator and condenser

\section{A.9 Uncertainty Analysis Software}

The uncertainty analyses on each of the performance metrics shown in Figure 4-1 through Figure 4-4 were calculated using the uncertainty propagation capability in EES. The software numerically computes the performance metric uncertainty by evaluating the partial derivatives with respect to each relevant measurement and applying the specified measurement uncertainty. Assuming the measurements are independent and uncorrelated, the uncertainty of a quantity is computed according to (Taylor \& Kuyatt, 1994):

$$
U_{Y}=\sqrt{\sum_{i}\left(\frac{\partial Y}{\partial X_{i}} U_{X_{i}}^{2}\right)^{2}}
$$

where the variables represent:

$$
\begin{aligned}
& Y=\text { calculated quantity } \\
& U_{y}=\text { uncertainty of calculated quantity } \\
& X_{i}=\text { measurement } \\
& U_{X i}=\text { uncertainty of measurement }
\end{aligned}
$$




\section{A.10 Moving Window and Steady State Uncertainty}

A moving window average was used to compute the measurements at steady state during the tests. In order to determine a proper window size, the variation of measurement steady state uncertainty with window size was examined. The steady state uncertainty is defined as the expanded standard uncertainty for the average reading within the window:

$$
U_{\bar{X}}=k \frac{S_{X}}{\sqrt{n}}
$$

where:

$$
\begin{aligned}
& k=\text { coverage factor }(k=2) \text { for } 95 \% \text { confidence interval } \\
& n=\text { number of samples in the window } \\
& S_{x}=\text { standard deviation of measurement } \\
& \bar{X}=\text { average value of measurement }
\end{aligned}
$$

The data for analysis were generated by holding the MBBHP at a nominal steady operating condition and recording the measurements at 1-minute intervals (same as collection rate for all performance testing) for an extended time ( 3 hours). Figure A-8 shows the fluctuation of steady state uncertainty for the evaporator inlet and outlet temperatures ( $T_{9}$ and $\left.T_{11}\right)$. The figure highlights two characteristic trends observed for all of the instruments, both of which suggest the need for a large moving window: (1) the steady state uncertainty decreases as the window size increases, and (2) the steady state uncertainty is highly oscillatory for small windows (the oscillations are undesirable because short-term fluctuations can have a disproportionate impact on the averaged result). A 30 sample moving window was selected to achieve low uncertainty while allowing for collection of data in a timely manner.

Figure A-8 shows that the measurement steady state uncertainty is not constant in time (it would be constant if the fluctuations at steady state were purely random), but rather exhibits drifting and periodic movements. This is possibly due to hunting by the PID controllers regulating HTF fluid temperatures, changes in air temperature in the lab space, or some other uncontrolled and/or uncharacterized phenomena. These non-random fluctuations are accounted for by using the maximum steady state uncertainty value observed during the extended steady state test. For example, Figure A-8(a) shows the maximum steady state uncertainty for the evaporator outlet $\left(T_{9}\right)$ is $\pm 0.06{ }^{\circ} \mathrm{C}$; this value and values for all other sensors are listed in Table $2-3$. The data in the moving window are only recorded when steady state uncertainties are below these established thresholds. The total uncertainty $\left( \pm 0.09^{\circ} \mathrm{C}\right)$, also shown in Table $2-3$, is subsequently computed by adding the instrument uncertainty $\left( \pm 0.08^{\circ} \mathrm{C}\right)$ and steady state uncertainty $\left( \pm 0.06^{\circ} \mathrm{C}\right)$ in quadrature.

Note that different sensors of the same type exhibit different levels of fluctuation; as a conservative estimate, the largest uncertainty of any one is applied to all of them. For example, Figure A-8(b) shows the fluctuations of steady state uncertainty for the evaporator inlet temperature $\left(T_{9}\right)$ are much smaller than for the evaporator outlet $\left(T_{11}\right)$. In fact, the evaporator outlet temperature $\left(T_{11}\right)$ shows the most fluctuation of all the ice-water bath compensated thermocouple probes; therefore, its value $\left( \pm 0.06^{\circ} \mathrm{C}\right)$ is used in Table 2-3 to represent them all. 


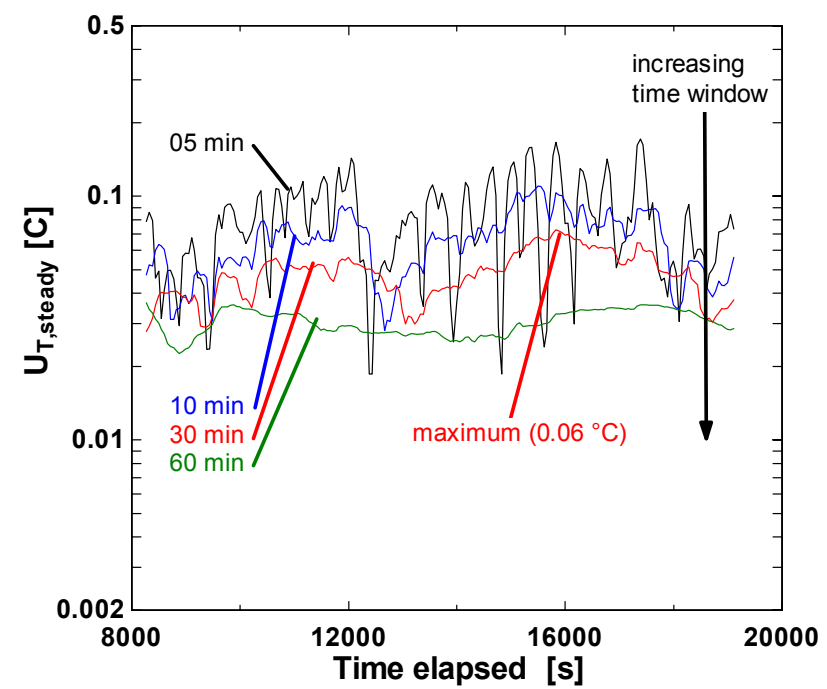

(a)

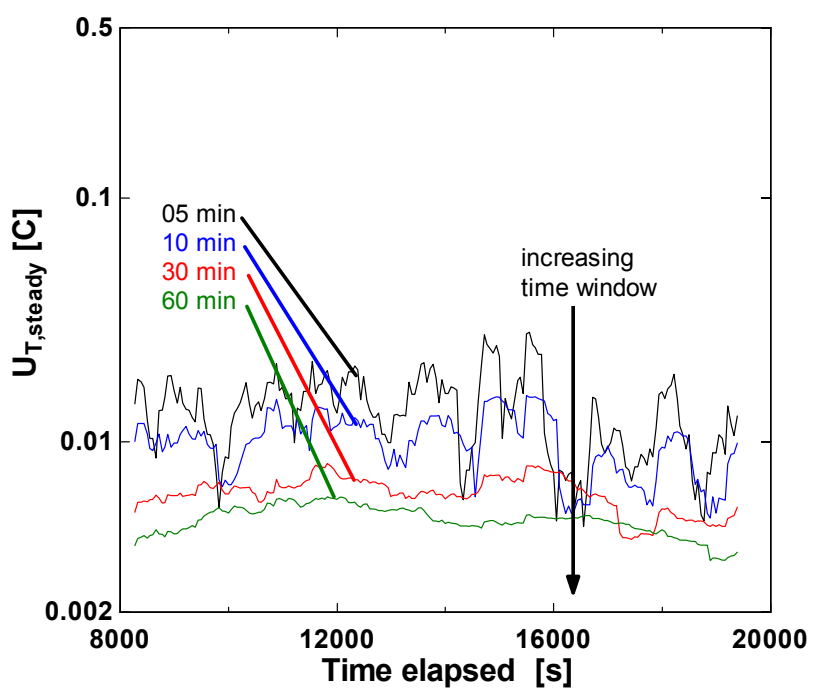

(b)

Figure A-8: - Uncertainty in temperature due to fluctuations at steady state for (a) evaporator outlet and (b) evaporator inlet

\section{A.11 Uncertainty Results Summary}

The detailed instrument uncertainty analysis for performance metrics including the refrigerant/HTF-side capacities and the COPs are tabulated in Appendices A.11.1 (cooling) and A.11.2 (heating). The tables show the performance metric and its total uncertainty (including both instrument and steady state contributions), as well as the measurements that contribute to the uncertainty. The measurement values, uncertainties, partial derivatives (of performance metric with respect to the measurement), and relative errors (contribution to the overall error in the performance metric) are also shown, where the measurements are listed in order of decreasing relative error. Uncertainties for other performance metrics (e.g. VCC/VHC, $\eta_{\text {isen }}$ ) were analyzed using similar techniques, but are not shown in detail in this report. Note that Appendices A.11.1 and A.11.2 show sample calculations for a single nominal operating condition, whereas the uncertainty values presented in the Section 4 figures are computed for each test run.

The uncertainty in cooling performance metrics are shown for a nominal operating point for R134a during a Cooling A test with a compressor speed of about $30 \mathrm{~Hz}$ (1800 RPM). Similarly, the uncertainty in heating performance metrics are shown for R134a during a Heating $\mathrm{H} 1$ test with a compressor speed of about $30 \mathrm{~Hz}$ (1800 RPM).

\section{A.11.1 Uncertainty Results Summary: Cooling}

Table A-3 shows that the dominant sources of instrument uncertainty for the refrigerant-side capacity are refrigerant mass flow (66\%), expansion valve inlet temperature $(17 \%)$, evaporator exit pressure ( $8 \%$ ), and evaporator exit temperature (7\%). Table A-4 shows the dominant source of instrument uncertainty for the HTF-side capacity is the HTF specific heat (97\%, estimate for instrument used to measure fluid properties). Table A-5 shows the dominant sources of instrument uncertainty for cooling COP are evaporator inlet pressure $(39 \%)$, compressor discharge temperature $(25 \%)$, and compressor suction temperature $(18 \%)$. 
Table A-3: Uncertainty of refrigerant-side evaporator cooling capacity

\begin{tabular}{lccccc} 
Parameter & Symbol & Value & $\begin{array}{c}\text { Total } \\
\text { Uncertainty }\end{array}$ & $\begin{array}{c}\text { Partial } \\
\text { Derivative }\end{array}$ & $\begin{array}{c}\text { Relative } \\
\text { Error }\end{array}$ \\
\hline Refrigerant-side evaporator capacity & $\dot{Q}_{\mathrm{e}, \text { ref }}$ & $1.692 \mathrm{~kW}$ & $\begin{array}{c} \pm 0.0035 \mathrm{~kW} \\
(0.20 \%)\end{array}$ & -- & -- \\
\hline Refrigerant mass flow & $\dot{m}_{r e f}$ & $11.00 \mathrm{~g} \mathrm{~s}^{-1}$ & $\pm 0.024 \mathrm{~g} \mathrm{~s}^{-1}$ & $1.538 \mathrm{E}-01$ & $66 \%$ \\
\hline Refrigerant temp. at expansion valve inlet & $T_{8}$ & $38.16 \mathrm{C}$ & $\pm 0.09{ }^{\circ} \mathrm{C}$ & $-1.634 \mathrm{E}-02$ & $17 \%$ \\
\hline Refrigerant press. at evaporator inlet & $P_{9}$ & $412 \mathrm{kPa}$ & $\pm 3.5 \mathrm{kPa}$ & $-2.817 \mathrm{E}-04$ & $8 \%$ \\
\hline Refrigerant temp. at evaporator exit & $T_{11}$ & $12.09 \mathrm{C}$ & $\pm 0.09{ }^{\circ} \mathrm{C}$ & $1.009 \mathrm{E}-02$ & $7 \%$ \\
\hline Refrigerant press. at condenser exit & $P_{7}$ & $1104 \mathrm{kPa}$ & $\pm 3.5 \mathrm{kPa}$ & $2.103 \mathrm{E}-06$ & $0 \%$ \\
\hline Refrigerant evaporator differential press. & $\Delta P_{\mathrm{e}}$ & $43.92 \mathrm{kPa}$ & $\pm 0.8 \mathrm{kPa}$ & $2.817 \mathrm{E}-04$ & $0 \%$
\end{tabular}

Table A-4: Uncertainty of HTF-side evaporator cooling capacity

\begin{tabular}{|c|c|c|c|c|c|}
\hline Parameter & Symbol & Value & $\begin{array}{c}\text { Total } \\
\text { Uncertainty }\end{array}$ & $\begin{array}{l}\text { Partial } \\
\text { Derivative }\end{array}$ & $\begin{array}{c}\text { Relative } \\
\text { Error }\end{array}$ \\
\hline HTF-side evaporator capacity & $\dot{Q}_{\mathrm{e}, H T F}$ & $1.672 \mathrm{~kW}$ & $\begin{array}{c} \pm 0.05 \mathrm{~kW} \\
(3.0 \%)\end{array}$ & -- & -- \\
\hline $\begin{array}{l}\text { Evaporator HTF capacity } \\
\text { calibration uncertainty }\end{array}$ & $c p_{H T F, e}$ & $2.59 \mathrm{~J} \mathrm{~g}^{-1} \mathrm{~K}^{-1}$ & $\pm 3 \%$ of $c p_{H T F, e}$ & $6.369 \mathrm{E}-01$ & $97 \%$ \\
\hline $\begin{array}{l}\text { Temperature of ambient air } \\
\text { surrounding evaporator }\end{array}$ & $T_{a m b, e}$ & $23.0^{\circ} \mathrm{C}$ & $\pm 0.6^{\circ} \mathrm{C}$ & $5.474 \mathrm{E}-03$ & $1 \%$ \\
\hline HTF mass flow & $\dot{m}_{H T F, e}$ & $131.2 \mathrm{~g} \mathrm{~s}^{-1}$ & $\pm 0.26 \mathrm{~g} \mathrm{~s}^{-1}$ & $1.257 \mathrm{E}-02$ & $1 \%$ \\
\hline Evaporator HTF thermopile voltage & $\Delta V_{T P, e}$ & $2.512 \mathrm{mV}$ & $\pm 0.007 \mathrm{mV}$ & $6.537 \mathrm{E}-01$ & $1 \%$ \\
\hline \multirow{5}{*}{$\begin{array}{l}\text { Evaporator HTF thermopile } \\
\text { polynomial coefficients }\end{array}$} & $a_{T P, e, 0}$ & $3.9243 \mathrm{E}-02$ & $\pm 4.1 \mathrm{E}-04$ & $4.047 \mathrm{E}-03$ & $0 \%$ \\
\hline & $a_{T P, e, 1}$ & $2.0243 \mathrm{E}+03$ & $\pm 1.2 \mathrm{E}-01$ & $8.832 \mathrm{E}-04$ & $0 \%$ \\
\hline & $a_{T P, e, 2}$ & $-5.5466 \mathrm{E}+03$ & $\pm 2.2 \mathrm{E}+01$ & $1.559 \mathrm{E}-05$ & $0 \%$ \\
\hline & $a_{T P, e, 3}$ & $3.9023 \mathrm{E}+04$ & $\pm 1.3 \mathrm{E}+03$ & $2.106 \mathrm{E}-07$ & $0 \%$ \\
\hline & $a_{T P, e, 4}$ & $-2.6229 \mathrm{E}+05$ & $\pm 2.2 \mathrm{E}+04$ & $2.554 \mathrm{E}-09$ & $0 \%$ \\
\hline \multirow{3}{*}{$\begin{array}{l}\text { Evaporator HTF capacity } \\
\text { polynomial coefficients }\end{array}$} & $a_{C p, e, 0}$ & $2.5643 \mathrm{E}+00$ & $\pm 1.6 \mathrm{E}-03$ & $6.369 \mathrm{E}-01$ & $0 \%$ \\
\hline & $a_{C p, e, 1}$ & $1.1015 \mathrm{E}-03$ & $\pm 2.1 \mathrm{E}-04$ & $1.135 \mathrm{E}+01$ & $0 \%$ \\
\hline & $a_{C p, e, 2}$ & $1.7422 \mathrm{E}-05$ & $\pm 9.5 \mathrm{E}-06$ & $2.024 \mathrm{E}+02$ & $0 \%$ \\
\hline $\begin{array}{l}\text { Temperature at cold end of } \\
\text { evaporator HTF thermopile }\end{array}$ & $T_{H T F, e, o u t}$ & $15.42{ }^{\circ} \mathrm{C}$ & $\pm 0.6^{\circ} \mathrm{C}$ & $-2.963 \mathrm{E}-03$ & $0 \%$ \\
\hline Evaporator insulation conductance & $U A_{\text {ins }, e}$ & $5.474 \mathrm{~W} \mathrm{~K}^{-1}$ & $\pm 0.3052 \mathrm{~W} \mathrm{~K}^{-1}$ & $4.175 \mathrm{E}-03$ & $0 \%$ \\
\hline
\end{tabular}


Table A-5: Uncertainty of cooling COP

\begin{tabular}{lccccc} 
Parameter & Symbol & Value & $\begin{array}{c}\text { Total } \\
\text { Uncertainty }\end{array}$ & $\begin{array}{c}\text { Partial } \\
\text { Derivative }\end{array}$ & $\begin{array}{c}\text { Relative } \\
\text { Error }\end{array}$ \\
\hline Cooling COP & COP cool & 2.844 & $\begin{array}{c} \pm 0.01 \\
(0.35 \%)\end{array}$ & -- & -- \\
\hline Refrigerant press. at evaporator inlet & $P_{9}$ & $412 \mathrm{kPa}$ & $\pm 3.5 \mathrm{kPa}$ & $-1.232 \mathrm{E}-02$ & $39 \%$ \\
\hline Refrigerant temp. at compressor discharge & $T_{3}$ & $81.97{ }^{\circ} \mathrm{C}$ & $\pm 0.09{ }^{\circ} \mathrm{C}$ & $5.571 \mathrm{E}-02$ & $25 \%$ \\
\hline Refrigerant temp. at compressor suction & $T_{1}$ & $12.73{ }^{\circ} \mathrm{C}$ & $\pm 0.09{ }^{\circ} \mathrm{C}$ & $4.788 \mathrm{E}-02$ & $18 \%$ \\
\hline Refrigerant press. at condenser exit & $P_{7}$ & $1104 \mathrm{kPa}$ & $\pm 3.5 \mathrm{kPa}$ & $5.144 \mathrm{E}-03$ & $7 \%$ \\
\hline Refrigerant temp. at expansion valve inlet & $T_{8}$ & $38.16^{\circ} \mathrm{C}$ & $\pm 0.09{ }^{\circ} \mathrm{C}$ & $-2.746 \mathrm{E}-02$ & $6 \%$ \\
\hline Refrigerant temp. at evaporator exit & $T_{11}$ & $12.09{ }^{\circ} \mathrm{C}$ & $\pm 0.09{ }^{\circ} \mathrm{C}$ & $1.696 \mathrm{E}-02$ & $2 \%$ \\
\hline Refrigerant evaporator diff. press. & $\Delta P_{\mathrm{e}}$ & $43.92 \mathrm{kPa}$ & $\pm 0.8 \mathrm{kPa}$ & $7.432 \mathrm{E}-04$ & $2 \%$ \\
\hline Refrigerant condenser diff. press. & $\Delta P_{\mathrm{c}}$ & $32.34 \mathrm{kPa}^{2}$ & $\pm 1.3 \mathrm{kPa}$ & $4.731 \mathrm{E}-04$ & $1 \%$ \\
\hline Refrigerant suction line diff. press. & $\Delta P_{\mathrm{s}}$ & $14.22 \mathrm{kPa}$ & $\pm 0.3 \mathrm{kPa}$ & $1.314 \mathrm{E}-03$ & $0 \%$ \\
\hline Refrigerant mass flow & $\dot{m}_{r e f}$ & $11.00 \mathrm{~g} \mathrm{~s}^{-1}$ & $\pm 0.016 \mathrm{~g} \mathrm{~s}-1$ & $2.209 \mathrm{E}-04$ & $0 \%$
\end{tabular}

\section{A.11.2 Uncertainty Results Summary: Heating}

Table A- 6 shows the dominant sources of instrument uncertainty for the refrigerant-side capacity are refrigerant mass flow (85\%), condenser exit temperature ( $9 \%$ ), and condenser inlet temperature (5\%). Table A-7 shows the dominant source of instrument uncertainty for the HTFside capacity is the HTF specific heat $(97 \%$, estimate for instrument used to measure specific heat of water in the reference). Table A- 8 shows the dominant sources of instrument uncertainty for cooling COP are evaporator inlet pressure (32\%), compressor discharge temperature (31\%), and compressor suction temperature (22\%). 
Table A-6: Uncertainty of refrigerant-side condenser heating capacity -

\begin{tabular}{lccccc} 
Parameter & Symbol & Value & $\begin{array}{c}\text { Total } \\
\text { Uncertainty }\end{array}$ & $\begin{array}{c}\text { Partial } \\
\text { Derivative }\end{array}$ & $\begin{array}{c}\text { Relative } \\
\text { Error }\end{array}$ \\
\hline Refrigerant-side condenser capacity & $\dot{Q}_{c, r e f}$ & $1.873 \mathrm{~kW}$ & $\begin{array}{c} \pm 0.004 \mathrm{~kW} \\
(0.2 \%)\end{array}$ & -- \\
\hline Refrigerant mass flow & $\dot{m}_{r e f}$ & $9.06 \mathrm{~g} \mathrm{~s}^{-1}$ & $\pm 0.016 \mathrm{~g} \mathrm{~s}^{-1}$ & $2.067 \mathrm{E}-01$ & $85 \%$ \\
\hline Refrigerant temp. at condenser exit & $T_{7}$ & $37.39{ }^{\circ} \mathrm{C}$ & $\pm 0.09{ }^{\circ} \mathrm{C}$ & $-1.343 \mathrm{E}-02$ & $9 \%$ \\
\hline Refrigerant temp. at condenser inlet & $T_{4}$ & $77.22{ }^{\circ} \mathrm{C}$ & $\pm 0.09{ }^{\circ} \mathrm{C}$ & $9.443 \mathrm{E}-03$ & $5 \%$ \\
\hline Refrigerant press. at condenser exit & $P_{7}$ & $992.8 \mathrm{kPa}$ & $\pm 3.5 \mathrm{kPa}$ & $-1.296 \mathrm{E}-04$ & $1 \%$ \\
\hline Refrigerant condenser differential press. & $\Delta P_{\mathrm{c}}$ & $27.2 \mathrm{kPa}$ & $\pm 1.3 \mathrm{kPa}$ & $-9.028 \mathrm{E}-04$ & $0 \%$
\end{tabular}

Table A-7: Uncertainty of HTF-side condenser heating capacity

\begin{tabular}{lccccc} 
Parameter & Symbol & Value & $\begin{array}{c}\text { Total } \\
\text { Uncertainty }\end{array}$ & $\begin{array}{c}\text { Partial } \\
\text { Derivative }\end{array}$ & $\begin{array}{c}\text { Relative } \\
\text { Error }\end{array}$ \\
\hline HTF-side condenser capacity & $\dot{Q}_{\mathrm{c}, H T F}$ & $1.852 \mathrm{~kW}$ & $\begin{array}{c} \pm 0.054 \mathrm{~kW} \\
(2.9 \%)\end{array}$ & -- & -- \\
\hline $\begin{array}{l}\text { Condenser HTF capacity calibration } \\
\text { uncertainty }\end{array}$ & $c p_{H T F, \mathrm{c}}$ & $4.183 \mathrm{~J} \mathrm{~g}^{-1} \mathrm{~K}^{-1}$ & $\pm 3 \%$ of $c p_{H T F, \mathrm{c}}$ & $4.262 \mathrm{E}-01$ & $97 \%$ \\
\hline Condenser insulation conductance & $U A_{\text {ins,c }}$ & $6.521 \mathrm{~W} \mathrm{~K}^{-1}$ & $\pm 0.4071 \mathrm{~W} \mathrm{~K}^{-1}$ & $1.056 \mathrm{E}-02$ & $1 \%$ \\
\hline HTF mass flow & $\dot{m}_{H T F, \mathrm{c}}$ & $98.81 \mathrm{~g} \mathrm{~s}^{-1}$ & $\pm 0.23 \mathrm{~g} \mathrm{~s}^{-1}$ & $1.804 \mathrm{E}-02$ & $1 \%$ \\
\hline Condenser HTF thermopile voltage & $\Delta V_{T P, c}$ & $2.318 \mathrm{mV}^{\prime}$ & $\pm 0.007 \mathrm{mV}$ & $7.652 \mathrm{E}-01$ & $1 \%$ \\
\hline $\begin{array}{l}\text { Condenser HTF thermopile } \\
\text { polynomial coefficients }\end{array}$ & $a_{T P, c, 0}$ & $3.8494 \mathrm{E}-02$ & $\pm 5.3 \mathrm{E}-04$ & $4.057 \mathrm{E}-03$ & $0 \%$ \\
& $a_{T P, c, 1}$ & $2.0241 \mathrm{E}+03$ & $\pm 1.5 \mathrm{E}-01$ & $1.025 \mathrm{E}-03$ & $0 \%$ \\
& $a_{T P, c, 2}$ & $-5.5190 \mathrm{E}+03$ & $\pm 2.8 \mathrm{E}+01$ & $3.481 \mathrm{E}-05$ & $0 \%$ \\
& $a_{T P, c, 3}$ & $3.8551 \mathrm{E}+04$ & $\pm 1.6 \mathrm{E}+03$ & $9.078 \mathrm{E}-07$ & $0 \%$ \\
& $a_{T P, c, 4}$ & $-2.5440 \mathrm{E}+05$ & $\pm 2.9 \mathrm{E}+04$ & $2.309 \mathrm{E}-08$ & $0 \%$ \\
\hline $\begin{array}{l}\text { Temperature of ambient air } \\
\text { surrounding condenser }\end{array}$ & $T_{a m b, c}$ & $24.3{ }^{\circ} \mathrm{C}$ & $\pm 0.6{ }^{\circ} \mathrm{C}$ & $-6.521 \mathrm{E}-03$ & $0 \%$ \\
\hline $\begin{array}{l}\text { Temperature at cold end of } \\
\text { condenser HTF thermopile }\end{array}$ & $T_{H T F, c, i n}$ & $31.96{ }^{\circ} \mathrm{C}$ & $\pm 0.6{ }^{\circ} \mathrm{C}$ & $-4.093 \mathrm{E}-03$ & $0 \%$ \\
& & & & &
\end{tabular}


Table A-8: Uncertainty of heating COP

\begin{tabular}{|c|c|c|c|c|c|}
\hline Parameter & Symbol & Value & $\begin{array}{c}\text { Total } \\
\text { Uncertainty }\end{array}$ & $\begin{array}{c}\text { Partial } \\
\text { Derivative }\end{array}$ & $\begin{array}{c}\text { Relative } \\
\text { Error }\end{array}$ \\
\hline Heating COP & $\mathrm{COP}_{\text {heat }}$ & 3.431 & $\begin{array}{c} \pm 0.01 \\
(0.28 \%)\end{array}$ & -- & -- \\
\hline Refrigerant press. at evaporator inlet & $\overline{P_{9}}$ & $314.8 \mathrm{kPa}$ & $\pm 3.5 \mathrm{kPa}$ & $-1.520 \mathrm{E}-03$ & $32 \%$ \\
\hline Refrigerant temp. at compressor discharge & $T_{3}$ & $80.73^{\circ} \mathrm{C}$ & $\pm 0.09^{\circ} \mathrm{C}$ & $-5.933 \mathrm{E}-02$ & $31 \%$ \\
\hline Refrigerant temp. at compressor suction & $T_{1}$ & $3.54{ }^{\circ} \mathrm{C}$ & $\pm 0.09{ }^{\circ} \mathrm{C}$ & $5.000 \mathrm{E}-02$ & $22 \%$ \\
\hline Refrigerant temp. at condenser inlet & $T_{7}$ & $37.39^{\circ} \mathrm{C}$ & $\pm 0.09{ }^{\circ} \mathrm{C}$ & $-2.461 \mathrm{E}-02$ & $6 \%$ \\
\hline Refrigerant press. at condenser exit & $P_{7}$ & $992.8 \mathrm{kPa}$ & $\pm 3.5 \mathrm{kPa}$ & $5.532 \mathrm{E}-04$ & $5 \%$ \\
\hline Refrigerant temp. at condenser inlet & $T_{4}$ & $77.22^{\circ} \mathrm{C}$ & $\pm 0.09^{\circ} \mathrm{C}$ & $1.731 \mathrm{E}-02$ & $3 \%$ \\
\hline Refrigerant condenser differential press. & $\Delta P_{\mathrm{c}}$ & $27.2 \mathrm{kPa}$ & $\pm 1.3 \mathrm{kPa}$ & $5.509 \mathrm{E}-04$ & $1 \%$ \\
\hline Refrigerant suction line diff. press. & $\Delta P_{\mathrm{s}}$ & $12.69 \mathrm{kPa}$ & $\pm 0.3 \mathrm{kPa}$ & $1.520 \mathrm{E}-03$ & $0 \%$ \\
\hline Refrigerant evaporator diff. press. & $\Delta P_{\mathrm{e}}$ & $39.99 \mathrm{kPa}$ & $\pm 0.8 \mathrm{kPa}$ & $1.520 \mathrm{E}-03$ & $0 \%$ \\
\hline Refrigerant mass flow & $\dot{m}_{r e f}$ & $9.06 \mathrm{~g} \mathrm{~s}^{-1}$ & $\pm 0.016 \mathrm{~g} \mathrm{~s}^{-1}$ & 2.187 E-04 & $0 \%$ \\
\hline
\end{tabular}




\section{Appendix B: Instrumentation with DAQ Number Convention -}

The instrument numbering scheme shown in Figure 2-1 and Figure 2-5 is based on the thermodynamic states 1 to 11 . However, the raw data files recorded by the DAQ system use a different numbering scheme shown in Figure B-1 and Figure B-2.

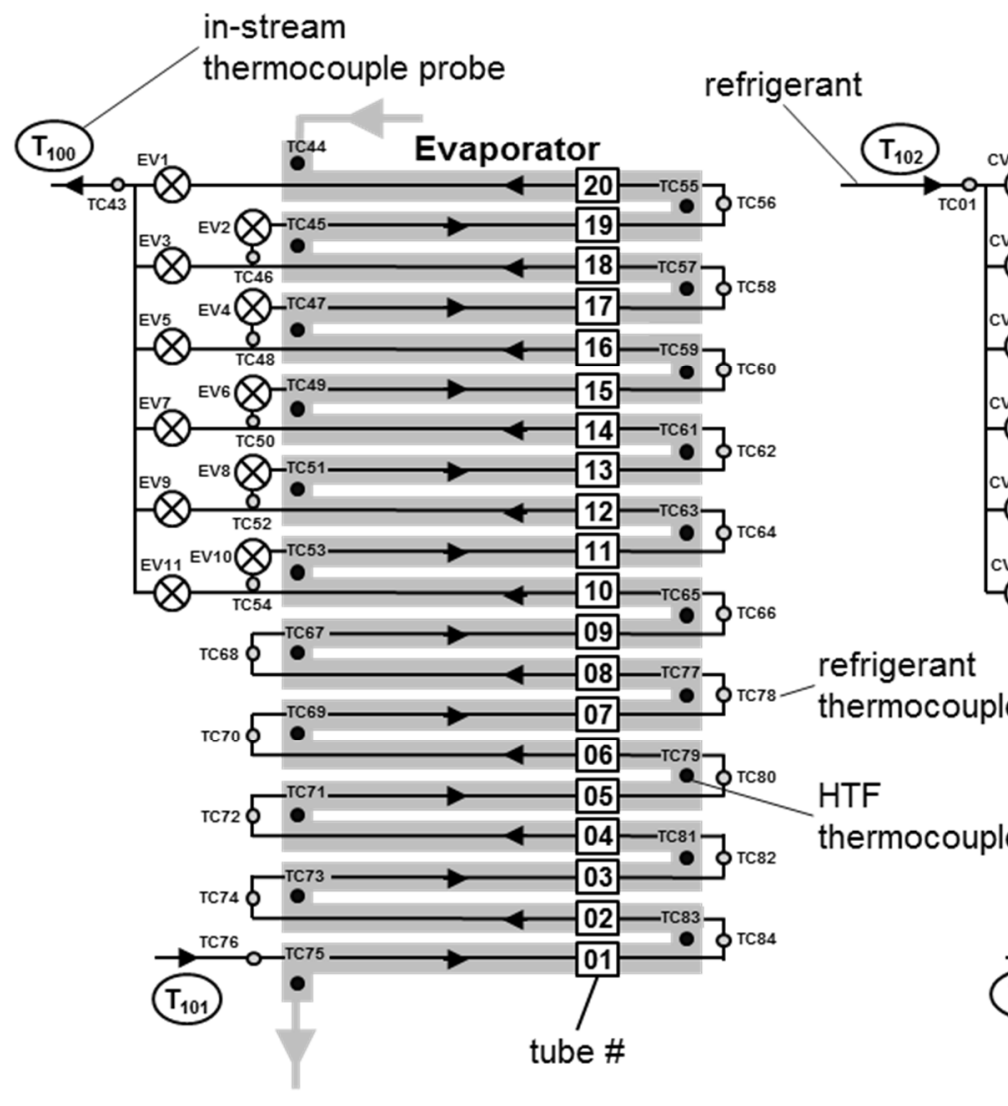

(a) -

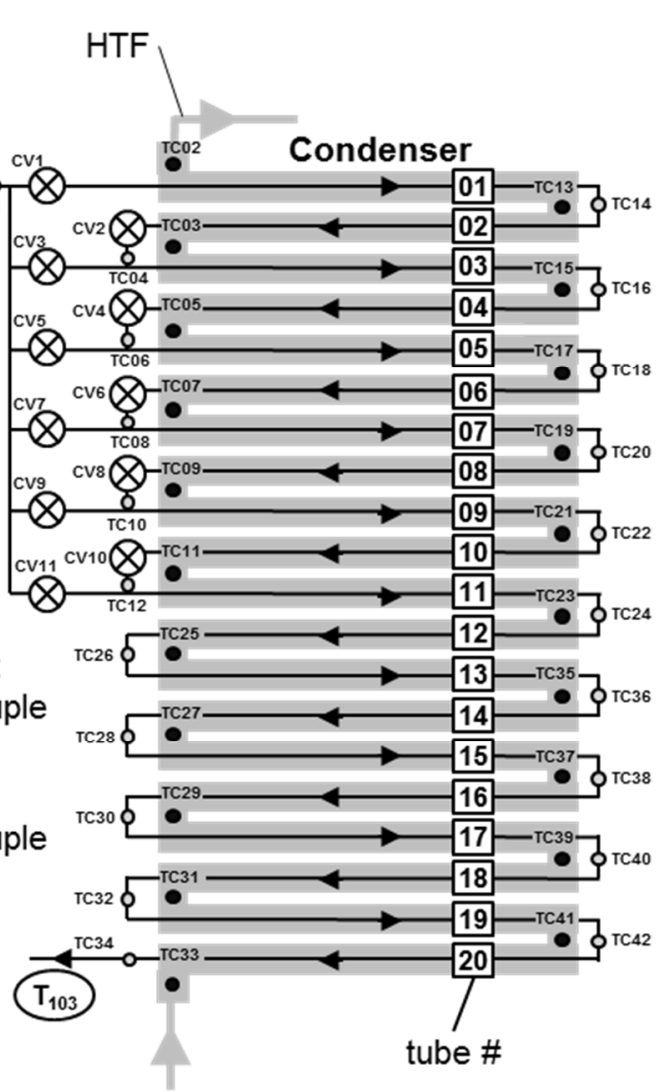

(b)

Figure B-1: - Schematic of (a) condenser and (b) evaporator, showing the instrument numbering convention used in the DAQ system. 


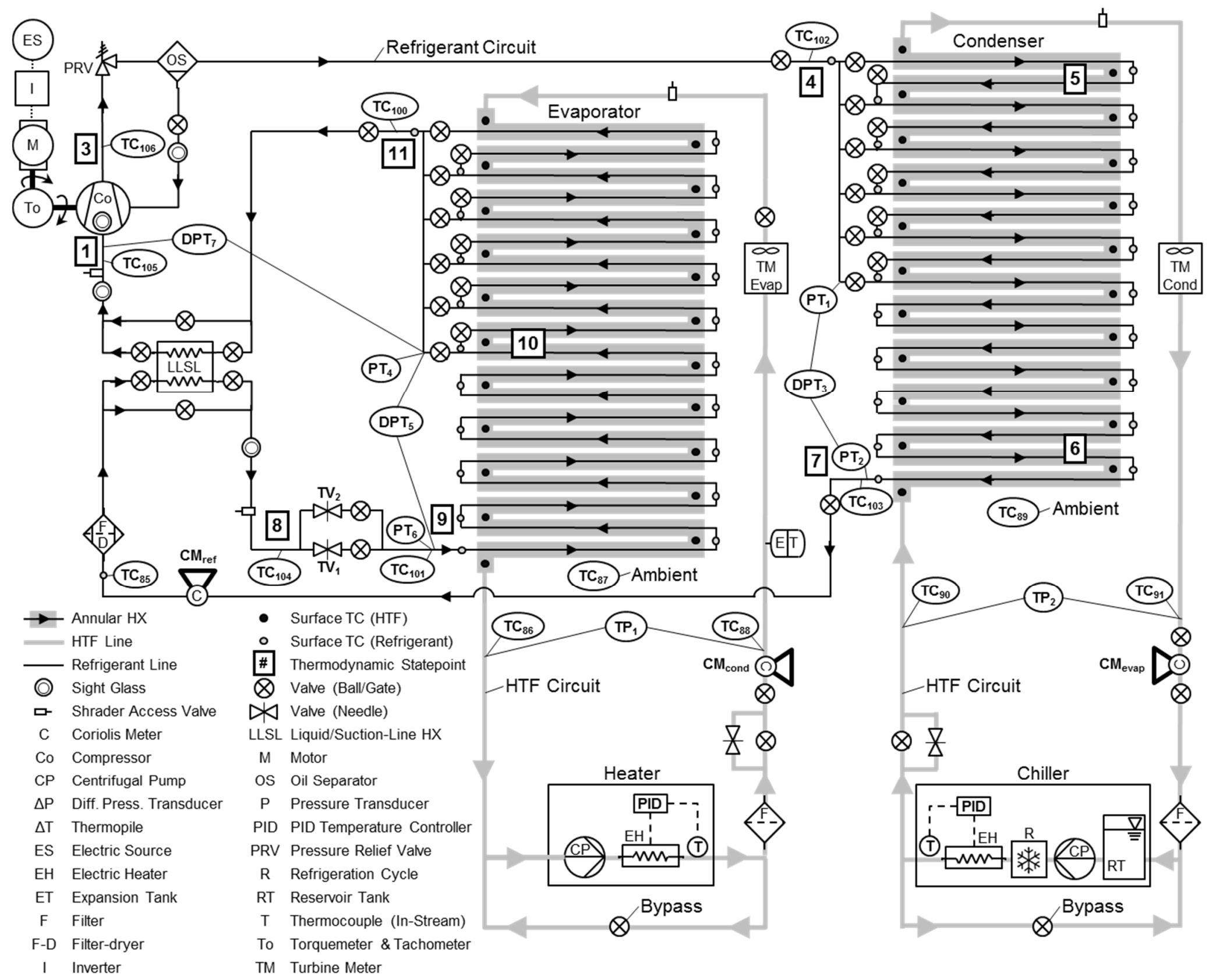

Figure B-2: Schematic of MBBHP test apparatus including instrument numbering convention used in the DAQ system 


\section{Appendix C: Microfin Tube Surface Area -}

The microfinned surface area (per tube length) is estimated according to:

$$
\frac{A_{i}}{L}=N_{f}\left(\frac{s_{f}}{\cos \alpha}+\frac{2 e}{\cos \alpha \cos (\beta / 2)}\right)
$$

where the variables represent:

$$
\begin{aligned}
e & =\text { fin height } \\
N_{f} & =\text { number of fins } \\
s_{f} & =\text { fin spacing } \\
\alpha & =\text { fin helix angle } \\
\beta & =\text { fin angle }
\end{aligned}
$$

and $A_{i} / L$ is computed as $0.0424 \mathrm{~m}$ (1.67 in). The fin parameters are shown in Figure 2-5 and Table 2-2. 